Contract Program or Project Title:

Subject of this Document

Type of Document:

Authors:

Date of Document:

Responsible NRC Individual and NRC Office or Division
Heavy-Section Steel Technology (HSST) Program Engineering Technology Division

Fracture Assessment of HSST Plate 14 ShallowFlaw Cruciform Bend Specimens Tested under Biaxial Loading Conditions

Letter Report

B. R. Bass

W. J. McAfee

P. T. Williams

W. E. Pennell

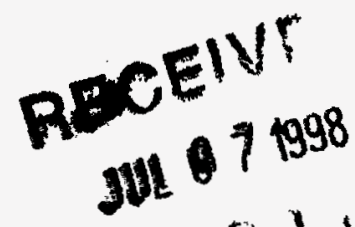

June 1998

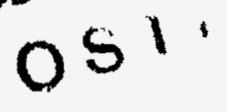

M. G. Vassilaros (301) 415-6000

Division of Engineering Technology,

U. S. Nuclear Regulatory Commission

Prepared for the

U.S. Nuclear Regulatory Commission

Washington, D.C. 20555-0001

Under Interagency Agreement DOE 1886-N011-9B

NRC JCN B0119

\author{
OAK RIDGE NATIONAL LABORATORY \\ Oak Ridge, Tennessee 37831-8056 \\ managed by \\ LOCKHEED MARTIN ENERGY RESEARCH CORP. \\ for the \\ U. S. DEPARTMENT OF ENERGY \\ under Contract No. DE-AC05-960R22464
}

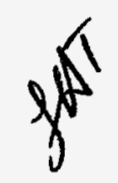




\section{DISCLAIMER}

This report was prepared as an account of work sponsored by an agency of the United States Government. Neither the United States Government nor any agency thereof, nor any of their employees, makes any warranty, express or implied, or assumes any legal liability or responsibility for the accuracy, completeness, or usefulness of any information, apparatus, product, or process disclosed, or represents that its use would not infringe privately owned rights. Reference herein to any specific commercial product, process, or service by trade name, trademark, manufacturer, or otherwise does not necessarily constitute or imply its endorsement, recommendation, or favoring by the United States Government or any agency thereof. The views and opinions of authors expressed herein do not necessarily state or reflect those of the United States Government or any agency thereof. 


\section{DISCLAIMER}

Portions of this document may be illegible in electronic image products. Images are produced from the best available original document. 
ORNL/NRC/LTR-98/9

\title{
Fracture Assessment of HSST Plate 14 Shallow-Flaw Cruciform Bend Specimens Tested under Biaxial Loading Conditions
}

\author{
B. R. Bass, W. J. McAfee, P. T. Williams, and W. E. Pennell \\ Oak Ridge National Laboratory \\ Oak Ridge, Tennessee
}

Manuscript Completed - June 1998

Date Published - June 1998

\author{
Prepared for the \\ U.S. Nuclear Regulatory Commission \\ Washington, D.C. 20555-0001 \\ Under Interagency Agreement DOE 1886-N011-9B
}

NRC JCN B0119

OAK RIDGE NATIONAL LABORATORY

Oak Ridge, Tennessee 37831-8056

managed by

LOCKHEED MARTIN ENERGY RESEARCH CORP.

for the

U. S. DEPARTMENT OF ENERGY

under Contract No. DE-AC05-96OR22464 


\title{
Fracture Assessment of HSST Plate 14 Shallow-Flaw \\ Cruciform Bend Specimens Tested under Biaxial Loading Conditions
}

\author{
B. R. Bass, W. J. McAfee, P. T. Williams, and W. E. Pennell \\ Oak Ridge National Laboratory \\ Oak Ridge, Tennessee
}

\begin{abstract}
A technology to determine shallow-flaw fracture toughness of reactor pressure vessel (RPV) steels is being developed for application to the safety assessment of RPVs containing postulated shallow surface flaws. Matrices of cruciform beam tests were developed to investigate and quantify the effects of temperature, biaxial loading, and specimen size on fracture initiation toughness of two-dimensional (constant depth), shallow, surface flaws. The cruciform beam specimens were developed at Oak Ridge National Laboratory (ORNL) to introduce a far-field, out-of-plane biaxial stress component in the test section that approximates the nonlinear stresses resulting from pressurized-thermalshock or pressure-temperature loading of an RPV. Tests were conducted under biaxial load ratios ranging from uniaxial to equibiaxial. These tests demonstrated that biaxial loading can have a pronounced effect on shallow-flaw fracture toughness in the lower transition temperature region for an RPV material. The cruciform fracture toughness data were used to evaluate fracture methodologies for predicting the observed effects of biaxial loading on shallow-flaw fracture toughness. Initial emphasis was placed on assessment of stressbased methodologies, namely, the $J-Q$ formulation, the Dodds-Anderson toughness scaling model, and the Weibull approach. Applications of these methodologies based on the hydrostatic stress fracture criterion indicated an effect of loading-biaxiality on fracture toughness; the conventional maximum principal stress criterion indicated no effect. A three-parameter Weibull model based on the hydrostatic stress criterion is shown to correlate the experimentally observed biaxial effect on cleavage fracture toughness by providing a scaling mechanism between uniaxial and biaxial loading states.
\end{abstract}

\section{Introduction}

The Heavy-Section Steel Technology (HSST) Program at Oak Ridge National Laboratory (ORNL) is developing technology to determine the shallow-flaw fracture toughness of steels for application to the safety assessment of reactor pressure vessels (RPVs). In the lower transition temperature region, shallow-flaw fracture toughness data for RPV materials exhibit mean values and scatter that are greater than those for deep flaws because of the relaxation of crack-tip constraint [1]. Previously, uniaxial full-thickness clad beam tests [2] were used to quantify this shallow-flaw effect in specimens (taken from 
an RPV of a canceled nuclear plant) which are representative of RPV wall thickness and material properties. However, the uniaxial beam tests did not address the issue of nearsurface biaxial stress fields produced by pressurized-thermal-shock (PTS) or pressuretemperature (P-T) loading of an RPV [see Fig. 1(a)]. The out-of-plane biaxial stress component has the potential to increase constraint at the tip of a shallow crack and thereby reduce the shallow-flaw fracture toughness enhancement.

Cruciform beam specimens [3-7] developed at ORNL introduce a far-field, out-ofplane biaxial stress component in the test section [see Fig. 1(b)] that approximates the nonlinear stresses of PTS or P-T loading [Fig. 1(a)]. The cruciform specimen (Fig. 2) permits controlled application of biaxial loading ratios that can produce controlled variations of crack-tip constraint for shallow surface flaws. The biaxial load ratio is defined as $P_{T} / P_{L}$, where $P_{T}$ is the total load applied to the transverse beam arms and $P_{L}$ is the total load applied to the longitudinal arms. A special test fixture was also designed and fabricated permitting testing under uniaxial loading, $P_{T} / P_{L}$ ratio of $(0: 1)$, and two biaxial loading ratios, $P_{T} / P_{L}$ ratios of $(0.6: 1)$ and (1:1). The specimen and test fixture have been described extensively in prior HSST publications [3-5].

Matrices of cruciform beam tests were defined within the HSST Program to evaluate biaxial loading effects on the fracture toughness of 2-dimensional (2-D) (infinite-length) [3] and 3-D (finite-length) [7] shallow surface flaws. An A 533 B steel, heat treated to obtain an elevated yield strength, was fabricated into cruciform specimens incorporating 2D flaws and tested with the load ratio and temperature as independent parameters [3]. Fracture toughness tests were run with biaxial load ratios, $P_{T} / P_{L}$, of $(0: 1),(0.6: 1)$, and $(1: 1)$. Five different temperatures through the transition temperature region for toughness were sampled in this series. These test data are essential for validation of a cleavage fracture methodology that can predict the observed effects of biaxial loading on shallow-flaw toughness of RPV steels in the lower transition temperature region.

Conventional fracture-prevention technology has relied on the use of fracture correlation parameters ( $K$ or $J$ ) to characterize both the applied loading and the resistance of engineering materials to crack initiation. As documented in numerous references (for example, see Refs. 8-12), the shortcomings of these one-parameter cleavage-fracture methodologies have been addressed using different strategies that share a common emphasis on inplane maximum principal (opening-mode) stress as the relevant criterion for unstable crack propagation. O'Dowd and Shih [9] introduced a correlative approach based on the twoparameter $J-Q$ description of the crack-tip fields. In that model, the $Q$-stress parameter 
characterizes the level of near-tip stress triaxiality (relative to small-scale yielding conditions) over distances extending a few crack-tip-opening displacements (CTODs) ahead of the crack tip. Dodds and Anderson (D-A) [10-11] employed a local fracture criterion in their toughness scaling model to characterize the relative effects of constraint on cleavage toughness. In the D-A model, the local fracture criterion is based on the material volume ahead of the crack front over which the maximum principal stress exceeds a critical value. Other stress-based local approaches adopted the Weibull stress [12] as a fracture parameter that reflects local damage near the crack tip and reaches a critical value at material failure. Conventional applications of the Weibull methodology utilize the maximum principal stress as the equivalent tensile stress in the integral representation of the Weibull stress.

Initial emphasis in the HSST studies was placed on assessment of three stressbased methodologies ( $J-Q$ formulation, D-A scaling model, and Weibull approach) as applied to the cruciform specimen and biaxial fracture toughness data. McAfee et al. [5] demonstrated that the $J-Q$ methodology and D-A toughness scaling model predicted essentially no effect of biaxial loading on cleavage fracture toughness in the cruciform bend specimen when the maximum principal stress is adopted as the fracture criterion. The latter result provided motivation for considering alternative fracture criteria that are sensitive to multiaxial loading states.

A number of previous studies (for example, see Refs. 13-15) investigated alternative fracture criteria using extended weakest-link models suitable for brittle materials (e.g., ceramics) subjected to multiaxial loading. These models consider flaws as planar cracks, with the loading expressed in terms of some suitably defined equivalent stress which depends on the orientation of the crack plane in the local stress field. Selected equivalent stress functions defined in terms of multiaxial stress components were used to evaluate failure criteria through applications to measured data. Another alternative is the hydrostatic stress function, which has been applied as a critical fracture parameter. Weiss [16] described an experimental program in which he investigated the effects of stress biaxiality on fracture strain and successfully reconciled measured data using a critical hydrostatic stress fracture criterion. Also, the $J-Q$ methodology utilized an operational definition of the $Q$ stress expressed in terms of the hydrostatic stress [17], which is consistent with its interpretation as a triaxiality parameter.

Recently, analyses of the cruciform specimen were performed within the HSST Program using functions of multiaxial stress components as failure criteria in the stressbased methodologies, in place of the maximum principal stress. Particular attention was 
given to construction of a scaling mechanism between uniaxial and biaxial loading states using a three-parameter Weibull model and the hydrostatic stress criterion. This paper provides an interim report on the results of these analyses. The following sections present a summary of the HSST biaxial testing program, the test results and fracture toughness determinations, and finally, applications of the constraint methodologies to the cruciform specimen and measured data from the biaxial testing program.

\section{Specimen Configuration and Testing Facility}

A basic functional requirement for the cruciform test specimen is that stresses in the ligament beneath the shallow flaw remain in the elastic range up to the point of fracture. Reasons for this requirement are (a) this is the condition which exists in an RPV under PTS loading, and (b) biaxial tests [18] have shown that when substantial plastic strains are allowed to develop in the ligament, the effects of biaxial loading on fracture toughness are lost. Thus, acceptance criteria were adopted for the cruciform bend specimen that require the specimen to exhibit contained yielding at the crack tip at cleavage fracture under biaxial (1:1) loading, at test temperatures in the lower transition region where biaxial loading effects on fracture toughness have been demonstrated. In Ref. 19, analysis results demonstrate that a cruciform specimen with a test section dimension of approximately $100 \mathrm{~mm}$ thickness is the smallest size that can meet the acceptance criteria for the heattreated Plate 14 material over the range of fracture toughness values of interest in PTS assessments. Plots of Mises stress contours in the cruciform specimen subjected to biaxial (1:1) loading indicate the onset of loss-of-containment in the cruciform specimen near a $K_{I}$ - level of approximately $200 \mathrm{MPa} \sqrt{\mathrm{m}}$.

The cruciform beam specimens are fabricated with a test section that has dimensions of $104 \mathrm{~mm} \times 104 \mathrm{~mm} \times 104 \mathrm{~mm}$ [see Fig. 2 (a)], except for three specimens that had a reduced thickness of $96 \mathrm{~mm}$ [see Fig. 2(b)]. For all cruciform beams, a 2-D shallow flaw having a flaw-depth ratio of $a / W=0.1$ was fabricated into the specimen. The flaw was located in material near the middle plane of the original plate. Load-diffusion control slots (LDCS) were machined into the specimen loading arms to create the boundary conditions required to achieve a uniform stress field in the central test section. For each cruciform specimen, the shallow 2-D flaw was fatigue-sharpened and a mechanical milling process used to relieve each corner of the sharpened flaw and remove a small region of material at the LDCS/flaw intersection. That region had exhibited preferential crack growth during the fatiguing process due to prior surface embrittlernent resulting from wire-EDM fabrication of 
the LDCS. (Development tests [5] confirmed that initiations occurred in the central portion of the crack front.) Next, the transverse loading arms were attached by electron-beam (EB) welding. Measured temperature data taken during EB welding of the transverse arms imply that temperatures produced in the cruciform test section $\left(<150^{\circ} \mathrm{C}\right)$ were not high enough to initiate processes which would reduce fracture toughness, such as locally-intensified strainaging embrittlement. The specimen design, coupled with a statically determinate loadreaction system installed in the ORNL testing machine, permitted the specimen to be loaded in either uniaxial (4-point bending) or biaxial (8-point bending) configurations. Tests of nominally identical specimens could be performed with the level of stress biaxiality as the only loading test variable.

Instrumentation applied to the test specimens included thermocouples, strain gages,

clip gages, and displacement transducers. Both crack-mouth-opening displacement (CMOD) and load-line displacement (LLD) were monitored continuously throughout each of the tests. Control of the test temperature was achieved with various liquid nitrogen distribution systems. Mechanical loading is applied to the cruciform specimens using a largescale cruciform test fixture mounted in a 3.1 MN Instron servo-hydraulic testing machine at ORNL.

\section{Material Preparation and Characterization}

HSST Plate 14 (A 533 B steel) was the source material for the cruciform bend specimens. A chemical analysis of Plate 14 is given in Table 1. This plate was selected primarily for its relatively high carbon content of 0.22 percent (specification for A 533 B steel is 0.25 percent maximum), which made it more responsive to increasing the yield strength by heat treatment and retaining relatively uniform properties through the thickness of the plate after tempering. The base material underwent heat treatment to achieve an elevated yield strength approximating that of a typical radiation-sensitive RPV steel irradiated to a fluence of $1.5 \times 10^{19} \mathrm{n} / \mathrm{cm}^{2}(>1 \mathrm{MeV}$ ). The heat treatment was performed successfully, providing a room temperature yield stress in the desired range. Fabrication of the cruciform specimens has been described in Refs. 3, 5, and 6 .

Characterization of the heat-treated material was performed to provide verification of properties and data for the determination of appropriate test conditions. Tensile, Charpy, drop-weight, and 1/2T compact tension specimens were tested. From Charpy V-notch (CVN) testing, $T_{C V}$ was determined to be $56^{\circ} \mathrm{C}\left(132^{\circ} \mathrm{F}\right)$, and the drop-weight nil-ductility temperature $(N D T)$ was found to be $40^{\circ} \mathrm{C}\left(104^{\circ} \mathrm{F}\right)$. Thus, $N D T$ controlled the reference 
temperature, and $R T_{N D T}=40^{\circ} \mathrm{C}$. A comparison was made between the Charpy results for Plate 14 and data from the HSSI Fifth Irradiation Series Weld 73W [20] in the irradiated $\left[1.51 \times 10^{19} \mathrm{n} / \mathrm{cm}^{2}(>1 \mathrm{MeV})\right]$ condition (see Fig. 3). From this comparison, it was observed that the trend of the Charpy data for Plate 14 very nearly matched that of the irradiated $73 \mathrm{~W}$ [20]. It can be concluded that the heat treatment was successful in providing the desired material properties.

American Society for Testing and Materials (ASTM) standard 6.35-mm (0.25-in.) gage diameter tensile specimens were machined from material near the midplane of the plate and at four locations through the half thickness. To characterize temperature dependency, tests were performed at four different temperatures using specimens taken from a single layer near the mid-plane of the plate. These test temperatures - $-30^{\circ} \mathrm{C}\left(-22^{\circ} \mathrm{F}\right), 10^{\circ} \mathrm{C}$ $\left(50^{\circ} \mathrm{F}\right), 40^{\circ} \mathrm{C}\left(104^{\circ} \mathrm{F}\right)$, and $60^{\circ} \mathrm{C}\left(140^{\circ} \mathrm{F}\right)$-- were selected as representative of the anticipated test temperature range for the cruciform specimens in the verification test matrix. Four locations through the thickness of the plate were also sampled. The variation of tensile properties with both temperature and location through the plate thickness was observed to be relatively small. Temperature-dependent material properties representing stress-strain behavior for this material at $-30^{\circ} \mathrm{C}$ and $-5{ }^{\circ} \mathrm{C}$ are given in Table 1 and Fig. 4 .

A series of $1 / 2 \mathrm{~T}$ compact specimens, taken from different locations within the parent plate, were tested over the range of $-130^{\circ} \mathrm{C}$ to room temperature. This data set was used to determine a reference temperature $T_{0}$ based on the Master Curve approach [21]. First, the $1 / 2 \mathrm{~T}$ data were adjusted to a $1 \mathrm{~T}$ constraint condition using

$$
K_{1 T}=20+\left(K_{1 / 2 T}-20\right)(0.5 / 1)^{\frac{1}{4}}
$$

The valid data were then fitted using the Master Curve equation,

$$
K_{J_{c}}(\mathrm{med})=30+70 \exp \left[0.019\left(T-T_{0}\right)\right],[\mathrm{MPa} \sqrt{\mathrm{m}}]
$$

from which a value of $T_{0}=-37.3^{\circ} \mathrm{C}\left(-35.1^{\circ} \mathrm{F}\right)$ was determined.

\section{Testing of Cruciform Specimens}

Six cruciform specimens were tested at $-30^{\circ} \mathrm{C}\left(T-T_{0}=7{ }^{\circ} \mathrm{C}\right)$ to provide data for (a) three biaxial load ratios and (b) two duplicate tests at each condition. The load vs CMOD data for these specimens are shown in Fig. 5, which compares the centerline 
CMOD for each of these six specimens. The deformation response for all specimens was in good agreement. The specimens exhibited very little plastic deformation as measured by both CMOD and LLD, regardless of the applied biaxial load. Failure conditions, load and deformation (CMOD and LLD), seemed to vary randomly; i.e., there was no clear correlation between applied biaxial loading and failure load or deformation. Examination of the fracture surfaces showed that initiation occurred within the center $50 \mathrm{~mm}$ of flaw front, indicating that the cleavage initiation toughness values were not influenced by edge conditions.

The estimated toughness values for these specimens are shown in Table 2. Estimates were made using CMOD and LLD results, the measured crack depth at the probable initiation site, and the $\eta$-factor procedures that have been used previously in estimating toughness from shallow-flaw tests $[1,6]$. The values for all these tests are near the estimated lower shelf toughness for this material, which is consistent with the observed deformation behavior, i.e., elastic tests. For cases where primarily elastic deformation occurs, biaxial loading would be expected to have little effect on constraint at the flaw tip, and thus little effect on toughness. The elastic response of these specimens gave an indication that the test temperature was too low (i.e., $-30^{\circ} \mathrm{C}$ was on or nearly on the lower shelf) to produce a biaxial loading effect.

A second set of fifteen cruciform specimens was tested at a nominal test temperature of $-5^{\circ} \mathrm{C}\left(23^{\circ} \mathrm{F}\right)$ (normalized temperature $T-T_{0}=32^{\circ} \mathrm{C}$ ). This higher temperature was expected to provide a better balance between cleavage behavior and accumulated plasticity at failure for evaluation of biaxial effects on toughness. Six specimens each were tested under uniaxial (0:1) and equibiaxial (1:1) loadings, and three specimens under (0.6:1) biaxial loading, as shown in Table 2. Deformation responses of longitudinal load vs CMOD results are shown in Fig. 6. The longitudinal load vs CMOD traces for these specimens were comparable, but the failure deformation magnitudes and scatter exhibited a strong dependence on the applied biaxial load as shown in Fig. 6. The unload/reload deformation trace of Specimen P2B was due to initial interference with the transverse beam arm load seats. The test was interrupted; the specimen was unloaded; and the fixture was then reconfigured while holding the specimen temperature near $-5^{\circ} \mathrm{C}$. It was concluded from post-test evaluation that this perturbation in the load histogram was insignificant as far as affecting the final toughness results.

Additional tests were performed at higher temperatures to investigate fracture behavior through the lower/mid-transition curve. The uniaxial tests at $-5{ }^{\circ} \mathrm{C}$ indicated border- 
line plastic collapse; therefore, no additional uniaxial specimens were tested at higher temperatures. Biaxial $(0.6: 1)$ and $(1: 1)$ tests were performed near $5^{\circ} \mathrm{C}$ and $15^{\circ} \mathrm{C}$, as shown in Table 2. Although scatter in the data set increased, the clear distinction between the effect on toughness of different biaxial load ratios was retained.

\section{Fracture Toughness Determination}

Three-dimensional elastic-plastic finite element analyses of the cruciform specimen were performed with the ABAQUS program [22] to generate $\eta$-factors for determination of fracture-toughness values from test data. For the $-30^{\circ} \mathrm{C}$ tests, generally good agreement was obtained for the deformation response, as expected since the tests were essentially elastic. These analyses over-predicted the stiffness of the specimen, with this overprediction being greatest for the biaxial (1:1) load case. A comparison of analysis and experiment is shown in Fig. 7 for this biaxial case. For the tests performed at $-5^{\circ} \mathrm{C}$, the agreement was dependent on the biaxial load ratio. Good agreement was obtained between the biaxial (1:1) analytical and experimental results; however, comparison of the uniaxial results showed the analysis to predict substantially stiffer longitudinal load vs CMOD responses than were measured in the test (see Fig. 8).

The estimated toughness values obtained from the Plate 14 cruciform specimens are shown graphically in Figs. 9 and 10 for the $-30{ }^{\circ} \mathrm{C}$ and $-5{ }^{\circ} \mathrm{C}$ test sets, respectively. The $-30{ }^{\circ} \mathrm{C}$ specimens behaved in an elastic manner and little biaxial effect was observed. For the six specimens tested, the toughness increased slightly with an increase in biaxial ratio. It is expected that additional specimens would show statistically no difference between uniaxial and biaxial loading at this temperature. For the tests performed at $-5^{\circ} \mathrm{C}$, the test data demonstrate a significant effect of biaxial loading on shallow-flaw fracture toughness, as is shown in Fig. 10. The mean value of the biaxial (1:1) toughness resulted in approximately a 42 percent decrease from the mean uniaxial toughness $\left(K_{J c(I: I)} / K_{J c(0: I)}\right.$ $=0.58$ ).

Figure 11 is a summary of all the cruciform data generated in this test series presented as a function of normalized test temperature $\left(T-T_{0}\right)$. Trend curves were developed through these data to provide a visual interpretation of the relationship between biaxial loading and temperature. Note that these trend curves are not rigorous fits to all the data but are intended primarily to identify and separate clata sets. The curves were all normalized to the same toughness values for normalized temperatures less than $0{ }^{\circ} \mathrm{C}$. These toughness values were developed using data from the 1/2T CT specimens tested on the lower shelf 
which were then adjusted to a full-constraint condition using the modified Irwin $\beta_{l c}$ approach [23]. Also, the mean of the data set for the cruciform tests at $-30^{\circ} \mathrm{C}$ was used as a common point for all three curves. The trend curve for the $(0.6: 1)$ data was developed by ratioing the biaxial $(1: 1)$ trend line upward so that it would pass through the centroid of the (0.6:1) data set. Figure 11 shows the development of a family of curves, each corresponding to a particular biaxial load ratio. The biaxial (1:1) data form a lower bound to this data set. Based on these trend lines, the mean of the estimated toughness values from the uniaxial tests increases much more sharply with increasing temperature than do those of the biaxial tests.

\section{Applications of Constraint Methodologies}

\subsection{Finite Element Models and Local Crack-Tip Fields}

Three-dimensional finite-element models were developed for local crack-tip field analyses of the cruciform bend specimens subjected to the uniaxial and biaxial loading conditions represented by the test data in Fig. 10. The cruciform bend specimen shown in Fig. 2(a) is modeled in Fig. 12 and the reduced thickness specimen [Fig. 2(b)] in Fig. 13. Both blunt-crack (20,754 nodes and 4317 20-node isoparametric brick elements) and sharpcrack $(18,775$ nodes and 3886 elements) models were generated for these analyses. For the blunt-crack model, the initial finite-root-radius at the crack tip was $0.0254 \mathrm{~mm}(0.001 \mathrm{in}$.) (see Fig. 14). Corresponding $J$-integrals were calculated with the sharp-crack models to obtain a more accurate determination of $J$ as a function of loading. All models were analyzed with the ABAQUS code utilizing a nonlinear elastic-plastic constitutive formulation with incremental loading of the specimen. Temperature-dependent properties were taken from tensile characterization tests of the heat-treated Plate 14 material (see Table 1, Fig. 4 and Ref. 3). All model results reported herein assumed a specimen temperature of $-5^{\circ} \mathrm{C}$, consistent with the toughness data shown in Fig. 10. Also, these assessments neglected the potential impact of ductile tearing observed in three of the uniaxially loaded cruciform specimens, which were tested at $-5^{\circ} \mathrm{C}$ and failed at high toughness values (see Fig. 10).

Applied load vs $J$-integral values computed for the original and reduced-thickness specimens are compared in Fig. 15. A similar comparison for CMOD shown in Fig. 16 illustrates the increased compliance associated with a reduction in test section thickness of the cruciform specimen.

Results generated from local crack-tip field analyses include the profiles of effective

stress, $\sigma_{e f f}$ and total effective plastic strain, $\varepsilon_{p}$, depicted in Fig. 17 for the uniaxial $(0: 1)$ 
and biaxial $(x: 1)(x=0.6$ and 1.0) loading cases. The parameters are computed at $J \approx 131 \mathrm{~kJ} / \mathrm{m}^{2}\left(0.75 \mathrm{in}\right.$ - $\left.\mathrm{kip} / \mathrm{in}^{2}\right)$, which corresponds approximately to a measured fracture toughness data point for biaxial (1:1) loading depicted in Fig. 10. Profiles of these parameters are plotted vs distance $r$ in front of the crack tip ( $\theta=0$, Fig. 14) normalized by $J / \sigma_{0}$, where $\sigma_{0}$ is the proportional limit of $512 \mathrm{MPa}(74.2 \mathrm{ksi})$. These fields clearly demonstrate that biaxial loading suppresses development of plasticity in front of the crack tip, with the effect becoming more pronounced with increasing biaxiality ratio.

\section{$6.2 J-Q$ Theory}

O'Dowd and Shih [9] developed the $J-Q$ methodology in which the $J$-integral sets the scale of deformation at the crack tip, and the hydrostatic stress parameter, $Q$, quantifies the level of stress triaxiality over distances of approximately $1<r /\left(J / \sigma_{0}\right)<5$ ahead of the crack tip. The annular zone over which the family of stress fields described by

$$
\frac{\sigma_{i j}}{\sigma_{0}}=f_{i j}\left(\frac{r}{J / \sigma_{0}}, \theta ; Q\right)
$$

accurately determines the actual field is called the $J-Q$ annulus. In Eq. (3), $r$ and $\theta$ are cylindrical coordinates (Fig. 14) with the origin at the crack tip. The crack-tip stress fields within the $J-Q$ annulus were represented by the sum of a $J$-dominant reference solution and a difference field $\left(\sigma_{i j}\right)_{D F F}$. O'Dowd and Shih [9] observed that the difference field corresponds approximately to a uniform hydrostatic shift in the stress field in front of the crack tip. They designated the amplitude of this approximate difference field by the letter $Q$,

$$
\sigma_{i j} \approx\left(\sigma_{i j}\right)_{Q=0}+Q \sigma_{0} \delta_{i j}(|\theta| \leq \pi / 2)
$$

Two operational definitions of the $Q$-family of fields are presented in Ref. 17 . The first definition is given in terms of the opening-mode stress, $\sigma_{z z}$,

$$
Q=\frac{\sigma_{z z}-\left(\sigma_{z z}\right)_{S S Y ; Q=0}}{\sigma_{0}} \text { at } \theta=0, \frac{r}{\left(J / \sigma_{0}\right)}=2 \text {, }
$$

where SSY refers to the small-scale-yielding reference solution. The second definition, which is consistent with the interpretation of $Q$ as a triaxiality parameter, is based on the hydrostatic stress, $\sigma_{H}$, 


$$
Q_{H}=\frac{\sigma_{H}-\left(\sigma_{H}\right)_{S S Y ; Q=0}}{\sigma_{0}} \text { at } \theta=0, \frac{r}{\left(J / \sigma_{0}\right)}=2
$$

where $\sigma_{H}$ (also known as the mean stress) is $1 / 3$ of the first invariant of the Cauchy stress tensor. These two operational definitions of $Q$-stress are applied in Fig. 18 to the local crack-tip field analysis of the uniaxially-loaded cruciform bend specimen. Normalized opening-mode stress vs normalized distance in front of the crack tip is compared with SSY results for a range of $J$-values in Fig. 18(a); results based on the hydrostatic stress are shown in Fig. 18(b). The SSY solution was developed using a 2-D plane-strain modified boundary layer (MBL) [8] model with the same finite-root-tip geometry and material properties as the 3-D finite-strain model. For the uniaxially-loaded specimen, the two definitions of $Q$-stress provide results that are equivalent, a result confirmed previously in Ref. 17.

In Fig. 19, opening-mode stress profiles for the three loading cases under study are plotted with the SSY solution. In Fig. 19(a), the $Q$-stresses calculated using the first definition for $Q$, Eq. (5), do not present significant differences among the loading cases due to the observed insensitivity of the opening-mode stress to biaxial loading. The second definition, Eq. (6), was used in Fig. 19(b) to calculate a $Q_{H}$-stress based on the hydrostatic stress profiles. At a nominal $J$-level of $131 \mathrm{~kJ} / \mathrm{m}^{2}$, the $Q_{H}$-stress differentiates between the different levels of biaxiality, such that the $Q_{H}$-stress decreases (in absolute value) monotonically with increasing biaxiality ratio. The peak values of normalized stress coincide for the three loading cases. In contrast to the uniaxial loading case, the difference fields for the biaxial loading cases vary with normalized distance over the range of $1<r /\left(J / \sigma_{0}\right)<5$; i.e., they do not correspond to a uniform shift in the hydrostatic stress field relative to the 2-D SSY solution. ${ }^{1}$

In Fig. 20, the two definitions of $Q$-stress are plotted as a function of normalized $J$ to determine their evolution over the loading path for the three biaxiality loading ratios. These curves terminate approximately at $J$-values corresponding to fracture toughness data points given in Fig. 10 for the three loading conditions. The $J$-integral in Fig. 20 has been normalized by the initial crack depth, $a$, and the proportional limit, $\sigma_{0}$. For both definitions of $Q$, the loss-of-constraint increases with increasing load. The $Q$-stress based on the opening mode stress (Fig. 20(a)) shows no significant differentiation among the three loading cases. For the biaxial (0.6:1) and equibiaxial (1:1) loading cases, the $Q_{H}$ parameter

\footnotetext{
${ }^{1}$ In Section 7, it is shown that the distribution of cleavage initiation sites determined from fracture surfaces of a limited number of the heat-treated Plate 14 cruciform specimens falls predominately in a region $(0.4<$ $\left.\Delta a /\left(J / \sigma_{0}\right)<1.2\right)$ where normalized hydrostatic stress is not significantly influenced by biaxial loading ratio.
} 
based on the hydrostatic stress (Fig. 20(b)) diverges from the uniaxial (0:1) path as the load level increases. A conventional interpretation of the $Q_{H}$ parameter in Fig. 20(b) is that a higher level of crack-tip constraint is maintained under increasing load as the biaxiality ratio is varied from uniaxial $(0: 1)$ to equibiaxial $(1: 1)$ conditions.

\subsection{Cleavage Toughness Scaling Model}

Dodds and Anderson (D-A) [10-11] quantified effects of constraint on cleavage fracture toughness using a toughness scaling model that couples the global parameter $J$ with a local failure criterion. The D-A model adopts the material volume ahead of the crack tip, over which the normalized maximum principal stress $\left(\sigma_{3} / \sigma_{0}\right)$ exceeds a critical value, as the local fracture criterion. See Appendix A for a discussion of some computational aspects of the D-A model. The convention applied in this paper for ordering the principal stresses is $\sigma_{3} \geq \sigma_{2} \geq \sigma_{1}$, where $\sigma_{3}$ is essentially equivalent to the opening-mode stress, $\sigma_{z z}$, in the cruciform specimen. The toughness scaling model requires that equal-stressed volumes ( or equal areas in 2-D models) be attained ahead of the crack tip for cleavage fracture to be realized in different specimens. Equality of stressed volumes implies an equal probability of achieving cleavage fracture, even though $J$-values may be markedly different.

For the plane strain model described in Ref. 17, the normalized maximum principal stress has the approximate form

$$
\frac{\sigma_{3}}{\sigma_{0}}=f_{0}\left(\frac{r}{\left(J / \sigma_{0}\right)}, \theta\right)+Q
$$

The area enclosed within the specified contour $\sigma_{3} / \sigma_{0}=C$ depends on $J$ and the triaxiality level as quantified by $Q$. Let $A_{o}$ and $J_{o}$ represent the area and $J$-value for the SSY condition with zero $T$-stress and $Q=0$ field. If $A_{f}$ and $J_{f}$ represent corresponding values in a finite cracked structure having a $Q<0$ field, then the ratio of $J_{f} / J_{0}$ for which $A_{0}\left(\sigma_{3} / \sigma_{0}\right)=A_{f}\left(\sigma_{3} / \sigma_{0}\right)$ serves to quantify the size and geometry dependence of fracture toughness. For the latter conditions, a ratio $J_{f} / J_{0}>1$ implies a loss of constraint in the finite structure that is associated with an increase in measured cleavage fracture toughness.

Computational studies of shallow-flawed, uniaxially-loaded, bend specimens performed by D-A [17] revealed that computed ratios of $J_{f} / J_{o}$ are relatively insensitive to the magnitude of the selected $\sigma_{3} / \sigma_{0}$ contour (for sufficiently large values) up to large-scale yielding. The principal stress contours were shown to exhibit a self-similarity that is implied by the $J-Q$ relation of Eq. (7); i.e., the shape of the contour is preserved with in- 
creasing load as measured by $J$, even though the enclosed area of the contour varies with the hydrostatic stress $Q \sigma_{0}$. At high loads, this similitude breaks down and the ratio $J_{f} / J_{o}$ becomes strongly dependent on the magnitude of $\sigma_{3} / \sigma_{0}$.

Previously, McAfee et al. [5] demonstrated that the D-A toughness scaling model predicted essentially no effect of biaxial loading on cleavage fracture toughness in the cruciform bend specimen due to the insensitivity of in-plane maximum principal stresses to farfield out-of-plane biaxial loading. Recently, analyses were carried out which utilized the hydrostatic stress variable as the failure criterion in the D-A scaling model in place of the maximum principal stress. Applications of this modified D-A model involved integrating over the volume contained within a range of selected hydrostatic stress contours immediately ahead of the crack front for a range of applied loads as measured by $J$. Effective cross-sectional areas for these contours could then be calculated by simply dividing the computed volume by the half-length of the crack front in the finite-element model $\left[x_{\max }=56 \mathrm{~mm}(2.2\right.$ in. $\left.)\right]$.

Figure 21 shows the variation of the predicted fracture toughness ratio $J_{0: I} / J_{s s y}$ with $\sigma_{H} / \sigma_{\mathrm{o}}$ for the shallow-flaw cruciform specimen subjected to uniaxial (0:1) loading. Each curve represents a given applied $J$-value, normalized using the constants $a$ and $\sigma_{0}$. The ratio $J_{0: I} / J_{s s y}$ is relatively insensitive to the selected $\sigma_{H} / \sigma_{\mathrm{o}}$ over the interval $1.8<\sigma_{H} / \sigma_{0}<2.35$ for the range of applied loads considered in the analysis. In Fig. 22, values of $J_{0: 1}$ and $J_{s s y}$, producing equal-stressed areas of material in the uniaxially loaded cruciform specimen and in the SSY model, are plotted on separate axes. The analysis is based on hydrostatic stress contours having a normalized stress ratio of $\sigma_{H} / \sigma_{o}=2.35$. With increasing load, extensive plastic flow develops in the cruciform specimen and more applied $J$ is required to produce the same stressed effective area as compared to the SSY model.

Figure 23 depicts results from a fracture toughness scaling analysis of the cruciform specimen for the three loading cases represented by the measured data in Fig. 10. A value of $\sigma_{H} / \sigma_{0}=2.35$ was selected as the stress contour for use in the scaling model. In Fig. 23(a), the evolution of applied loading $(J)$ vs equal-stressed volumes within the contour $\sigma_{H} / \sigma_{0}=2.35$ is shown for uniaxial and biaxial loading conditions. The $J$-value required to achieve a critical equal-stressed volume within the critical stress contour decreases with increasing biaxiality ratio. Furthermore, the uniaxial $(0: 1)$ loading condition approaches saturation beyond $J=500 \mathrm{~kJ} / \mathrm{m}^{2}$; i.e., the volume within the critical stress contour no longer increases with increasing applied $J$-value. In contrast, the biaxial loading 
conditions do not exhibit any tendency to saturate for the range of loadings considered in the analysis. Analysis results from Fig 23(a) were used to produce the plots of $J_{x: I}$ vs $J_{0: 1}$ ( $x=0.6$ and 1.0) in Fig. 23(b) that correspond to equal-stressed volumes of hydrostatic stress within the contour $\sigma_{H} / \sigma_{0}=2.35$ for the three loading cases. The biaxial loading values were used in place of the conventional SSY values in Fig. 23(b) in order to compare the relative effects of biaxial and uniaxial loading on the crack tip fields. As demonstrated in Fig. 23(b), the departure from the no-effect line is significant for both biaxial $(0.6: 1)$ and $(1: 1)$ loading cases, the effect being more pronounced with increasing biaxiality ratio. Also shown in Fig. 23(b) are the measured cruciform data for the heat-treated Plate 14 material tested at $-5^{\circ} \mathrm{C}$ (Fig. 10), where biaxial data are plotted near the vertical axis and uniaxial data near the horizontal axis. The D-A toughness scaling model, modified to use hydrostatic stress, is shown to provide an approximate correlation of the effects of biaxial loading on cleavage fracture toughness depicted in Fig. 10, based on a critical contour $\sigma_{H} / \sigma_{0}=2.35$. Figures 23(c) and (d) present $J_{x: 1}(x=0.6$ and 1.0) vs equalstressed volume and $J_{1: 1}$ vs $J_{0: 1}$ curve, respectively, for the cruciform specimen based on the maximum principal stress fracture criterion (critical contour $\sigma_{3} / \sigma_{0}=2.8$ ). These results [Fig. 23(d)] incorrectly predict essentially no effect of biaxial loading on toughness at $-5{ }^{\circ} \mathrm{C}$.

Figures 24(a) and (b) illustrate the evolution of maximum principal $\left(\sigma_{3} / \sigma_{0}=2.8\right)$ and hydrostatic $\left(\sigma_{H} / \sigma_{0}=2.35\right)$ stress contours, respectively, ahead of the crack tip for both uniaxial $(0: 1)$ and biaxial (1:1) loading conditions. The maximum principal stress contours indicate some difference in enclosed area between the two loading states for the lower $J$-values shown. As $J$ ircreases, this differentiation decreases. For comparable $J$-values, the area enclosed within the hydrostatic critical stress contour is shown to be greater for the biaxial loading case as compared to the uniaxial case, with the difference becoming more pronounced with increasing $J$-values.

The sensitivity of $J_{x: I}$ vs $J_{O: I}(x=0.6$ and 1.0) curves to selection of the critical stress ratio $\sigma_{H} / \sigma_{0}$ is depicted in Fig. 25 for the range $1.8 \leq \sigma_{H} / \sigma_{0} \leq 2.35$. Increasing the stress ratio beyond this range [toward the common peak value of $\sigma_{H} / \sigma_{0} \sim 3.2$ calculated for the three loading conditions in Fig. 19(b)] would produce a family of curves that converges monotonically to the "no effect" line shown in Fig. 25. In Fig. 26, curves of $J_{0: 1} / J_{x: 1}$ ratio $(x=0.6$ and 1.0$)$ for equivalent-stressed areas vs critical $\sigma_{H} / \sigma_{0}$ ratio are computed over a range of applied $J$-values. The dependence is shown to be more pronounced for $\sigma_{H} / \sigma_{0} \leq 2.2$. A critical stress ratio of $\sigma_{H} / \sigma_{0}=2.35$ was selected for the 
toughness scaling analysis presented in Fig. 23(b) to provide a reasonable correlation for the measured cruciform data given in Fig. 10.

\subsection{Weibull Stress Applications}

The methodology implemented in the WSTRESS (Version 2.0) computer code [24] was used to study effects of biaxial loading on Weibull analyses of shallow-flaw fracture toughness data in the lower transition temperature region. The WSTRESS code employs a multiaxial form of the weakest link model applicable for a 3-D cracked solid; the Weibull stress, $\sigma_{w}$, is characterized as a fracture parameter reflecting the local damage of the material near the crack tip. The Weibull stress, $\sigma_{w}$, given by the expression

$$
\sigma_{w}=\left[\frac{1}{4 \pi V_{o}} \int_{\Omega} \int_{0}^{2 \pi} \int_{0}^{\pi} \sigma_{q}^{m} \sin \varphi \mathrm{d} \varphi \mathrm{d} \theta \mathrm{d} \Omega\right]^{\frac{1}{m}},
$$

is evaluated by integration of the equivalent stress, $\sigma_{q}$, over the process zone. In Eq. (8), $V_{o}$ is the reference volume; $m$ is the Weibull modulus; $\theta$ and $\varphi$ are curvilinear coordinates for integration of the tensile stress; and $\Omega$ denotes the volume of the near-tip fracture process zone. Details regarding the derivation of Eq. (8) are presented in Appendix B.

\subsubsection{Fracture Criteria}

A fracture criterion must be specified to determine the equivalent (tensile) stress, $\sigma_{q}$, acting on a microcrack included into the fracture process zone. Three options for fracture criteria are implemented in the distributed version of WSTRESS [24] to evaluate the critical stress at which the crack becomes unstable: maximum principal stress (MPS), coplanar energy release (CER) rate, and normal stress averaging (NSA). Three additional fracture criteria were added to WSTRESS: the principal of independent action (PIA) [25] as proposed by Dortmans et al. [26], the noncoplanar energy release (NCER) rate [27-28], and the hydrostatic stress (HYDRO) criterion, developed during the present study. These criteria are implemented using the following definitions for the equivalent tensile stress, $\sigma_{q}$ : 


$\begin{array}{lll}\text { MPS } & \text { Maximum Principal Stress } & \sigma_{q}=\max \left(\sigma_{1}, \sigma_{2}, \sigma_{3}\right) \\ \text { NSA } & \text { Normal Stress Averaging } & \sigma_{q}=\sigma_{n} \\ \text { PIA } & \text { Principal of Independent Action } & \sigma_{q}=\left(\left\langle\sigma_{1}\right\rangle^{m}+\left\langle\sigma_{2}\right\rangle^{m}+\left\langle\sigma_{3}\right\rangle^{m}\right)^{\frac{1}{m}} \\ \text { CER } & \text { Coplanar Energy Release Rate } & \sigma_{q}=\left(\sigma_{n}{ }^{2}+\frac{4 \tau^{2}}{(2-v)^{2}}\right)^{\frac{1}{2}} \\ \text { NCER } & \text { Noncoplanar Energy Release Rate } & \sigma_{q}=\left(\sigma_{n}{ }^{4}+6 \sigma_{n}{ }^{2} \tau^{2}+\tau^{4}\right)^{\frac{1}{4}} \\ \text { HYDRO } & \text { Hydrostatic Stress } & \sigma_{q}=\frac{\operatorname{tr} \sigma}{3}=\frac{\sigma_{1}+\sigma_{2}+\sigma_{3}}{3}\end{array}$

where the state of stress is defined by the principal stresses $\left(\sigma_{1}, \sigma_{2}, \sigma_{3}\right)$ and the normal $\sigma_{n}$ and shear $\tau$ stresses are calculated by

$$
\begin{array}{ll}
\text { Normal Stress } & \sigma_{n}=\sigma_{3} \sin ^{2} \varphi \cos ^{2} \theta+\sigma_{2} \sin ^{2} \varphi \sin ^{2} \theta+\sigma_{1} \cos ^{2} \varphi \\
\text { Shear Stress } & \tau^{2}=\sigma_{3}{ }^{2} \sin ^{2} \varphi \cos ^{2} \theta+\sigma_{2}{ }^{2} \sin ^{2} \varphi \sin ^{2} \theta+\sigma_{1}{ }^{2} \cos ^{2} \varphi-\sigma_{n}{ }^{2}
\end{array}
$$

See the discussion in Appendix B for definitions of the angles $\varphi$ and $\theta$.

Figure 27 illustrates the response of the Weibull stress function for a range of $m$ values and two definitions of $\sigma_{q}$, when applied to the Plate 14 cruciform specimen subjected to uniaxial $(0: 1)$ and biaxial (1:1) loading conditions. The equivalent stress options selected for analysis were MPS and HYDRO. For those two choices, the values of $\sigma_{q}$ are independent of microcrack location and orientation, and the Weibull stress is, therefore,

$$
\sigma_{w}=\left[\frac{1}{V_{o}} \int_{\Omega} \sigma_{q}^{m} d \Omega\right]^{\frac{1}{m}} .
$$

In Fig. 27(a), the equivalent stress was set to MPS, and the Weibull stress was then calculated for values of the modulus $m=8,10$, and 20 . No significant effects of biaxial loading were detected for the three $m$ values using the MPS criterion. In Fig. 27(b), the calculation is repeated with the equivalent stress taken as HYDRO. Differentiation between uniaxial (0:1) and biaxial (1:1) loading can be observed when the Weibull modulus $m$ is set to values of 8 and 10. By increasing the Weibull modulus to 20 , any distinction between uniaxial and biaxial loading is essentially lost. (Computations of $m$ values appropriate for the cruciform fracture toughness data in Fig. 10 are described in following sections.) 


\subsubsection{Cumulative Probability of Failure}

The cumulative probability of cleavage fracture $\left(\wp_{0}\right)$ is estimated by either a twoparameter Weibull distribution of the form

$$
\wp_{0}\left(\sigma_{w}\right)=1-\exp \left[-\left(\frac{\sigma_{w}}{\sigma_{u}}\right)^{m}\right]
$$

or a three-parameter Weibull distribution

$$
\wp_{0}\left(\sigma_{w}\right)=1-\exp \left[-\left(\frac{\sigma_{w}-\sigma_{w-\min }}{\sigma_{u}-\sigma_{w-\min }}\right)^{m}\right]
$$

where the parameters of the distribution are the Weibull modulus $m$, the scaling stress (scaling factor) $\sigma_{u}$, and the minimum Weibull stress for cleavage fracture $\sigma_{w-\min }$.

\subsubsection{Required Experimental Data and Finite Element Models}

The WSTRESS code requires experimental fracture toughness data and the results of a finite element analysis in which the stress and deformation fields ahead of the crack tip are calculated as a function of the $J$-integral over a range of loading states. The toughness data for cruciform specimens $(a / W=0.1)$ fabricated using Plate 14 material and tested at $5^{\circ} \mathrm{C}$ are given in Table 3 and compared to the results of a finite element model in Figs. 28 and 29 for uniaxial $(0: 1)$ and biaxial (1:1) loading cases, respectively. The finite element results were obtained from the 3-D elastic-plastic models of the cruciform specimen depicted in Fig. 12 (for calculation of "FEM" curves) and Fig. 13 (for calculation of "FEM REDUCED" curve) using the ABAQUS [22] code. The finite element curves for the $J$ integral were calculated in the ABAQUS code by the domain integral method, and the experimental $J$-integral values were calculated using the $\eta$-factor technique described previously [6].

\subsubsection{Weibull Parameter Estimation: Statistical Inference Method}

The maximum likelihood (ML) method is implemented in WSTRESS to calculate, by statistical inference, point estimates for the parameters of the Weibull distribution. As discussed in the previous section, the estimation of the Weibull parameters $m$ and $\sigma_{u}$ requires both the results of experimental fracture mechanics testing to produce a sample 
population of toughness data and the results of a finite element analysis of the specimen for a range of loading states (as measured by the $J$-integral). The results of the Weibull parameter estimation calculations for each of the six equivalent stress criteria (using the twoparameter model) are summarized in Table 4, where the sample population included all 15 toughness data points at $-5^{\circ} \mathrm{C}: 6$ at $(0: 1)$ loading, 6 at (1:1) loading, and 3 at $(0.6: 1)$ loading. As noted in Ref. 24, despite the large-sample properties of the ML estimates, the resulting Weibull parameters are biased to higher values for small sample population sizes. The degree of bias in $m$ is independent of the true value of $\left(\hat{m}, \sigma_{u}\right)$; however, the bias is a function of the sample size (i.e., the number of experimental fracture toughness data points, $\left.N_{\text {exp }}\right)$. WSTRESS calculates a corrected estimate $m_{\text {corr }}$ using unbiasing factors $B\left(N_{\text {exp }}\right)$ generated from an appropriate asymptotic distribution.

A comparison of Weibull parameter estimates for three sample populations is given in Table 5 for the two-parameter model. The first two sample populations consist of the toughness data partitioned by loading state, with 6 data points each for both the uniaxial $(0: 1)$ and biaxial (1:1) loading cases. Table 5 demonstrates a significant dependence of the estimated Weibull parameters on population size and loading state.

Figure 30 shows a Weibull probability plot of the cumulative failure probability $\wp\left(\sigma_{w}\right)$ formulated as the $\log$-log parameter $\ln \ln \left[1 /\left(1-\wp\left(\sigma_{w}\right)\right)\right]$ vs the log of the Weibull stress, $\sigma_{w}$, normalized by the scaling stress, $\sigma_{u}$. With this scaling, the failure probabilities are functions only of the Weibull modulus, highlighting variations in the Weibull modulus as demonstrated by differences in the slopes of the straight lines in the plot. As shown in Fig. 30, the first five criteria form a relatively consistent grouping; however, the hydrostatic stress (HYDRO) criterion is separated from this group by a lower Weibull modulus.

The evolution of the Weibull stress for the six fracture criteria under uniaxial $(0: 1)$ loading is shown in Fig. 31 for the two-paraneter model. The estimated Weibull parameters $m$ given in Table 4 (based on $N_{\text {exp }}=15$ ) for the MPS and PIA criteria produce essentially identical Weibull stresses in Fig. 31. These two criteria also form an upper bound for the Weibull stresses. The NCER, CER, and NSA criteria (all involving a dominant normal tensile stress) group together with intermediate values for the Weibull stress. The HYDRO criterion provides a lower bound. The 15 toughness data points are plotted in Fig. 31 along the abscissa to demonstrate the range of the distribution.

Figure 32 compares the biaxial (1:1) and uniaxial (0:1) normalized Weibull stress curves for the (a) maximum principal stress (MPS) and (b) hydrostatic stress (HYDRO) fracture criteria. The MPS response is typical of the PIA, NCER, CER, and NSA criteria in 
showing no significant sensitivity to the loading state. HYDRO is the only fracture criterion tested that is responsive to the out-of-plane stress field.

A three-parameter Weibull distribution was also investigated using the HYDRO fracture criterion. The minimum Weibull stress for which cleavage is assumed to be possible, $\sigma_{w-\min }$, is calculated from the functional relationship between the Weibull stress and the loading parameter, the $J$-integral, that evolves during the iterative process within WSTRESS. The third parameter $\sigma_{w-\min }$ (continually updated during the iterations) is calculated from the intercept of the $\sigma_{w}=F(J, m)$ curve at $K_{J}=20 \mathrm{MPa}-\sqrt{\mathrm{m}} \Rightarrow$ $J=2.05 \mathrm{~kJ} / \mathrm{m}^{2}$. Table 6 presents a comparison between the two- and three-parameter model parameters for the partitioned biaxial (1:1) and uniaxial (0:1) sample populations and the mixed sample population of 15 toughness data points.

The WSTRESS code offers an alternative approach for calculating point estimates for the Weibull distribution parameters that involves a stochastic simulation of the fracture toughness data. In this approach, a statistical sample of fracture toughness is generated from a Weibull distribution. The fracture parameter, $J_{c}$, is assumed to be described by either a two-parameter Weibull distribution of the form

$$
\wp\left(J_{c}\right)=1-\exp \left[-\left(\frac{J_{c}}{\beta}\right)^{\alpha}\right]
$$

or a three-parameter Weibull distribution

$$
\wp\left(J_{c}\right)=1-\exp \left[-\left(\frac{J_{c}-\gamma}{\beta}\right)^{\alpha}\right]
$$

where $\alpha, \beta$, and $\gamma$ are the shape, scale, and threshold parameters of the distribution, respectively. The shape and scale parameters can be input explicitly or can be estimated by the maximum likelihood method based on the experimental toughness data set. The threshold parameter must be input as problem data if a three-parameter Weibull distribution is to be applied. The WSTRESS code uses a Monte Carlo simulation with inverse transformation to generate a large statistical sample. This Monte Carlo simulation has the form

$$
J_{c(g e n)}=\beta[-\ln (1-U)]^{1 / \alpha}+\gamma
$$

where $U$ is a random variate uniformly distributed between $[0,1]$. Table 7 presents a comparison of Weibull parameter point estimates based on Monte-Carlo-generated sample 
populations of 10,000 data points for both two- and three-parameter Weibull distributions of the toughness data. For the three-parameter models, the threshold value of $\gamma=2.05 \mathrm{~kJ} / \mathrm{m}^{2}$ corresponding to a $K_{\min }$ of $20 \mathrm{MPa}-\sqrt{\mathrm{m}}$ is explicitly specified. Figure 33 compares the resulting Weibull distributions in terms of the associated Weibull probability density function

$$
f\left(J_{c}, \alpha, \beta, \gamma\right)=\frac{\alpha}{\beta}\left(\frac{J_{c}-\gamma}{\beta}\right)^{\alpha-1} \exp \left(-\left(\frac{J_{c}-\gamma}{\beta}\right)^{\alpha}\right)
$$

In Fig. 33, the two curves that represent a partitioning of the data by loading state $\left(N_{\exp }=6\right)$ demonstrate that the highest $(1: 1)$ and the lowest $(0: 1)$ data points are located in the tails of their respective distributions.

\subsubsection{Weibull Parameter Estimation: Gao-Ruggieri-Dodds (G-R-D) Method - Multiconstraint Mapping to SSY Weibull Stress Space}

A new calibration scheme has been proposed by Gao, Ruggieri, and Dodds [31] to determine unique values of the Weibull parameters $\left(m, \sigma_{u}\right)$ by applying toughness data measured under low and high constraint conditions at the crack front. This new scheme (GR-D Method) arises from the authors' experience [31] with calibration methods based on statistical inference (as discussed in Sect. 6.4.4) in which they observed a strong sensitivity to the number of toughness data values $\left(J_{c}\right)$ comprising the sample population. They estimated that reliable estimates for the shape parameter, $\alpha$, in the Weibull distribution of the toughness data (see Eqs. (12) and (13)) would require many tens of $J_{c}$-values; however, fewer $J_{c}$-values (approximately 6-10) might be required to establish the median value of the distribution, $\beta$. This new scheme involves mapping the available toughness data back to a small scale yielding (SSY) Weibull stress space where $\alpha$ takes on the theoretical values of 2 or 4 for Weibull distributions expressed in terms of $J_{c}$ or $K_{J c}$, respectively. In the SSY Weibull stress space, the scheme requires iterations with the Weibull modulus $m$ to determine a unique value of $\beta$ and thereby a unique $m$-value. The calibration process employs large scale yielding (LSY) toughness data from two sample populations that represent distinctly different levels of crack tip constraint. The procedure then seeks the unique $m$-value that, upon mapping the two LSY sample populations back to the corresponding SSY Weibull stress space, results in constraint-corrected toughness distributions that have the same statistical properties, specifically the same SSY Weibull distributions as described by the $(\alpha, \beta)$ parameters. 
In addition to elastic-plastic analyses of the LSY specimens, the G-R-D calibration scheme also requires the results of a finite element analysis of a stationary crack under small scale yielding conditions. The plane-strain, modified boundary layer (MBL) model $[8,32]$ provides asymptotic crack-tip stress fields which have the general form

$$
\sigma_{i j}=\frac{K}{\sqrt{2 \pi r}} f_{i j}(\theta)+T \delta_{1 i} \delta_{1 j},
$$

where $K$ is the stress intensity factor. The special case of $T=0$ corresponds to the small scale yielding limit. An MBL finite-element model (see Fig. 34) was obtained from the authors of Ref. (31) and converted into an ABAQUS model with the same material property data used in the analyses of the Plate 14 cruciform specimens at $-5{ }^{\circ} \mathrm{C}$. Small scale yielding solutions, corresponding to an applied Mode I loading of the finite-root-tip crack, can be obtained by imposing the displacements

$$
\begin{aligned}
& u_{x}(R, \theta)=\frac{K_{I}(1+v)}{E} \sqrt{\frac{r}{2 \pi}} \cos \left(\frac{\theta}{2}\right)[3-4 v-\cos \theta] \\
& u_{y}(R, \theta)=\frac{K_{I}(1+v)}{E} \sqrt{\frac{r}{2 \pi}} \sin \left(\frac{\theta}{2}\right)[3-4 v-\cos \theta]
\end{aligned}
$$

along the outer circular boundary $(r=R)$ of the model, where the stress intensity factor $K$ is related to the $J$-integral by the plane-strain formula

$$
K_{I J}=\sqrt{\left(\frac{E}{1-v^{2}}\right) J} .
$$

The MBL model shown in Fig. 34 has one layer of 2,671 3-D elements (20-node isoparametric) with plane-strain constraints ( $u_{z}=0$ imposed on all 5708 nodes). The Weibull stress for the plane-strain case is

$$
\sigma_{w}=\left[\frac{B}{V_{0}} \int_{0}^{2 \pi} \int_{0}^{r^{*}} \sigma_{q}^{m} r \mathrm{~d} r \mathrm{~d} \theta\right]^{\frac{1}{m}},
$$

where $B$ is the finite thickness of the model and $r^{*}$ is the radius of the fracture process zone. To be consistent with the Weibull stresses calculated for the cruciform specimen, the reference volume, $V_{0}$, that is input to the WSTRESS code for the MBL model should maintain the same $B^{*} / V_{0}^{*}$ ratio implied by the geometry of the cruciform specimen. The 
MBL model had a thickness $B=0.0254 \mathrm{~mm}$, and the thickness and reference volume for the $1 / 4$ model of the cruciform are $B^{*}=55.88 \mathrm{~mm}$ and $V_{0}^{*}=1.0 \mathrm{~mm}^{3}$, respectively; therefore, the reference volume input to the WSTRESS code for the MBL model calculations was

$$
V_{0}=B\left(\frac{V_{0}^{*}}{B^{*}}\right)=0.0254\left(\frac{1.0}{55.88}\right)=0.00045455 \mathrm{~mm}^{3}
$$

The G-R-D calibration scheme proceeds by the following steps:

Step 1. Test two sets of specimens with different levels of crack tip constraint. In the terminology of Ref. [31], the biaxial (1:1) data are designated as Configuration $A$ (high constraint), and the uniaxial $(0: 1)$ data are designated as Configuration $\mathrm{B}$ (low constraint).

Step 2. Perform detailed 3-D finite element analyses for Configurations A and B and for a plane-strain SSY model with a reference thickness adjusted to be consistent with the specimens in Configurations $\mathrm{A}$ or $\mathrm{B}$. The nature of this adjustment is described above.

Step 3. Assume a trial $m$-value, and calculate the $\sigma_{w}$ vs $J$ histories for Configurations A and B and the SSY model. Constraint-correct the Configuration A and B toughness data by mapping the data points on the $\sigma_{w}$ vs $J$ curves back to the SSY curve as shown in Figs. 35(a) and (b) such that $J_{c-(i)} \rightarrow J_{(i)-S S Y}$.

Step 4. Estimate $\beta_{(0: 1)}$ and $\beta_{(1: 1)}$ in SSY Weibull stress space for the two configurations by the maximum likelihood point estimate relation

$$
\beta=\sqrt{\frac{1}{n} \sum_{i=1}^{n}\left(J_{(i)-S S Y}\right)^{2}}
$$

and calculate a relative error $R(m)$ by

$$
R(m)=\frac{\left(\beta_{(0: 1)}-\beta_{(1: 1)}\right)}{\beta_{(1: 1)}}
$$

Step 5. Repeat Steps 3 and 4 for a range of trial $m$-values and determine the $m$-value that produces an acceptably small relative error $R(m)$. 
The scaling stress, $\sigma_{u}$, can be calculated from the converged SSY-( $\sigma_{w-S S Y}$ vs $\left.J\right)$ curve by

$$
\sigma_{u}=\sigma_{w-S S Y} \text { at } J_{S S Y}=\beta_{(0: 1)}=\beta_{(1: 1)} \text {. }
$$

For the 3-parameter Weibull distribution, the third parameter, $\sigma_{w-\min }$, is calculated from the intercept of the $\sigma_{w-S S Y}$ vs $J$ curve at $J=2.05 \mathrm{~kJ} / \mathrm{m}^{2}\left(K_{J}=20 \mathrm{MPa}-\sqrt{\mathrm{m}}\right)$.

The G-R-D calibration scheme was carried out using the toughness data presented in Table 3 for the uniaxial $(0: 1)$ and biaxial (1:1) cruciform tests. As noted in Table 3, two of the uniaxial $(0: 1)$ specimens experienced precleavage ductile tearing. These tests produced the two highest toughness data values in the sample population. However, finite element ABAQUS solutions were unobtainable for these two high ductile tearing data points. At these high loading levels, the nonlinear elastic-plastic problem in ABAQUS failed to converge. As a result, two approximations were tested to assess the sensitivity of the calibration scheme to uncertainties in the Weibull stresses calculated for these two uniaxial (0:1) points. For the first approximation, a form of censoring was applied to the uniaxial $(0: 1)$ sample population by estimating the Weibull stresses for the two highest data points (specimens P9A and P2B.2) by a horizontal line extended to the right of the highest calculated Weibull stress (specimen P17A) as shown in Fig. 35(b). With this approximation, the iterations were carried out over a range of $m$-values with a converged solution obtained at $m=8.45$ as presented in Figs. 35(c) and (d). The second approximation involved a linear extrapolation of the uniaxial $(0: 1) \sigma_{w}$ vs $J$ curve, using the final two calculated $\left(J_{c}, \sigma_{w}\right)$ data points (specimens P19B and P17A) to estimate the slope of the linear extrapolation, as shown in Fig. 36(b). The G-R-D iterations resulted in a converged solution of $m=7.45$ as depicted in Figs. 36(c) and (d). The biaxial (1:1) $\sigma_{w}$ vs $J$ curves shown in Figs. 35(a) and 36(a) demonstrate that although the biaxial (1:1) loading state is considered a high-constraint condition relative to uniaxial $(0: 1)$ loading, biaxial $(1: 1)$ loading of the cruciform specimen still results in a significant loss of constraint relative to the idealized high-constraint condition of the SSY MBL solution. As a result, the importance of mapping both sets of toughness data back to a common SSY Weibull stress space should be emphasized. In Ref. (31), the option of replacing the SSY solution with a deep flaw, high-constraint model is discussed as a possible alternative calibration procedure. As applied to the cruciform data where both loading states involve shallow flaw geometries, however, this option did not prove to be feasible. 
The $m=8.45$ and $m=7.45$ solutions for the cumulative probability of cleavage fracture as a function of the $J$-integral are presented for the two sample populations partitioned by loading state (uniaxial (0:1) in Figs. 37(a) and 38(a) and biaxial (1:1) in Figs. 37(b) and 38 (b), respectively) and the combined populations expressed in terms of the SSY constraint-corrected toughness data (in Figs. 37(c) and 38(c), respectively). Both the two- and three-parameter Weibull model results are plotted. The probability of cleavage fracture for the experimental toughness data is calculated from the rank ordering relationship

$$
P^{(i)}=\frac{i-0.3}{N_{\text {exp }}+0.4}
$$

where the experimental toughness data are ordered in ascending rank by $1 \leq i \leq N_{\text {exp }}$. As shown in these figures, the three-parameter Weibull model discussed in Sect. 6.4.2 more closely fits the experimental data, relative to the two-parameter model, for all cases.

Figure 39 presents a comparison of the probability density distributions of the partitioned data sets (see Fig. 33) to the converged SSY Weibull stress space distribution corresponding to an $m$-value of 8.45 . Scaling toughness models are shown in Fig. 40 for $m=8.45$ and 7.45 . The biaxial (1:1) and uniaxial (0:1) toughness data are plotted along the ordinate and abscissa, respectively, in Figs. 40 (b) and (d) within their partitioned probability density distributions. The curves in Fig. 40 demonstrate that the Weibull correlative approach produces a scaling model that captures the significant effect of biaxial loading on shallow flaw fracture toughness.

\section{Cleavage Initiation Sites}

Fractographic studies were conducted on a subset of the Plate 14 cruciform beam specimens listed in Table 2 to identify locations of cleavage initiation sites (CISs). Results from these measurements are depicted in a plot of $\Delta a$ vs test temperature [Fig 41(a)], where $\Delta a$ is defined as the measured perpendicular distance from the CIS to the fatigue precrack front [Fig. 41(b)]. The CIS values for specimens tested at $-30^{\circ} \mathrm{C}$ under three different biaxiality ratios are tightly clustered, while those data for specimens tested at higher temperatures exhibit substantially greater scatter. In Fig. 42, measured cleavage fracture toughness is plotted as a function of measured distance to the CIS for the same set of specimens. These data imply that increasing fracture toughness correlates with increasing distance of the CIS from the fatigue precrack front. Anderson et al. [29], in their discussion 
of the micromechanics of cleavage fracture, observed that lower toughness is associated with cleavage triggering particles located near the crack tip, whereas substantially higher toughness is measured when the cleavage triggers are farther away. Similar trends were observed in measured CIS data obtained by Herrens et al. [30] from CT specimens of a pressure vessel steel.

In Fig. 43, fracture toughness and CIS distribution are plotted vs normalized distance $\Delta a /\left(J / \sigma_{\mathrm{o}}\right)$ to the CIS. The majority of data points are grouped in the interval $0.4<$ $\Delta a /\left(J / \sigma_{0}\right)<1.2$ [see Fig. 43(a)]. The latter observation is further emphasized in the plot of Fig. 43(b), which depicts the distribution of CIS vs normalized distance to the CIS. Also included as an inset in Fig. 43(b) is a plot of normalized hydrostatic stress vs normalized distance in front of the crack tip, with applied $J$ a parameter, for the uniaxially loaded cruciform beam [taken from Fig. 18(b)]. In a previous section, peak values of the normalized hydrostatic stress were shown to be insensitive to biaxial loading ratio [see Fig. 19(b)]. The normalized distance to the peak CIS distribution is approximately the same as that to the interval of peak normalized hydrostatic stress shown in the inset of Fig. 43(b). Thus, for this limited data set, the CIS distribution falls predominately in a region where normalized hydrostatic stress is not significantly influenced by biaxial loading ratio.

The CIS distribution in Fig. 43 provides an interesting correlation with results of an unpublished study recently conducted at ORNL. In that study, a penny-shaped microcrack $\left(r_{0}=10 \mu \mathrm{m}\right)$ embedded in a unit-cell model was used to estimate the recoverable elastic strain energy available to grow a microcrack in the cruciform specimen. Analysis results indicated that, for a normalized distance ahead of the cruciform macrocrack of 0.7 $\leq r /\left(J / \sigma_{0}\right) \leq 1.4$ and at a fixed biaxial $J_{C}$ of $121.5 \mathrm{~kJ} / \mathrm{m}^{2}$ (corresponding to specimen P15A in Table 2), biaxial loading produces a higher elastic strain energy release rate than the uniaxial loading state. Farther into the blunting region $\left(r /\left(J / \sigma_{0}\right) \leq 0.5\right)$ this biaxial effect disappears. These preliminary results provide some indication that, at the mesoscale level, biaxial loading offers a more favorable stress/strain state (relative to uniaxial loading) for continued growth of an initiated microcrack.

The three-parameter Weibull methodology represented by the results in Figs. 35-40 provides a correlative model of biaxial loading effects on cleavage fracture toughness for the Plate 14 material (at $-5^{\circ} \mathrm{C}$ ). Further study is required to reconcile the cruciform CIS distribution in Fig. 43 with this Weibull model based on hydrostatic stress. Conclusions inferred from the data set given in Figs. 41-43 may be premature, since a limited number of 
the Plate 14 cruciform specimens listed in Table 2 have been subjected to CIS measurements. Currently, fractographic studies are under way at ORNL to compile a CIS data base that includes all of the specimens in Table 2. The various elements of the current CIS data base summarized in Figs. 41-43 will be updated as soon as these additional measurements become available.

\section{Conclusions}

- For Plate 14 cruciform beam tests performed at $-5^{\circ} \mathrm{C}$, the test data demonstrate a significant effect of biaxial loading on shallow-flaw fracture toughness. The mean value of the biaxial (1:1) toughness resulted in approximately a 42 percent decrease from the mean uniaxial toughness $\left(K_{J c(1: 1)} / K_{J c(0: 1)}=0.58\right)$. Essentially no biaxial loading effect on fracture toughness was observed in tests performed at $-30^{\circ} \mathrm{C}$.

- The $Q_{H}$-stress parameter, based on hydrostatic stress, implies that a higher level of crack-tip constraint is maintained under increasing load as the biaxiality ratio is varied from uniaxial $(0: 1)$ to equibiaxial $(1: 1)$ conditions.

- The D-A toughness scaling model was shown to provide an approximate correlation of the effects of biaxial loading on cleavage fracture toughness for a limited data set, based on a critical contour $\sigma_{H} / \sigma_{0}=2.35$.

- A three-parameter Weibull model based on the hydrostatic stress criterion is shown to capture the experimentally observed biaxial effect by providing a scaling mechanism between uniaxial and biaxial loading states. Other fracture criteria employed in the Weibull model, including that of maximum principal stress, indicated essentially no effect of biaxial loading on fracture toughness.

- Experimental and analytical results presented herein provide the motivation to reconsider micromechanical models of cleavage fracture initiation and to develop a metallurgically-based argument for $\sigma_{H}$ as a driver of cleavage fracture under multiaxial loading conditions.

- Tests scheduled in 1998 of large-scale Plate 14 cruciform beam specimens, fabricated with a $140 \mathrm{~mm}$ test section and crack depth ratio of $\mathrm{a} / \mathrm{W}=0.1$, will provide additional fracture toughness data for calibration of parameters in the biaxial Weibull model currently under development within the HSST Program. 


\section{Acknowledgments}

The authors wish to thank Professor Robert H. Dodds, Jr., University of Illinois, for his many helpful contributions to the constraint applications described in this paper.

The authors acknowledge the support provided by S. N. M. Malik, M. G. Vassilaros, E. H. Hackett, and M. W. Mayfield of the USNRC.

The finite-element models of the cruciform specimen were developed by J. W. Bryson, and the initial ABAQUS stress analyses of the cruciform specimen were carried out by J. A. Keeney.

\section{References}

1. T. H. Theiss and D. K. M. Shum, Experimental and Analytical Investigation of the Shallow-Flaw Effect in Reactor Pressure Vessels, USNRC Report NUREG/CR-5886 (ORNL/TM-12115), Oak Ridge National Laboratory, July 1992.

2. B. R. Bass, J. A. Keeney, and W. J. McAfee, "Assessment of the Fracture Behavior of Weld Material from a Full-Thickness Clad RPV Shell Segment," Fatigue and Fracture Mechanics in Pressure Vessels and Piping, ASME Pressure Vessel and Piping Conference, Honolulu, Hawaii, July 23-27, 1995, PVP-Vol. 304, pp. 299-311.

3. W. J. McAfee, B. R. Bass, and J. W. Bryson, Jr., "Development of a Methodology for the Assessment of Shallow-Flaw Fracture in Nuclear Reactor Pressure Vessels," ASME Pressure Vessel and Piping Conference, Orlando, Florida, July 27-31, 1997, PVP-Vol. 346, pp. 85-94.

4. W. E. Pennell, B. R. Bass, J. W. Bryson, Jr., T. L. Dickson, and J. G. Merkle, "Preliminary Assessment of the Effects of Biaxial Loading on Reactor Pressure Vessel Structural-Integrity-Assessment Technology," Proceedings of 4th ASME/JSME International Conference in Nuclear Engineering, New Orleans, Louisiana, March 10-14, 1996.

5. W. J. McAfee, B. R. Bass, J. W. Bryson, Jr., and W. E. Pennell, Biaxial Loading Effects on Fracture Toughness of Reactor Pressure Vessel Steel, USNRC Report NUREG/CR-6273 (ORNL/TM-12866), Oak Ridge National Laboratory, March 1995.

6. T. H. Theiss et al., Initial Results of the Influence of Biaxial Loading on Fracture Toughness, USNRC Report NUREG/CR-6132 (ORNL/TM-12498), Oak Ridge National Laboratory, July 1994. 
7. B. R. Bass, W. J. McAfee, J. W. Bryson, Jr., and W. E. Pennell, "Determination of Cladding Effects on Shallow-Flaw Fracture Toughness of Reactor Pressure Vessel Steel under Prototypic Biaxial Loading," 5th International Conference on Nuclear Engineering, Nice, France, May 26-30, 1997.

8. S. G. Larsson and A. J. Carlson, "Influence of Non-Singular Stress Terms and Specimen Geometry on Small Scale Yielding at Crack-Tips in Elastic-Plastic Materials," Journal of the Mechanics and Physics of Solids 21, 447-473 (1973).

9. N. P. O'Dowd and C. F. Shih, "Family of Crack-Tip Fields Characterized by a Triaxiality Parameter: Part I - Structure of Fields," Journal of the Mechanics and Physics of Solids 39(8), 989-1015 (1991).

10. R. H. Dodds, Jr., T. L. Anderson, and M. T. Kirk, "A Framework to Correlate $a / W$ Ratio Effects on Elastic-Plastic Fracture Toughness $\left(J_{c}\right)$," International Journal of Fracture 48, 1-22 (1991).

11. T. L. Anderson and R. H. Dodds, Jr., "Specimen Size Requirements for Fracture Toughness Testing in the Ductile-Brittle Transition Region," Journal of Testing and Evaluation 19, 123-134 (1991).

12. C. Ruggieri and R. H. Dodds, Jr., "Probabilistic Modeling of Brittle Fracture Including 3-D Effects on Constraint Loss and Ductile Tearing," in International Conference on Local Approach to Fracture (MECAMAT 96), Fontainebleau, France, 1996.

13. A. G. Evans, "A General Approach for the Statistical Analysis of Multiaxial Fracture," Journal of the American Ceramic Society 61 (7-8), 302-308 (1978).

14. S. B. Batdorf and H. L. Heinisch, Jr., "Weakest-Link Theory Reformulated for Arbitrary Fracture Criterion," Journal of the American Ceramic Society 61 (7-8), 355-358 (1978).

15. T. Thiemeier and A. Brückner-Foit, "Influence of the Fracture Criterion on the Failure Prediction of Ceramics Loaded in Biaxial Flexure," Journal of the American Ceramic Society 74 (1), 48-52 (1991).

16. V. Weiss, "Material Ductility and Fracture Toughness of Metals," Proceedings of the International Conference on Mechanical Behavior of Materials, Kyoto, Japan, August 15-20, 1971, The Society of Materials Science, Japan, 1972. 
17. R. H. Dodds, Jr., C. F. Shih, and T. L. Anderson, Continuum and Micromechanics Treatment of Constraint in Fracture, UILU-ENG-92-2014, Dept. of Civil Engineering, University of Illinois, Urbana, Illinois, November 1992.

18. S. J. Garwood, "The Significance of Biaxial Loading on the Fracture Performance of a Pressure Vessel Steel," PVP-Vol. 213/MPC-Vol. 32, Pressure Vessel Integrity, ASME 1991, pp. 113-123.

19. B. R. Bass, J. W. Bryson and W. J. McAfee, "Analytical Assessment of a ReducedSize ORNL Cruciform Bend Specimen," Report ORNL/NRC/LTR-97/20, Oak Ridge National Laboratory, March 1998.

20. R. K. Nanstad et al., Irradiation Effects on Fracture Toughness of Two High-Copper Submerged-Arc Welds, HSSI Series 5, USNRC Report NUREG/CR-5913 (ORNL/TM-12156/V1), Oak Ridge National Laboratory, October 1992.

21. D. E. McCabe, U. Zerbst, and J. Heerens, Development of Test Practice Requirements for a Standard Method of Fracture Toughness Testing in the Transition Range, GKSS Report 93/E/81, GKSS Forschungszentrum, Geesthacht, GmBH, Germany, 1993.

22. ABAQUS Theory Manual, Version 5.7, Hibbit, Karlson and Sorensen, Inc., Providence, RI, 1997.

23. J. G. Merkle, An Examination of the Size Effects and Data Scatter Observed in SmallSpecimen Cleavage Fracture Toughness Testing, USNRC Report NUREG/CR-3672 (ORNL/TM-9088), Oak Ridge National Laboratory, April 1984.

24. C. Ruggieri and R. H. Dodds, Jr., WSTRESS 2.0: Numerical Computation of Probabilistic Fracture Parameters, Department of Civil Engineering, University of Illinois, UILU-ENG-95-2013, May 1998.

25. A. M. Freudenthal, "Statistical Approach to Brittle Fracture," Fracture: An Advanced Treatise, Vol. 2, Mathematical Fundamentals, ed. H. Liebowitz, Academic Press, New York, pp. 591-619, 1968.

26. L. Dortmans, T. Thiemeier, A. Brückner-Foit, and J. Smart, "WELFEP: A Round Robin for Weakest-Link Finite Element Postprocessors," Journal of the European Ceramic Society, 0955-2219/93/S6.00, Elsevier Science Publishers Ltd, England, 1993. 
27. T. K. Hellen and W. S. Blackburn, "The Calculation of Stress Intensity Factors for Combined Tension and Shear Loading," International Journal of Fracture 11, (1975) 605-617.

28. J. Lamon and A. G. Evans, "Statistical Analysis of Bending Strengths for Brittle Solids: A Multiaxial Fracture Problem," Journal of the American Ceramic Society 66, (1983) 177-182.

29. T. L. Anderson, D. Stienstra and R. H. Dodds, Jr., "A Theoretical Framework for Addressing Fracture in the Ductile-Brittle Transition Region," Fracture Mechanics: Twenty-Fourth Volume, ASTM STP 1207, J. D. Landes, D. E. McCabe, and J. A. M. Boulet, Eds., American Society for Testing and Materials, Philadelphia, 1994, pp. 186-214.

30. J. Heerens, D. T. Read, A. Cornec, and K.-H. Schwalbe, "Interpretations of Fracture Toughness in the Ductile-to-Brittle Transition Region by Fractographic Observations, Defect Assessment in Components - Fundomentals and Applications, ESIS/EGF9 (Edited by J. G. Blauel and K. H.-Schwalbe) 1991, Mechanical Engineering Publications, London, pp. 659-678.

31. X. Gao, C. Ruggieri, and R. H. Dodds, Jr., "Calibration of Weibull Stress Parameters Using Fracture Toughness Data," submitted for publication in the International Journal of Fracture, May 1998.

32. J. R. Rice, "Limitations to the Small Scale Yielding Approximation for Crack Tip Plasticity," Journal of the Mechanics and Physics of Solids 21, (1974) 17-26. 
Table 1. Properties of Heat-Treated Plate 14 Cruciform Specimens

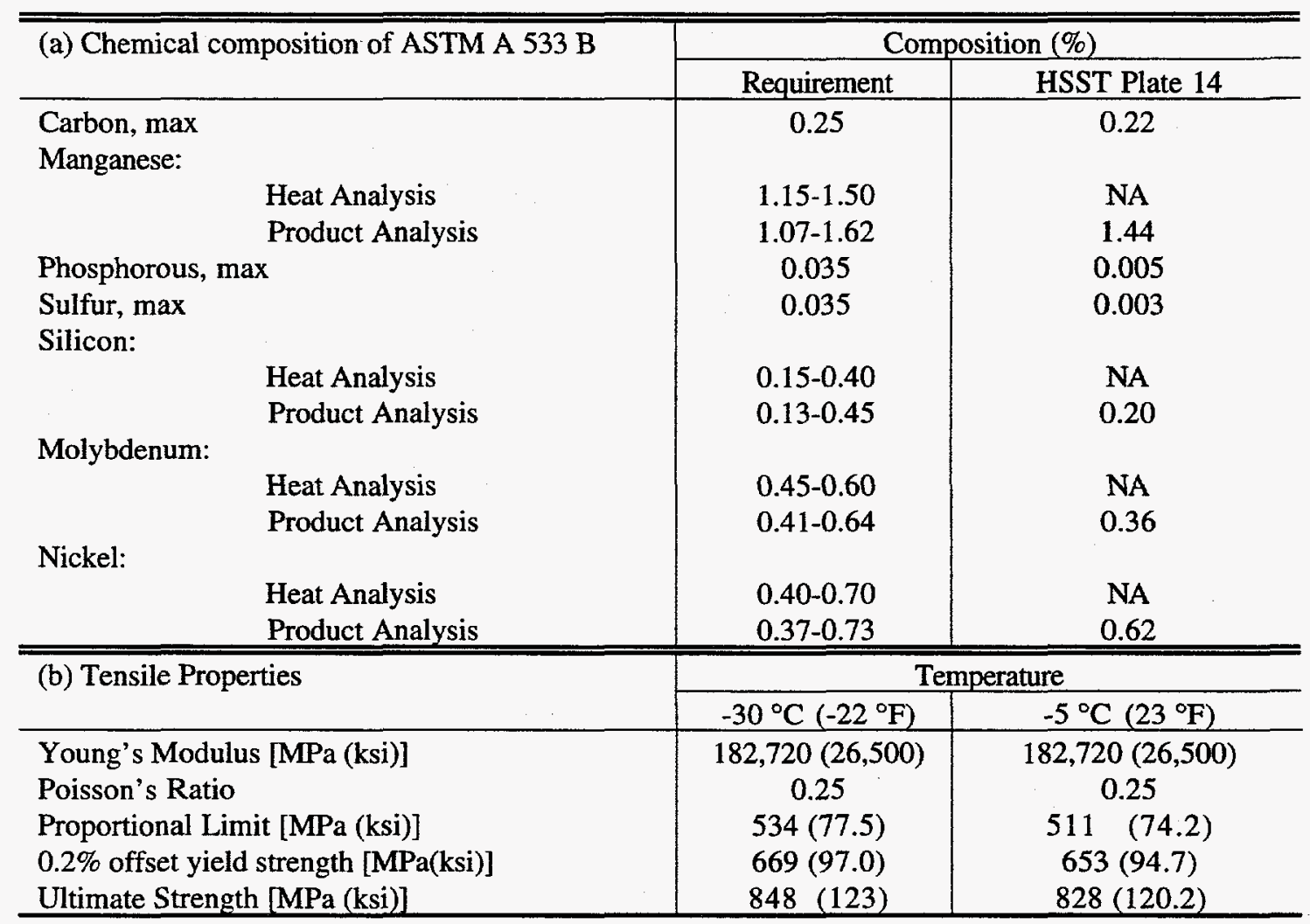


Table 2. Summary of Heat-Treated Plate 14 Cruciform Specimen Test Results

\begin{tabular}{|c|c|c|c|c|c|c|c|}
\hline \multirow[t]{2}{*}{ Spec. } & $\begin{array}{c}\text { Test } \\
\text { Temp. }\end{array}$ & $\begin{array}{c}\text { Biaxiality } \\
\text { Ratio }\end{array}$ & $\begin{array}{c}\text { Failure } \\
\text { Load }\end{array}$ & $\begin{array}{c}\text { Failure } \\
\text { LLD }\end{array}$ & $\begin{array}{l}\text { Failure } \\
\text { CMOD }\end{array}$ & $\begin{array}{l}K_{J} \text { from } \\
\text { P-LLD }\end{array}$ & $\begin{array}{c}K_{J} \text { from } \\
\text { P-CMOD }\end{array}$ \\
\hline & ${ }^{\circ} \mathrm{C}\left({ }^{\circ} \mathrm{F}\right)$ & & $\begin{array}{c}\mathrm{kN} \\
\text { (kips) }\end{array}$ & $\begin{array}{l}\mathrm{mm} \\
\text { (in.) }\end{array}$ & $\begin{array}{l}\mathrm{mm} \\
\text { (in.) }\end{array}$ & $\begin{array}{l}\text { MPaVm } \\
\text { (ksi } \sqrt{\text { in })}\end{array}$ & $\begin{array}{l}\text { MPa Vm } \\
\left(\mathrm{ksi} \gamma_{\mathrm{in}}\right)\end{array}$ \\
\hline${\mathrm{P} 2 \mathrm{~A}^{\mathrm{I}}}^{\mathrm{s}}$ & $38(100)$ & $0: 1$ & $\begin{array}{l}1785.2 \\
(401.3)\end{array}$ & $\begin{array}{c}29.561 \\
(1.1638)\end{array}$ & $\begin{array}{l}2.0269 \\
(.0798)\end{array}$ & $\mathrm{NA}^{*}$ & $\mathrm{NA}^{*}$ \\
\hline P12B & $-30(-22)$ & $0: 1$ & $\begin{array}{c}638.4 \\
(143.5)\end{array}$ & $\begin{array}{l}1.938 \\
(.0763)\end{array}$ & $\begin{array}{l}.1372 \\
(.0054)\end{array}$ & $\begin{array}{c}76.3 \\
(69.5)\end{array}$ & $\begin{array}{c}88.0 \\
(80.1)\end{array}$ \\
\hline P3A & $-31(-24)$ & $0: 1$ & $\begin{array}{c}736.1 \\
(165.5)\end{array}$ & $\begin{array}{l}2.276 \\
(.0896)\end{array}$ & $\begin{array}{r}.1753 \\
(.0069)\end{array}$ & $\begin{array}{r}97.2 \\
(88.4)\end{array}$ & $\begin{array}{l}103.0 \\
(93.7)\end{array}$ \\
\hline P14B & $-31(-24)$ & $0.6: 1$ & $\begin{array}{c}508.2 \\
(134.6)\end{array}$ & $\begin{array}{l}1.504 \\
(.0592)\end{array}$ & $\begin{array}{r}.1118 \\
(.0044)\end{array}$ & $\begin{array}{r}99.6 \\
(90.7)\end{array}$ & $\begin{array}{c}70.3 \\
(64.0)\end{array}$ \\
\hline P7B & $-30(-22)$ & $0.6: 1$ & $\begin{array}{c}965.8 \\
(217.1)\end{array}$ & $\begin{array}{c}2.802 \\
(.1103)\end{array}$ & $\begin{array}{r}.2362 \\
(.0093)\end{array}$ & $\begin{array}{r}129.2 \\
(117.6)\end{array}$ & $\begin{array}{r}136.3 \\
(124.0)\end{array}$ \\
\hline P13B & $-28(-18)$ & $1: 1$ & $\begin{array}{c}840.4 \\
(188.9)\end{array}$ & $\begin{array}{c}2.398 \\
(.0944)\end{array}$ & $\begin{array}{r}.2032 \\
(.0080)\end{array}$ & $\begin{array}{r}97.9 \\
(89.1)\end{array}$ & $\begin{array}{c}112.1 \\
(102.0)\end{array}$ \\
\hline P4A & $-29(-21)$ & $1: 1$ & $\begin{array}{l}1026.7 \\
(230.8)\end{array}$ & $\begin{array}{c}2.936 \\
(.1156)\end{array}$ & $\begin{array}{r}.2946 \\
(.0116)\end{array}$ & $\begin{array}{r}139.7 \\
(127.1)\end{array}$ & $\begin{array}{r}141.2 \\
(128.5)\end{array}$ \\
\hline P9A & $-3(26)$ & $0: 1$ & $\begin{array}{r}1529.0 \\
(343.7)\end{array}$ & $\begin{array}{l}14.575 \\
(.5738)\end{array}$ & $\begin{array}{c}1.6916 \\
(.0666)\end{array}$ & $\begin{array}{r}362.7 \\
(330.1)\end{array}$ & $\begin{array}{r}399.8 \\
(363.8)\end{array}$ \\
\hline P2B.1 & $-4(24)$ & $0: 1$ & $\begin{array}{l}1351.0 \\
(303.7)\end{array}$ & $\begin{array}{c}7.330 \\
(.2886)\end{array}$ & $\begin{array}{r}.7036 \\
(.0277)\end{array}$ & $\begin{array}{r}245.3 \\
(223.2)\end{array}$ & $\begin{array}{r}261.5 \\
(238.0)\end{array}$ \\
\hline P2B. 2 & $-3(26)$ & $0: 1$ & $\begin{array}{l}1504.4 \\
(338.2)\end{array}$ & $\begin{array}{l}13.774 \\
(.5423)\end{array}$ & $\begin{array}{c}1.4173 \\
(.0558)\end{array}$ & $\begin{array}{r}351.3 \\
(319.7)\end{array}$ & $\begin{array}{r}379.7 \\
(345.5)\end{array}$ \\
\hline P3B & $-4(24)$ & $0.6: 1$ & $\begin{array}{r}1449.6 \\
(325.9)\end{array}$ & $\begin{array}{c}8.440 \\
(.3323)\end{array}$ & $\begin{array}{r}.7645 \\
(.0301)\end{array}$ & $\begin{array}{r}273.0 \\
(248.5)\end{array}$ & $\begin{array}{r}269.8 \\
(245.5)\end{array}$ \\
\hline P12A & $-6(21)$ & $0.6: 1$ & $\begin{array}{l}1349.4 \\
(303.4)\end{array}$ & $\begin{array}{c}5.923 \\
(.2332)\end{array}$ & $\begin{array}{r}.5715 \\
(.0225)\end{array}$ & $\begin{array}{r}214.0 \\
(194.8)\end{array}$ & $\begin{array}{r}225.8 \\
(225.8)\end{array}$ \\
\hline P15A & $-4(25)$ & $1: 1$ & $\begin{array}{l}1072.6 \\
(241.1)\end{array}$ & $\begin{array}{c}3.424 \\
(.1348)\end{array}$ & $\begin{array}{r}.3150 \\
(.0124)\end{array}$ & $\begin{array}{r}155.9 \\
(141.9)\end{array}$ & $\begin{array}{r}154.6 \\
(140.7)\end{array}$ \\
\hline P6B & $-4(24)$ & $1: 1$ & $\begin{array}{l}1096.0 \\
(246.4)\end{array}$ & $\begin{array}{l}3.637 \\
(.1432)\end{array}$ & $\begin{array}{r}.3505 \\
(.0138)\end{array}$ & $\begin{array}{r}166.9 \\
(151.9)\end{array}$ & $\begin{array}{r}162.3 \\
(147.8)\end{array}$ \\
\hline $\mathrm{P} 4 \mathrm{~B}$ & $6(42)$ & $1: 1$ & $\begin{array}{l}1118.5 \\
(251.5)\end{array}$ & $\begin{array}{l}4.651 \\
(.1831)\end{array}$ & $\begin{array}{c}.3430 \\
(.0132)\end{array}$ & $\begin{array}{c}183.2 \\
(166.7)\end{array}$ & $\begin{array}{c}167.5 \\
(152.5)\end{array}$ \\
\hline P6A & $4(40)$ & $0.6: 1$ & $\begin{array}{l}1255.1^{2} \\
(282.2)\end{array}$ & $\begin{array}{l}5.210 \\
(.2051)\end{array}$ & $\begin{array}{c}.3384 \\
(.0161)\end{array}$ & $\begin{array}{c}204.3 \\
(186.0)\end{array}$ & $\begin{array}{c}195.2 \\
(177.6)\end{array}$ \\
\hline P10A & $8(46)$ & $0.6: 1$ & $\begin{array}{l}1570.8^{2} \\
(353.2)\end{array}$ & $\begin{array}{c}10.714 \\
(.4218)\end{array}$ & $\begin{array}{l}0.9042 \\
(.0356)\end{array}$ & $\begin{array}{c}308.1 \\
(280.4)\end{array}$ & $\begin{array}{c}297.4 \\
(270.6)\end{array}$ \\
\hline P7A & $15(60)$ & $1: 1$ & $\begin{array}{l}1303.7^{2} \\
(293.1)\end{array}$ & $\begin{array}{l}6.012 \\
(.2367)\end{array}$ & $\begin{array}{c}.6121 \\
(.0241) \\
\end{array}$ & $\begin{array}{c}248.3 \\
(226.0) \\
\end{array}$ & $\begin{array}{c}229.3 \\
(208.7) \\
\end{array}$ \\
\hline
\end{tabular}

${ }^{1}$ Test discontinued, no cleavage.

${ }^{2}$ Failure load based on equivalent $254 \mathrm{~mm}$ ( $10 \mathrm{in}$ ) beam arm length.

${ }^{3}$ Reduced thickness specimens. 
Table 2. Summary of Heat-Treated Plate 14 Cruciform Specimen Test Results (continued)

\begin{tabular}{|c|c|c|c|c|c|c|c|}
\hline Spec. & $\begin{array}{c}\text { Test } \\
\text { Temp. }\end{array}$ & $\begin{array}{c}\text { Biaxiality } \\
\text { Ratio }\end{array}$ & $\begin{array}{l}\text { Failure } \\
\text { Load }\end{array}$ & $\begin{array}{c}\text { Failure } \\
\text { LLD }\end{array}$ & $\begin{array}{l}\text { Failure } \\
\text { CMOD }\end{array}$ & $\begin{array}{l}K_{J} \text { from } \\
\text { P-LLD }\end{array}$ & $\begin{array}{c}K_{J} \text { from } \\
\text { P-CMOD }\end{array}$ \\
\hline & ${ }^{\circ} \mathrm{C}\left({ }^{\circ} \mathrm{F}\right)$ & & $\begin{array}{c}\text { kN } \\
\text { (kips) }\end{array}$ & $\begin{array}{l}\text { mm } \\
\text { (in.) }\end{array}$ & $\begin{array}{l}\mathrm{mm} \\
\text { (in.) }\end{array}$ & $\begin{array}{l}\text { MPaVm } \\
\text { (ksiVin) }\end{array}$ & $\begin{array}{l}\text { MPa } V_{m} \\
\left.\text { (ksi } \bigvee_{\text {in }}\right)\end{array}$ \\
\hline P9B & $15(60)$ & $0.6: 1$ & $\begin{array}{l}1500.9^{2} \\
(337.4)\end{array}$ & $\begin{array}{l}9.766 \\
(.3845)\end{array}$ & $\begin{array}{c}.8204 \\
(.0323)\end{array}$ & $\begin{array}{c}294.7 \\
(268.2)\end{array}$ & $\begin{array}{c}281.9 \\
(256.5)\end{array}$ \\
\hline P11B & $17(62)$ & $1: 1$ & $\begin{array}{l}1456.5^{2} \\
(327.5)\end{array}$ & $\begin{array}{l}9.934 \\
(.3911)\end{array}$ & $\begin{array}{l}.1090 \\
.0429)\end{array}$ & $\begin{array}{c}352.8 \\
(321.0)\end{array}$ & $\begin{array}{c}325.5 \\
(296.2)\end{array}$ \\
\hline P10B & $-6(22)$ & $1: 1$ & $\begin{array}{l}1246.2^{2} \\
(280.2)\end{array}$ & $\begin{array}{l}5.260 \\
(.2071)\end{array}$ & $\begin{array}{c}.4801 \\
(.0189)\end{array}$ & $\begin{array}{c}230.2 \\
(209.5)\end{array}$ & $\begin{array}{c}204.6 \\
(186.2)\end{array}$ \\
\hline P15B & $-4(25)$ & $0.6: 1$ & $\begin{array}{l}1431.1^{2} \\
(321.7)\end{array}$ & $\begin{array}{l}7.537 \\
(.2967)\end{array}$ & $\begin{array}{c}.5803 \\
(.0228)\end{array}$ & $\begin{array}{c}248.1 \\
(225.8)\end{array}$ & $\begin{array}{c}232.4 \\
(211.5)\end{array}$ \\
\hline P13A & $-6(21)$ & $0: 1$ & $\begin{array}{l}1035.7^{2} \\
(232.8)\end{array}$ & $\begin{array}{l}5.251 \\
(.2067)\end{array}$ & $\begin{array}{l}.3910 \\
(.0154)\end{array}$ & $\begin{array}{c}217.3 \\
(197.8)\end{array}$ & $\begin{array}{c}184.2 \\
(167.6)\end{array}$ \\
\hline P17B & $-5(24)$ & 1:1 & $\begin{array}{c}829.0^{2} \\
(186.4)\end{array}$ & $\begin{array}{l}4.170 \\
(.1642)\end{array}$ & $\begin{array}{l}0.2455 \\
(.0097)\end{array}$ & $\begin{array}{c}202.0 \\
(183.8)\end{array}$ & $\begin{array}{c}129.5 \\
(117.8)\end{array}$ \\
\hline P5A & $-3(26)$ & $1: 1$ & $\begin{array}{l}1269.4^{2} \\
(285.4)\end{array}$ & $\begin{array}{l}5.479 \\
(.2157)\end{array}$ & $\begin{array}{l}0.4597 \\
(.0181)\end{array}$ & $\begin{array}{c}228.3 \\
(207.8)\end{array}$ & $\begin{array}{c}210.0 \\
(191.1)\end{array}$ \\
\hline P5B & $-4(26)$ & $1: 1$ & $\begin{array}{l}1469.9^{2} \\
(330.5)\end{array}$ & $\begin{array}{l}10.251 \\
(.4036)\end{array}$ & $\begin{array}{l}1.0719 \\
(.0422)\end{array}$ & $\begin{array}{c}351.7 \\
(320.1)\end{array}$ & $\begin{array}{l}316.1 \\
(287.7)\end{array}$ \\
\hline $\mathrm{P} 18 \mathrm{~A}^{3}$ & $-3(27)$ & $0: 1$ & $\begin{array}{l}1329.9^{2} \\
(299.0)\end{array}$ & $\begin{array}{l}10.630 \\
(.4185)\end{array}$ & $\begin{array}{l}0.8560 \\
(.0337)\end{array}$ & $\begin{array}{c}302.6 \\
(275.4)\end{array}$ & $\begin{array}{c}280.5 \\
(255.3)\end{array}$ \\
\hline $\mathrm{P} 17 \mathrm{~A}^{3}$ & $-2(28)$ & $0: 1$ & $\begin{array}{l}1421.0^{2} \\
(319.5)\end{array}$ & $\begin{array}{c}13.904 \\
(.5474)\end{array}$ & $\begin{array}{l}1.1684 \\
(.0460)\end{array}$ & $\begin{array}{c}348.8 \\
(317.4)\end{array}$ & $\begin{array}{c}321.7 \\
(292.8)\end{array}$ \\
\hline $\mathrm{P} 19 \mathrm{~B}^{3}$ & $-2(28)$ & $0: 1$ & $\begin{array}{l}1342.2^{2} \\
(301.7)\end{array}$ & $\begin{array}{l}11.984 \\
(.4718)\end{array}$ & $\begin{array}{l}0.9982 \\
(.0393)\end{array}$ & $\begin{array}{c}319.6 \\
(290.9)\end{array}$ & $\begin{array}{c}302.3 \\
(275.1)\end{array}$ \\
\hline
\end{tabular}

${ }^{1}$ Test discontinued, no cleavage.

${ }^{2}$ Failure load based on equivalent $254 \mathrm{~mm}$ (10 in) beam arm length.

${ }^{3}$ Reduced thickness specimens. 
Table 3. Cruciform Toughness Data from FEM Model and Experimental Data

\begin{tabular}{|c|c|c|c|c|c|c|c|}
\hline \multirow[b]{2}{*}{ Specimen } & \multirow{2}{*}{$\begin{array}{l}\text { Test } \\
\text { Temp. } \\
{ }^{\circ} \mathrm{C}\end{array}$} & \multirow{2}{*}{$\begin{array}{c}\text { Biaxiality } \\
\text { Ratio }^{1}\end{array}$} & \multirow{2}{*}{$\begin{array}{c}\text { Failure } \\
\text { Load, } P_{L} \\
k N\end{array}$} & \multicolumn{2}{|c|}{ Toughness, $J_{c}$} & \multicolumn{2}{|c|}{ Toughness, $K_{J}$} \\
\hline & & & & $\begin{array}{l}\mathrm{FEM}^{3} \\
\mathrm{~kJ} / \mathrm{m}^{2}\end{array}$ & $\begin{array}{c}\mathrm{CMOD}^{4} \\
\mathrm{~kJ} / \mathrm{m}^{2}\end{array}$ & $\begin{array}{c}\mathrm{FEM}^{3} \\
\mathrm{MPa} \sqrt{\mathrm{m}}\end{array}$ & $\begin{array}{l}\mathrm{CMOD}^{4} \\
\mathrm{MPa}_{\mathrm{m}}\end{array}$ \\
\hline$\overline{\mathrm{P} 2 \mathrm{~B} .2 \mathrm{DT}^{6}}$ & -3 & $0: 1$ & $1 5 \longdiv { 0 4 . 4 }$ & 433.8 & 638.65 & 290.8 & 352.8 \\
\hline P9A DT & -3 & $0: 1$ & 1529.0 & 469.8 & 747.84 & 302.6 & 381.8 \\
\hline $\mathrm{P} 13 \mathrm{~A} 2$ & -6 & $0: 1$ & 1165.1 & 177.5 & 156.71 & 186.0 & 174.8 \\
\hline P17 $A^{2,5}$ & -2 & $0: 1$ & 1421.0 & 539.9 & 530.94 & 324.4 & 321.7 \\
\hline $\mathrm{P} 18 \mathrm{~A}^{2.5}$ & -3 & $0: 1$ & 1329.9 & 370.9 & 403.72 & 268.9 & 280.5 \\
\hline $\mathrm{P}^{19 \mathrm{~B}^{2,5}}$ & -2 & $0: 1$ & 1342.2 & 388.6 & 468.84 & 275.2 & 302.3 \\
\hline P3B & -4 & $0.6: 1$ & 1449.6 & 272.7 & 363.53 & 230.5 & 266.2 \\
\hline P12A & -6 & $0.6: 1$ & 1349.4 & 212.2 & 256.57 & 203.4 & 223.6 \\
\hline $\mathrm{P}^{15 \mathrm{~B}^{2}}$ & -4 & $0.6: 1$ & 1431.1 & 260.3 & 277.04 & 225.2 & 232.4 \\
\hline P15A & -4 & $1: 1$ & 1072.6 & 118.5 & 121.50 & 152.0 & 153.9 \\
\hline P6B & -4 & $1: 1$ & 1096.0 & 125.2 & 135.22 & 156.2 & 162.3 \\
\hline $\mathrm{P}_{17 \mathrm{~B}^{2}}$ & -5 & $1: 1$ & 932.6 & 80.5 & 85.98 & 125.2 & 129.4 \\
\hline $\mathrm{P}^{2} \mathrm{~A}^{2}$ & -3 & $1: 1$ & 1269.4 & 208.9 & 226.30 & 201.8 & 210.0 \\
\hline${\mathrm{P} 5 B^{2}}^{2}$ & -4 & $1: 1$ & 1469.9 & 404.2 & 512.64 & 280.7 & 316.1 \\
\hline $\mathrm{P} 10 \mathrm{~B}^{2}$ & -6 & $1: 1$ & 1246.2 & 193.9 & 214.72 & 194.4 & 204.6 \\
\hline
\end{tabular}

${ }^{1}$ Biaxiality ratio is the ratio of the transverse to longitudinal beam arm loads: $P_{T} / P_{L}$

${ }^{2}$ Failure load based on equivalent $254 \mathrm{~mm}$ (10 in.) beam arm length.

${ }^{3}$ Calculated using finite-element sharp-crack model of cruciform specimen with $254 \mathrm{~mm}$ (10 in.) beam arms

${ }^{4}$ Experimental values calculated from CMOD data

${ }^{5}$ Reduced specimen test section $a / W=0.1 ; a=9.65 \mathrm{~mm}(0.38 \mathrm{in}$.); $W=96.0 \mathrm{~mm}(3.78 \mathrm{in}$.)

${ }^{6} \mathrm{DT}$ indicates precleavage ductile tearing

Table 4. Parameter Estimates for the Weibull Modulus using Statistical Inference and Two-Parameter Model

\begin{tabular}{cl|ccc}
\hline & & \multicolumn{3}{|c}{ Weibull Parameters } \\
Case & \multicolumn{1}{c|}{ Criterion } & $m$ & $m_{\text {corr }} \sigma_{u}$ (MPa) \\
\hline 1 & Maximum Principal Stress (MPS) & 12.65 & 11.48 & 2851 \\
2 & Principal of Independent Action (PIA) & 12.31 & 11.18 & 2903 \\
3 & Noncoplanar Energy Release (NCER) & 12.12 & 11.09 & 2546 \\
4 & Coplanar Energy Release (CER) & 12.04 & 10.93 & 2521 \\
5 & Normal Stress Averaging & 11.89 & 10.80 & 2500 \\
6 & Hydrostatic Stress (HYDRO) & 10.27 & 9.33 & 2304 \\
\hline
\end{tabular}


Table 5. Comparison of Weibull Parameter Estimates Between Three Sample Population Sizes using Statistical Inference and a Two-Parameter Model

\begin{tabular}{|c|c|c|c|c|}
\hline Case & Equivalent Stress Criterion & $\begin{array}{l}\text { Experimental } \\
N_{\text {exp }} / \text { Loading }\end{array}$ & \multicolumn{2}{|c|}{$\begin{array}{l}\text { Weibull Parameters } \\
m_{\text {corr }} \sigma_{u},(\mathrm{MPa})\end{array}$} \\
\hline 1a & \multirow[t]{3}{*}{ Maximum Principal Stress (MPS) } & $6 /(1: 1)$ & 15.41 & 2321 \\
\hline $1 b$ & & $6 /(0: 1)$ & 10.21 & 3216 \\
\hline $1 c$ & & $15 /(\mathrm{mix})$ & 11.48 & 2851 \\
\hline $2 \mathrm{a}$ & \multirow[t]{3}{*}{ Principal of Independent Action (PIA) } & $6 /(1: 1)$ & 15.36 & 2326 \\
\hline $2 b$ & & $6 /(0: 1)$ & 10.17 & 3224 \\
\hline $2 c$ & & $15 /(\operatorname{mix})$ & 11.18 & 2903 \\
\hline $3 a$ & \multirow{3}{*}{ Noncoplanar Energy Release Rate (NCER) } & $6 /(1: 1)$ & 15.25 & 2110 \\
\hline $3 b$ & & $6 /(0: 1)$ & 9.90 & 2848 \\
\hline $3 \mathrm{c}$ & & $15 /(\operatorname{mix})$ & 11.09 & 2546 \\
\hline $4 a$ & \multirow[t]{3}{*}{ Coplanar Energy Release Rate (CER) } & $6 /(1: 1)$ & 15.08 & 2090 \\
\hline $4 \mathrm{~b}$ & & $6 /(0: 1)$ & 9.75 & 2821 \\
\hline $4 c$ & & $15 /(\operatorname{mix})$ & 10.93 & 2521 \\
\hline $5 a$ & \multirow[t]{3}{*}{ Normal Stress Averaging (NSA) } & $6 /(1: 1)$ & 14.94 & 2074 \\
\hline $5 b$ & & $6 /(0: 1)$ & 9.63 & 2799 \\
\hline $5 c$ & & $15 /(\operatorname{mix})$ & 10.80 & 2500 \\
\hline $6 a$ & \multirow[t]{3}{*}{ Hydrostatic Stress (HYDRO) } & $6 /(1: 1)$ & 12.98 & 1888 \\
\hline $6 \mathrm{~b}$ & & $6 /(0: 1)$ & 8.29 & 2646 \\
\hline $6 c$ & & $15 /(\mathrm{mix})$ & 9.33 & 2304 \\
\hline
\end{tabular}

Table 6. Comparison of Weibull Parameter Estimates Between the Two- and Three-Parameter Models using Statistical Inference with the Hydrostatic Stress Criterion

\begin{tabular}{ccccc}
\hline Loading & $\begin{array}{c}\text { Data } \\
N_{\exp }\end{array}$ & $m_{\text {corr }}$ & $\begin{array}{l}\sigma_{u} \\
(\mathrm{MPa})\end{array}$ & $\begin{array}{c}\sigma_{w-\min } \\
(\mathrm{MPa})\end{array}$ \\
\hline$(1: 1)$ & 6 & 12.98 & 1888 & 0 \\
$(1: 1)$ & 6 & 10.17 & 2126 & 751 \\
\hline$(0: 1)$ & 6 & 8.29 & 2646 & 0 \\
$(0: 1)$ & 6 & 7.60 & 2825 & 700 \\
\hline$(0: 1)$ & 15 & 9.33 & 2304 & 0 \\
$(0: 1)$ & 15 & 8.42 & 2427 & 692 \\
$(1: 1)$ & 15 & 8.42 & 2427 & 712 \\
\hline
\end{tabular}


Table 7. Comparison of Weibull Parameter Estimates Between the Two- and Three-Parameter Models using Statistical Inference with the Hydrostatic Stress Criterion and a Stochastically Simulated Sample Population Size of 10,000

\begin{tabular}{cccccccc}
\hline Loading & $\begin{array}{c}\text { Data } \\
N_{\text {exp }}\end{array}$ & $\alpha$ & $\begin{array}{c}\beta \\
\left(\mathrm{kJ} / \mathrm{m}^{2}\right)\end{array}$ & $\begin{array}{c}\gamma \\
\left(\mathrm{kJ} / \mathrm{m}^{2}\right)\end{array}$ & & $\begin{array}{c}\sigma_{u} \\
(\mathrm{MPa})\end{array}$ & $\begin{array}{c}\sigma_{w-\min } \\
(\mathrm{MPa})\end{array}$ \\
\hline$(1: 1)$ & 6 & 2.04 & 225 & 0 & 18.08 & 1757 & 0 \\
$(1: 1)$ & 6 & 2.04 & 225 & 2.05 & 13.90 & 1839 & 754 \\
$(1: 1)$ & 6 & 2.0 & 225 & 2.05 & 13.69 & 1848 & 752 \\
\hline$(0: 1)$ & 6 & 2.97 & 550 & 0 & 11.14 & 2296 & 0 \\
$(0: 1)$ & 6 & 2.97 & 550 & 2.05 & 10.16 & 2309 & 701 \\
$(0: 1)$ & 6 & 2.0 & 550 & 2.05 & 9.75 & 2260 & 697 \\
\hline$(0: 1)$ & 15 & 1.86 & 388 & 0 & 10.75 & 2145 & 0 \\
$(0: 1)$ & 15 & 1.86 & 388 & 2.05 & 9.64 & 2199 & 696 \\
$(0: 1)$ & 15 & 2.0 & 388 & 2.05 & 9.77 & 2198 & 697 \\
\hline$(1: 1)$ & 15 & 1.86 & 388 & 0 & 10.75 & 2145 & 0 \\
$(1: 1)$ & 15 & 1.86 & 388 & 2.05 & 9.64 & 2199 & 723 \\
$(1: 1)$ & 15 & 2.0 & 388 & 2.05 & 9.77 & 2198 & 724 \\
\hline
\end{tabular}



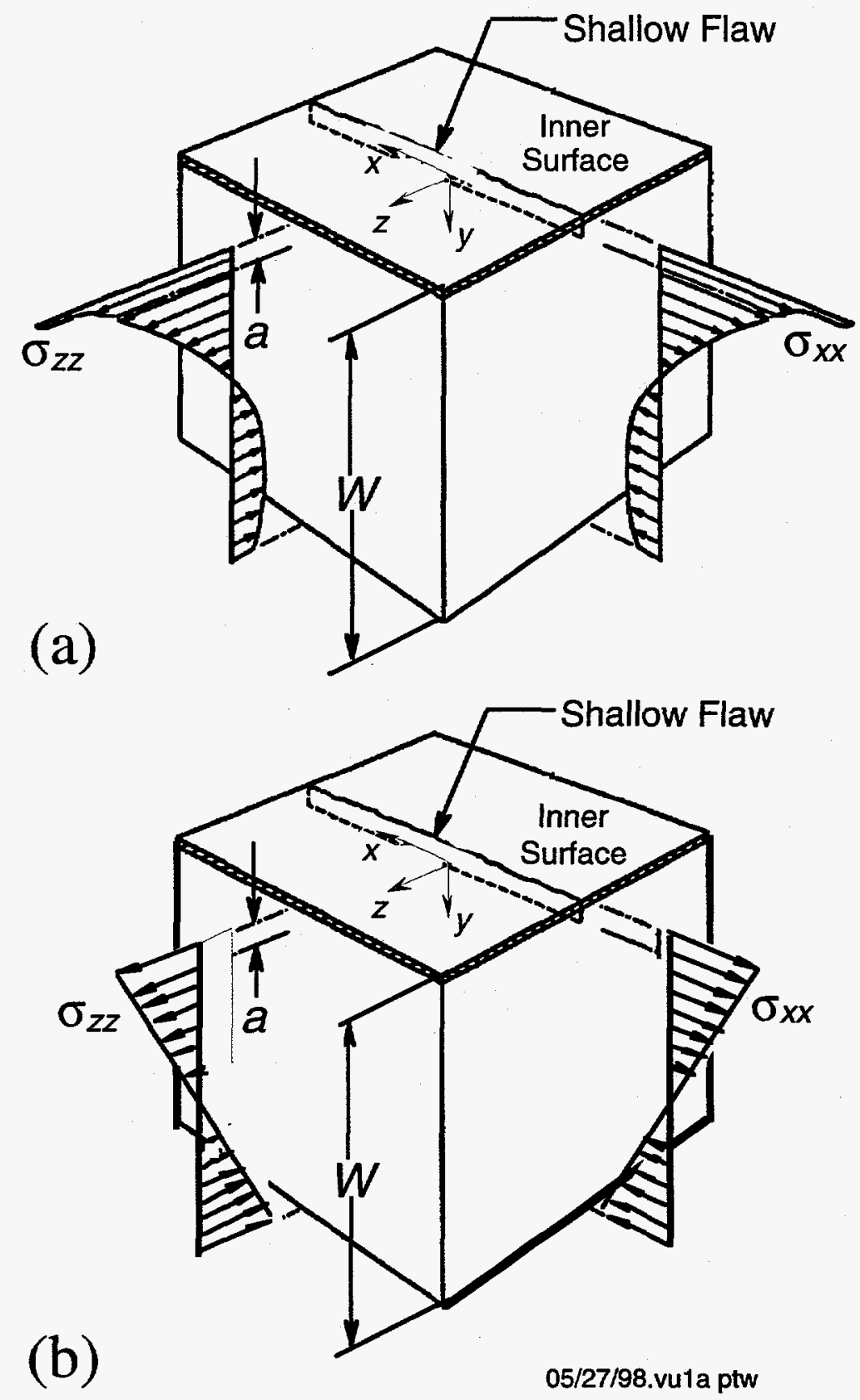

Fig. 1 (a) PTS loading produces nonlinear biaxial stress in an RPV wall with one of the principal stresses aligned parallel with the tip of the constant-depth shallow surface flaw; (b) 8-point bending in the cruciform specimen produces a linear approximation of the PTS biaxial stress field. 


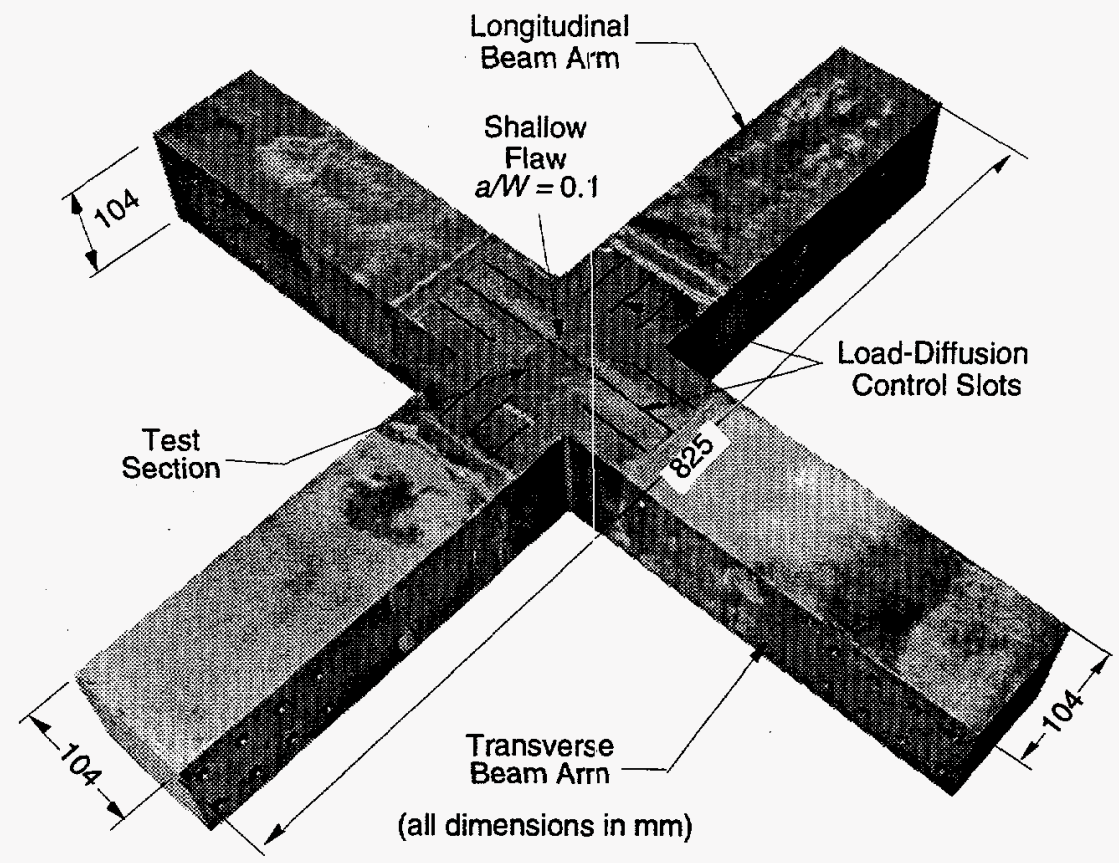

(a)

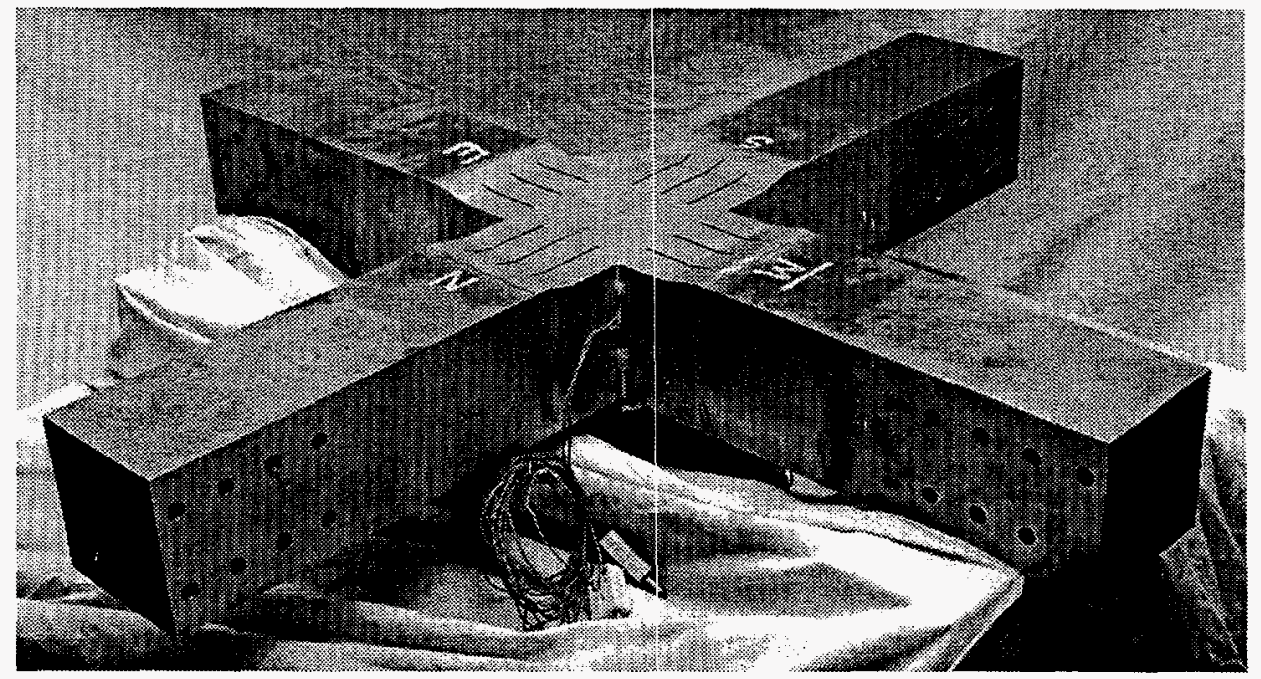

(b)

Fig. 2 Geometry of the cruciform shallow-flaw biaxial fracture toughness test specimen: (a) test section thickness - $104 \mathrm{~mm}$; (b) test section thickness $96 \mathrm{~mm}$. 


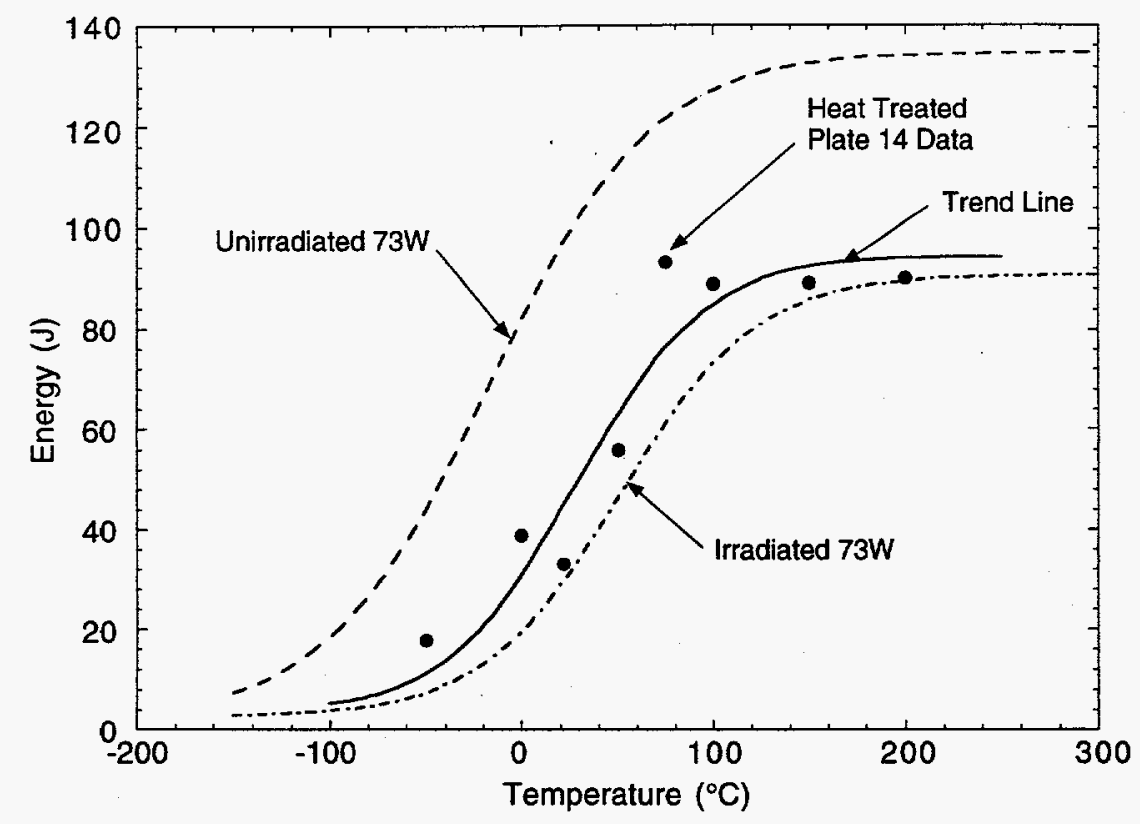

Fig. 3 Comparison of Charpy curves from heat-treated Plate 14 material with that from irradiated $73 \mathrm{~W}$ material.

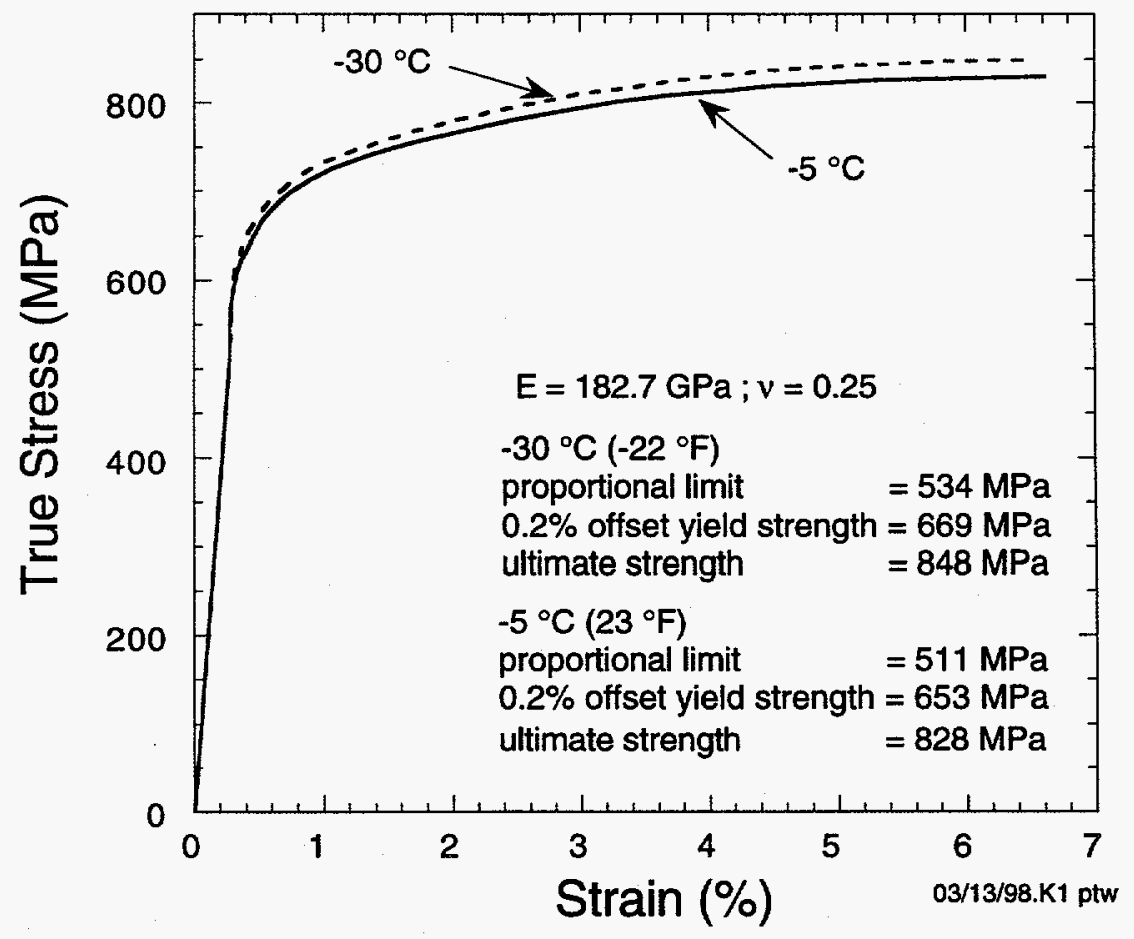

Fig. 4 Stress-strain behavior for plate 14 material measured at $-30^{\circ} \mathrm{C}$ and $-5^{\circ} \mathrm{C}$. 


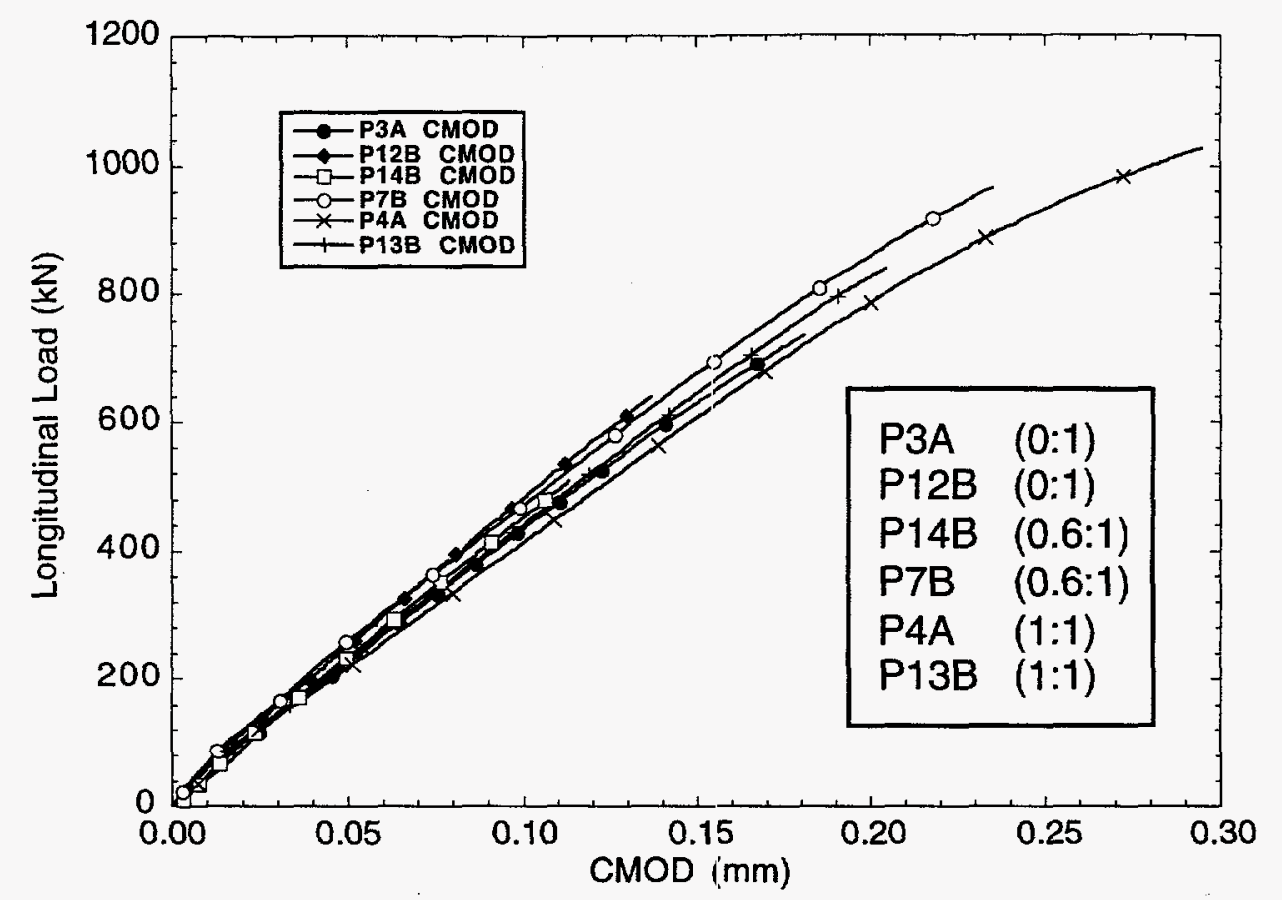

Fig. 5 Comparison of CMOD responses for cruciform specimens tested at $-30^{\circ} \mathrm{C}$ $\left(-22^{\circ} \mathrm{F}\right)$ for biaxial load ratios of $(0: 1),(0.6: 1)$, and $(1: 1)$.

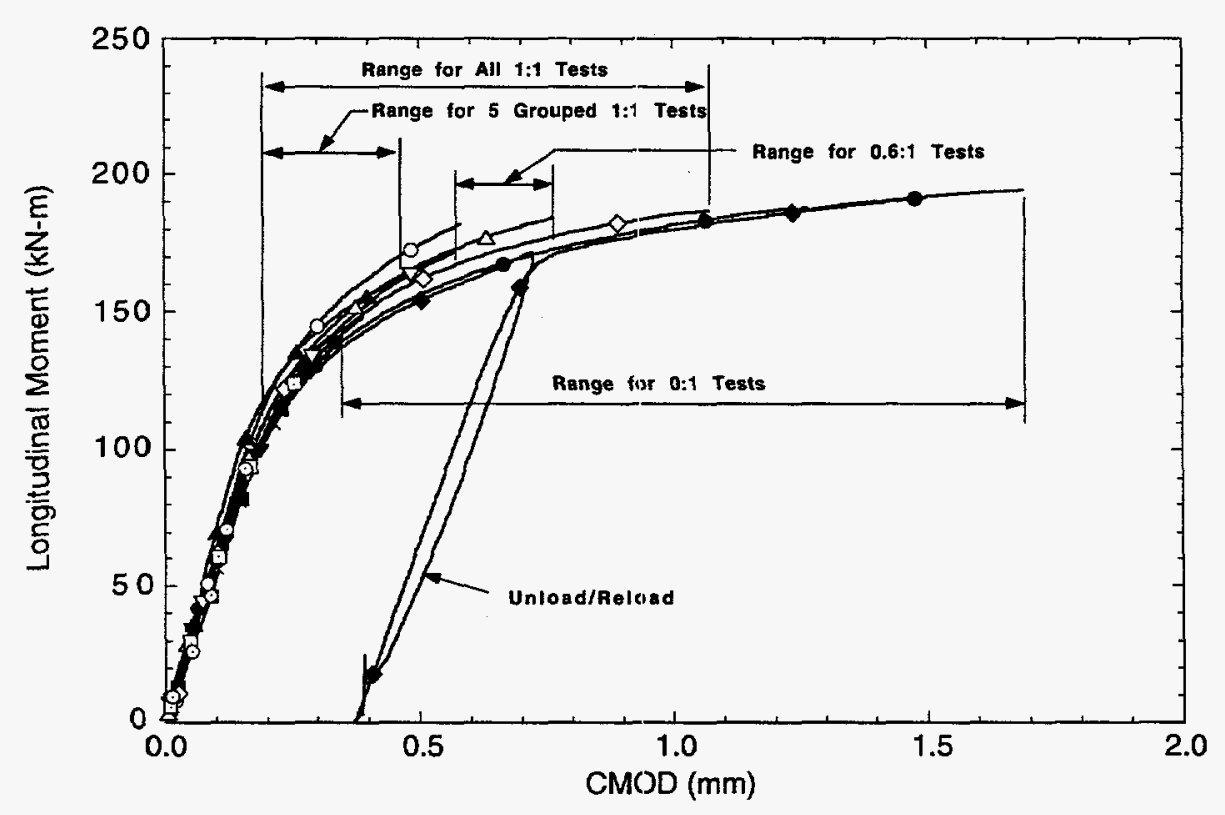

Fig. 6 Comparison of CMOD responses for cruciform specimens at nominal test temperature of $-5^{\circ} \mathrm{C}\left(23^{\circ} \mathrm{F}\right)$ for biaxial load ratios of $(0: 1),(0.6: 1)$, and (1:1). 


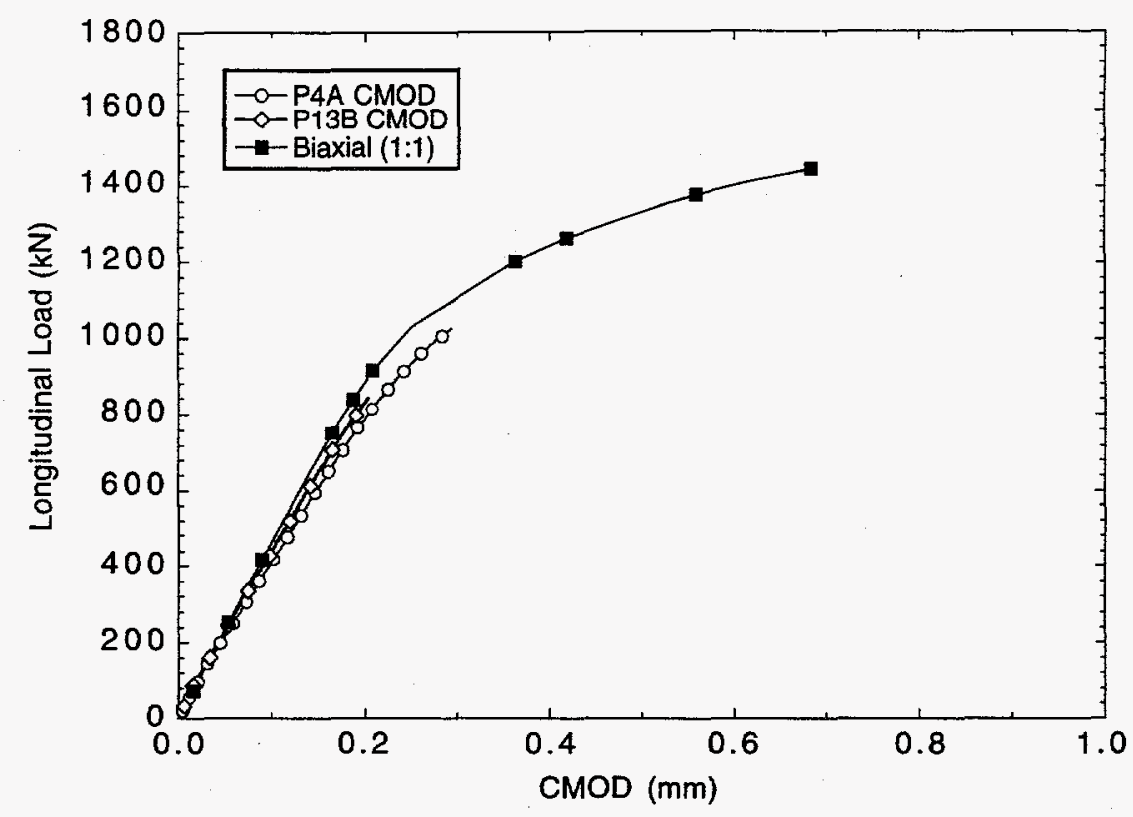

Fig. 7 Comparison of predicted and measured CMOD for biaxially (1:1) loaded cruciform test at $-30^{\circ} \mathrm{C}\left(-22^{\circ} \mathrm{F}\right)$.

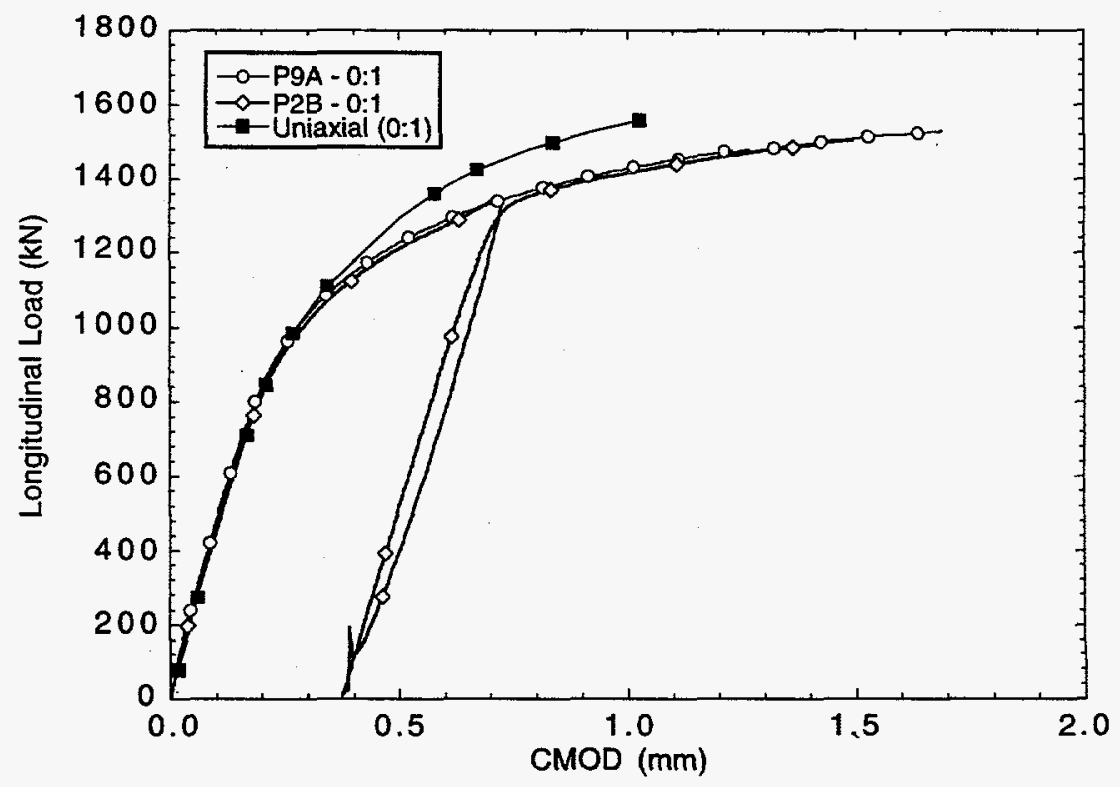

Fig. 8 Comparison of predicted and measured CMOD for uniaxially $(0: 1)$ loaded cruciform test at $-5^{\circ} \mathrm{C}\left(23^{\circ} \mathrm{F}\right)$. 


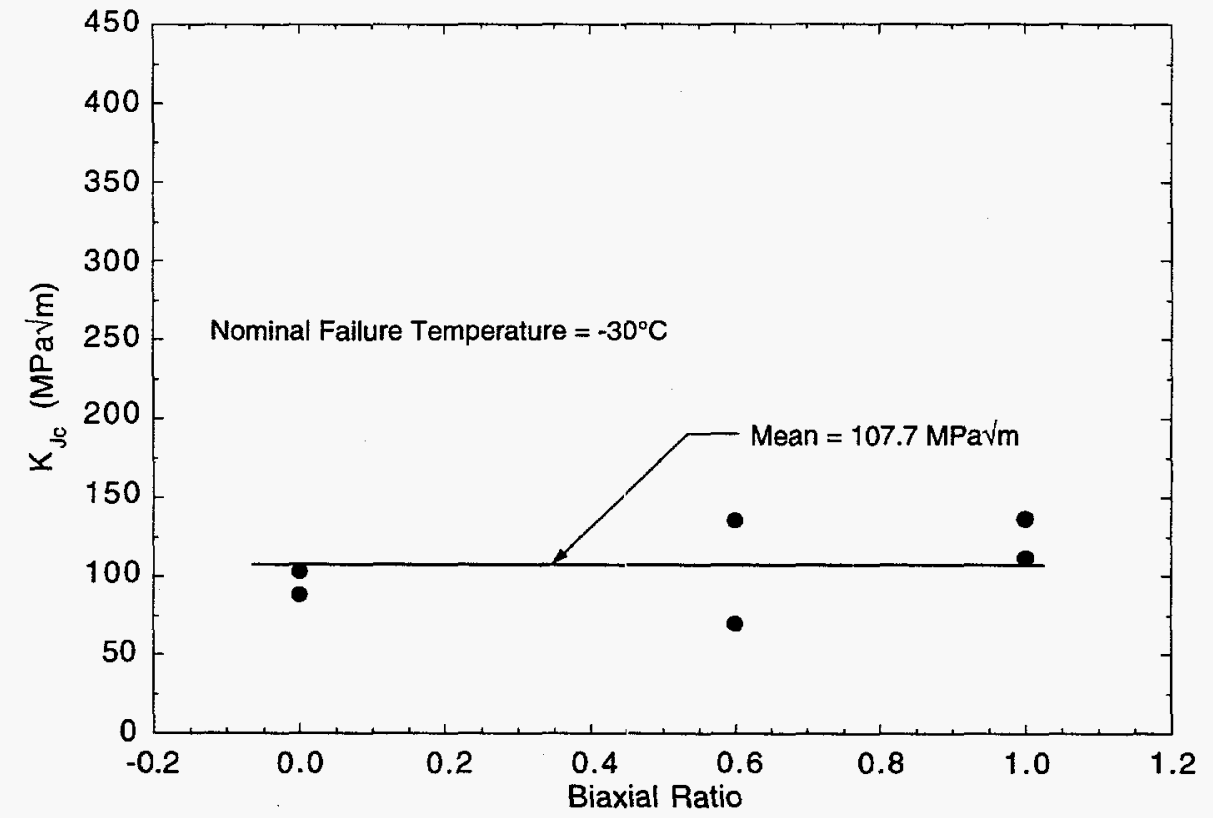

Fig. 9 Data determined for heat-treated Plate 14 tested at $-30^{\circ} \mathrm{C}\left(-22^{\circ} \mathrm{F}\right)$ indicating no effect of biaxial load ratio on fracture toughness at the lower-shelf temperature.

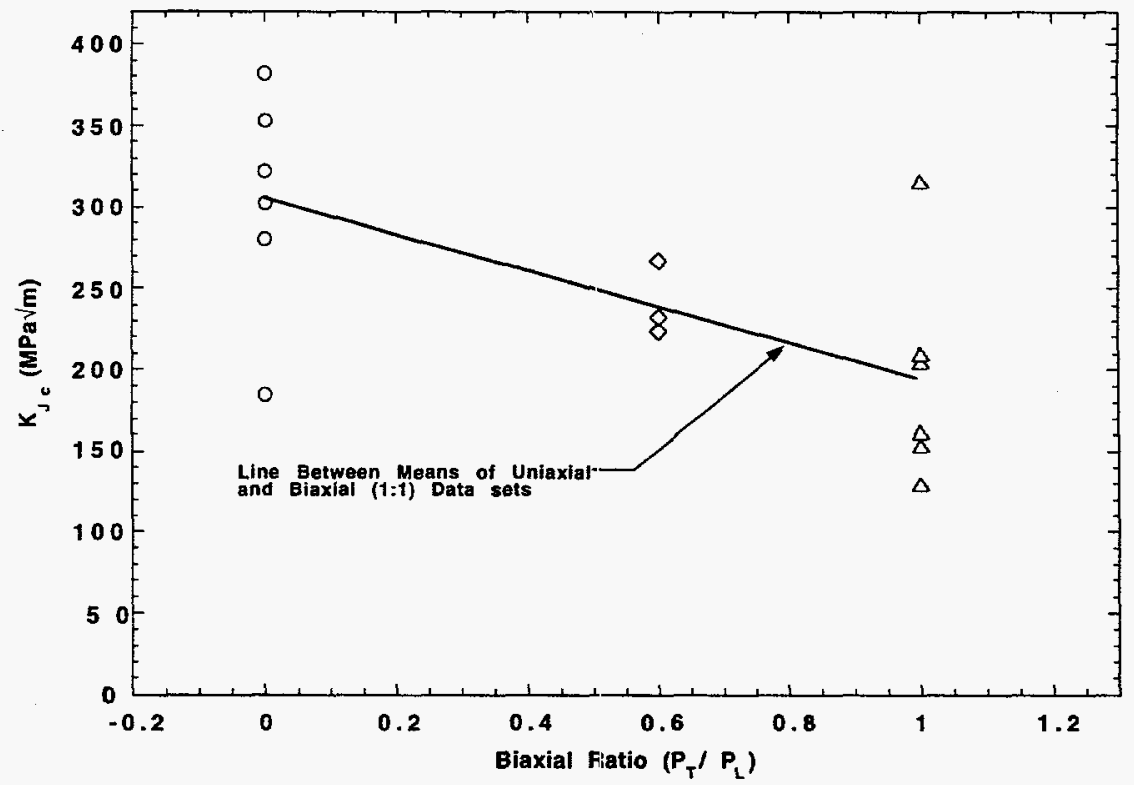

Fig. 10 The effect of biaxial load ratio on fracture toughness determined for heattreated Plate 14 tested at $-5^{\circ} \mathrm{C}\left(23^{\circ} \mathrm{F}\right)$. 


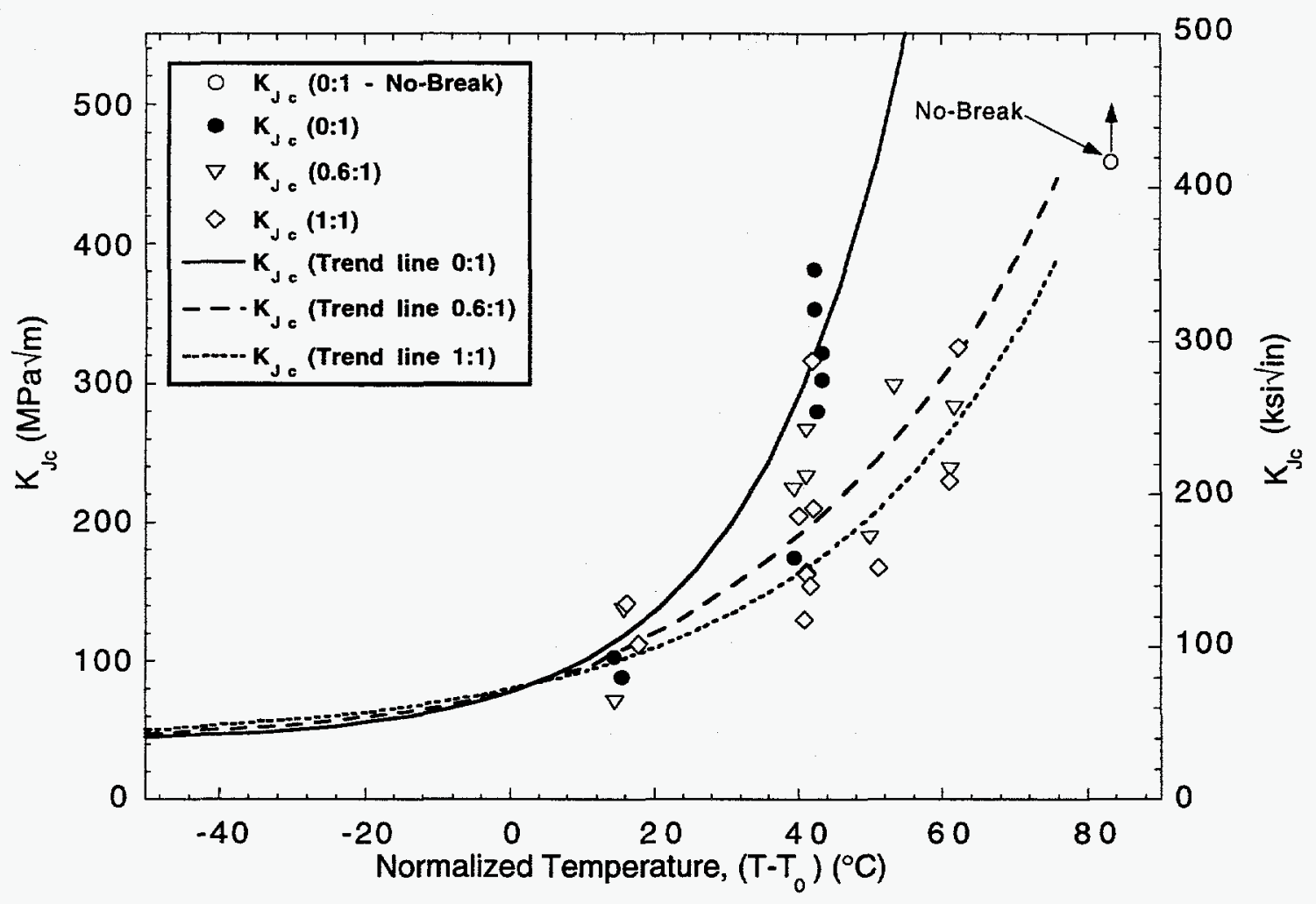

Fig. 11 A summary of all heat-treated Plate 14 cruciform data presented as a function of normalized $\left(T-T_{0}\right)$ test temperature. Trend curves fitted to data provide a visual interpretation of relationship between biaxial loading and temperature. 


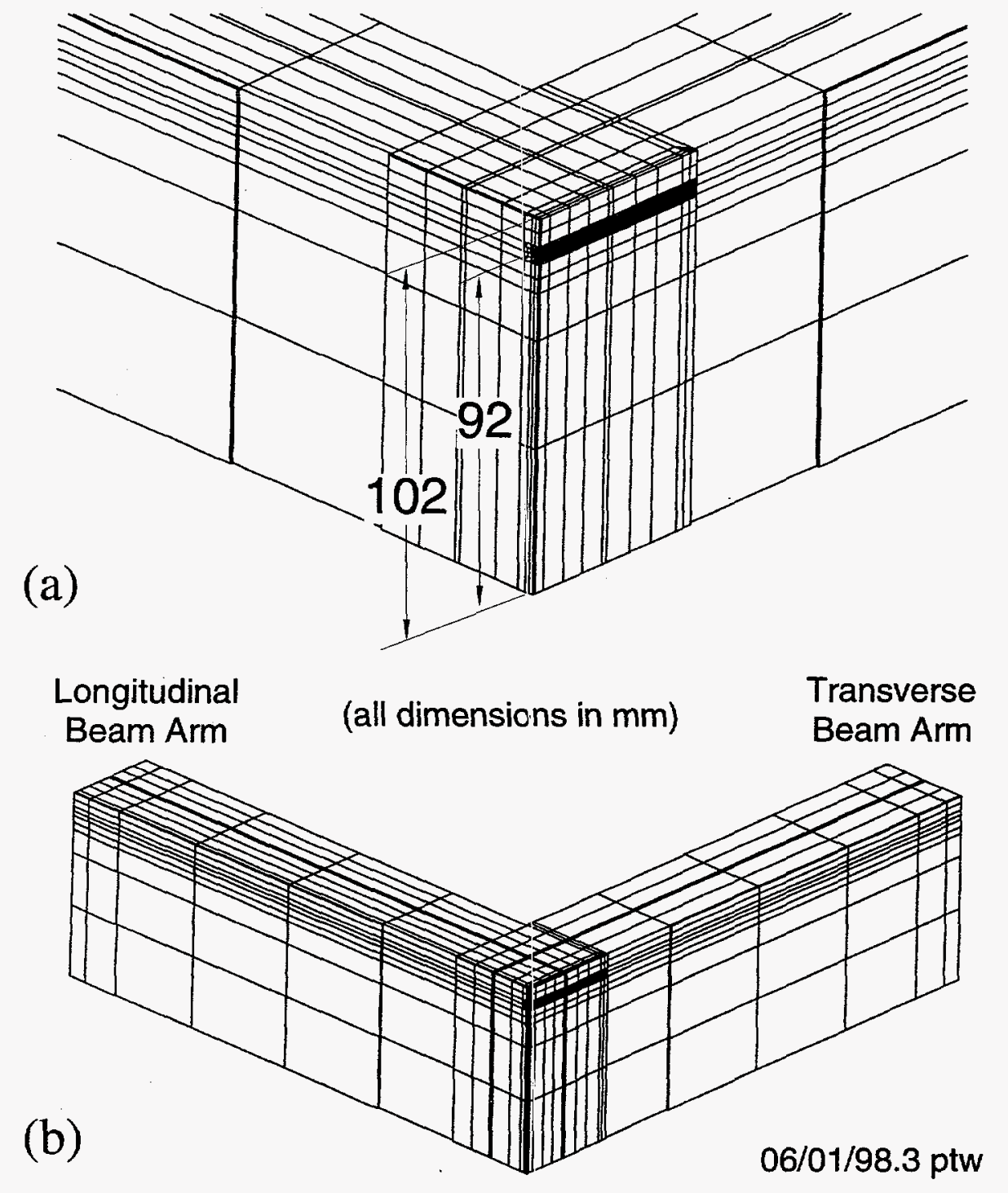

Fig. 12 Finite element model of original cruciform beam specimen: (a) detailed view of specimen containing shallow flaw $(a / W=0.10, a=10 \mathrm{~mm}, W=102 \mathrm{~mm})$; (b) complete mesh layout. 
(a)

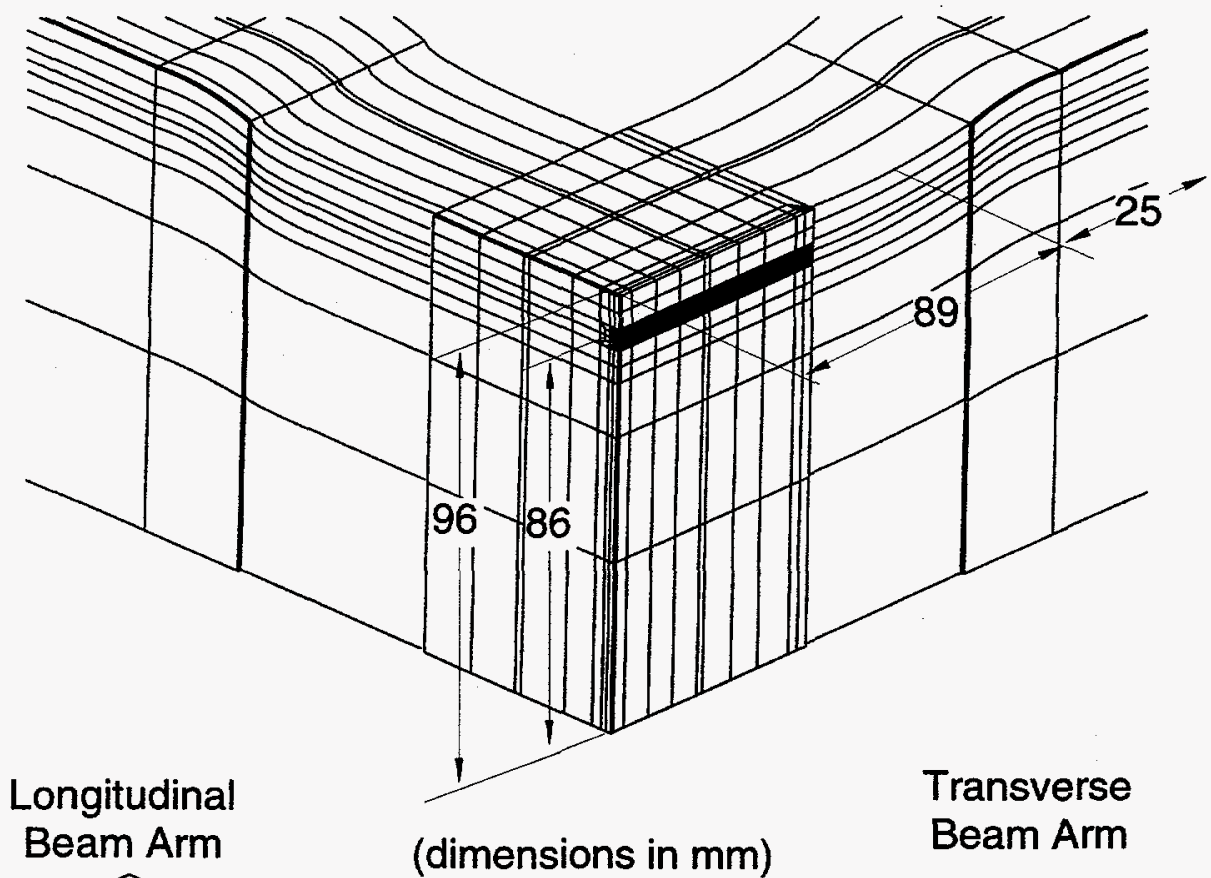

(b)

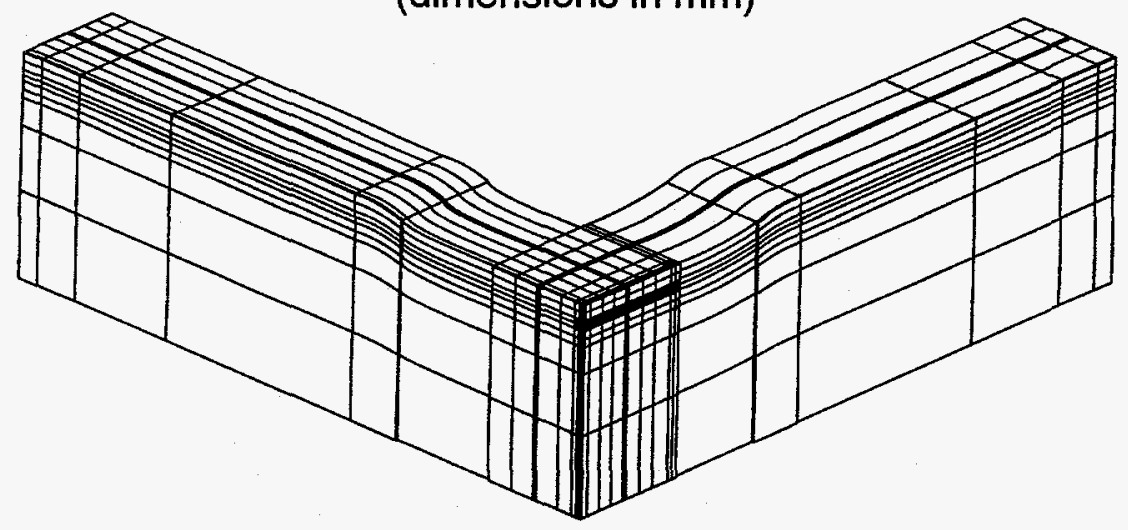

Fig. 13 Finite element model of cruciform beam specimen with reduced test section thickness: (a) detailed view of specimen containing shallow flaw $(a / W=0.10$, $a=9.65 \mathrm{~mm}, W=96 \mathrm{~mm}$ ); (b) complete mesh layout. 


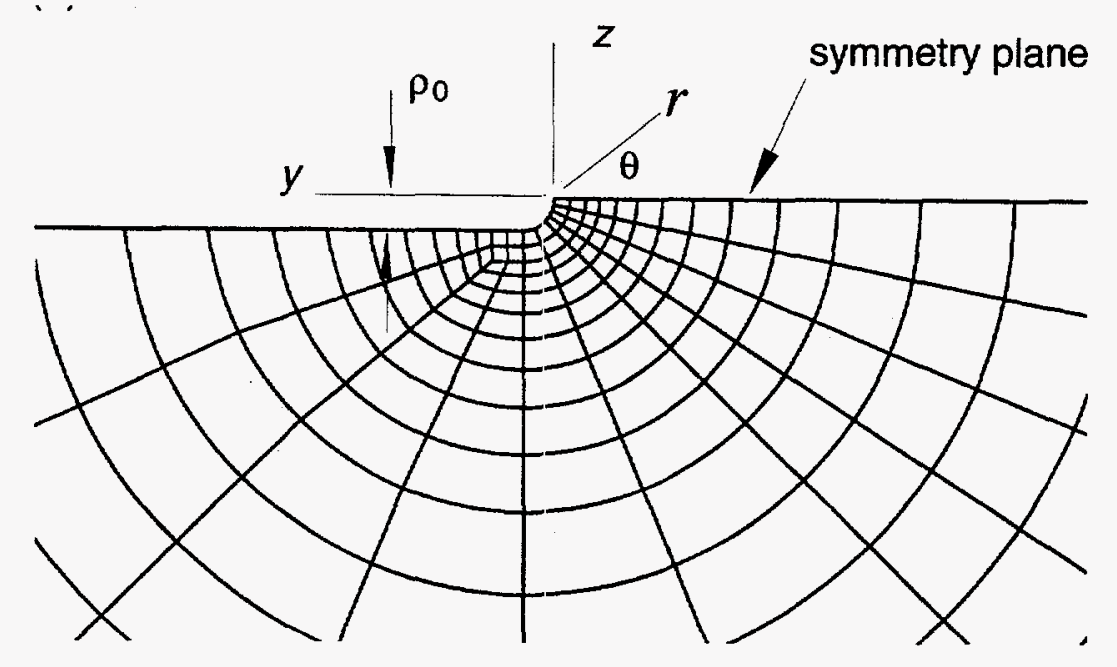

Fig. 14 Detail view of the finite-root-radius crack tip, with root-tip radius $\rho_{o}=0.0254 \mathrm{~mm}$ (0.001 in.). 


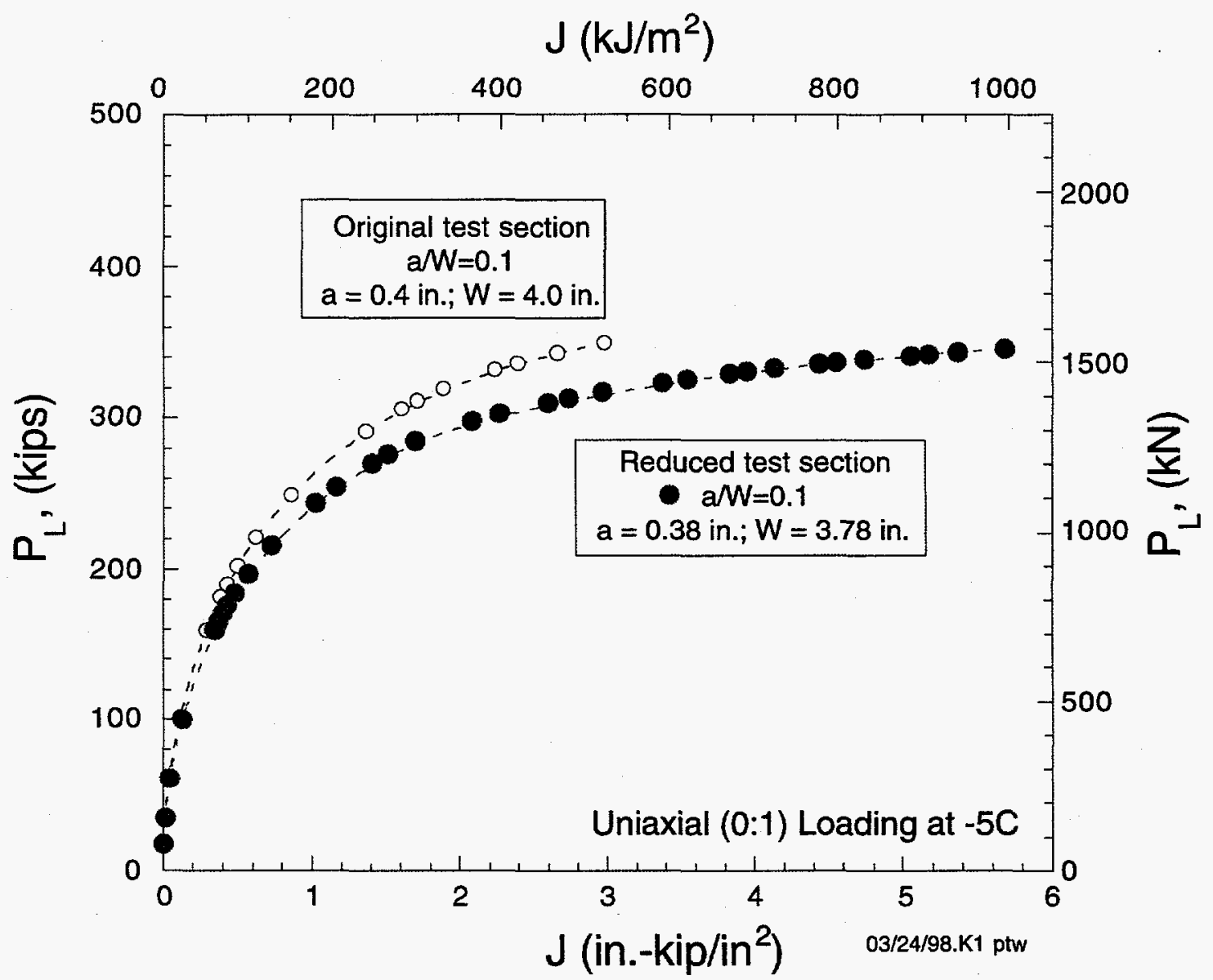

Fig. 15 Comparison of finite element model results for original and reduced cruciform test section: $P_{L}$ vs $J$-integral for uniaxial (0:1) loading. 


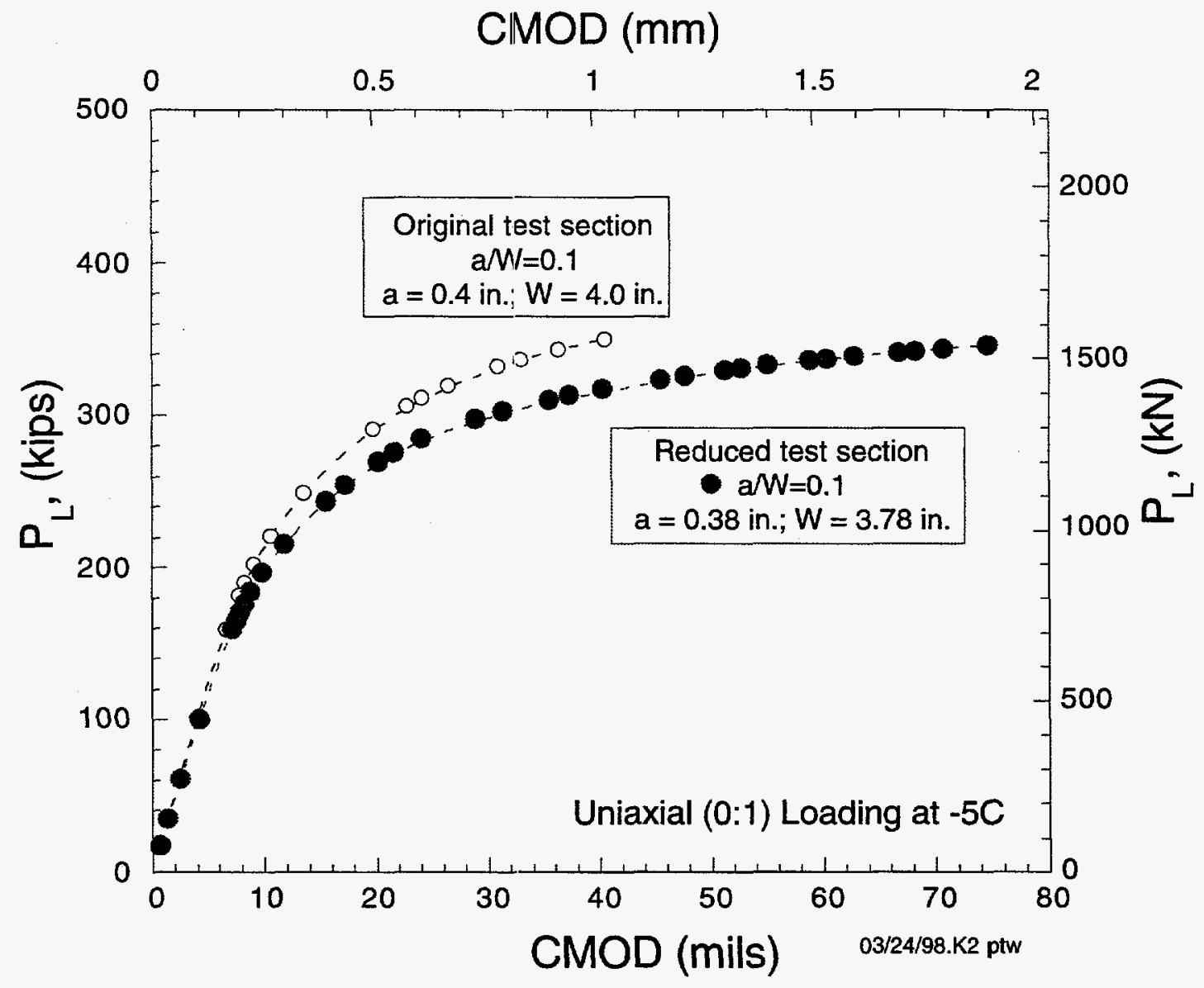

Fig. 16 Comparison of finite element model results for original and reduced cruciform test section: $P_{L}$ versus CMOD for uniaxial (0:1) loading. 

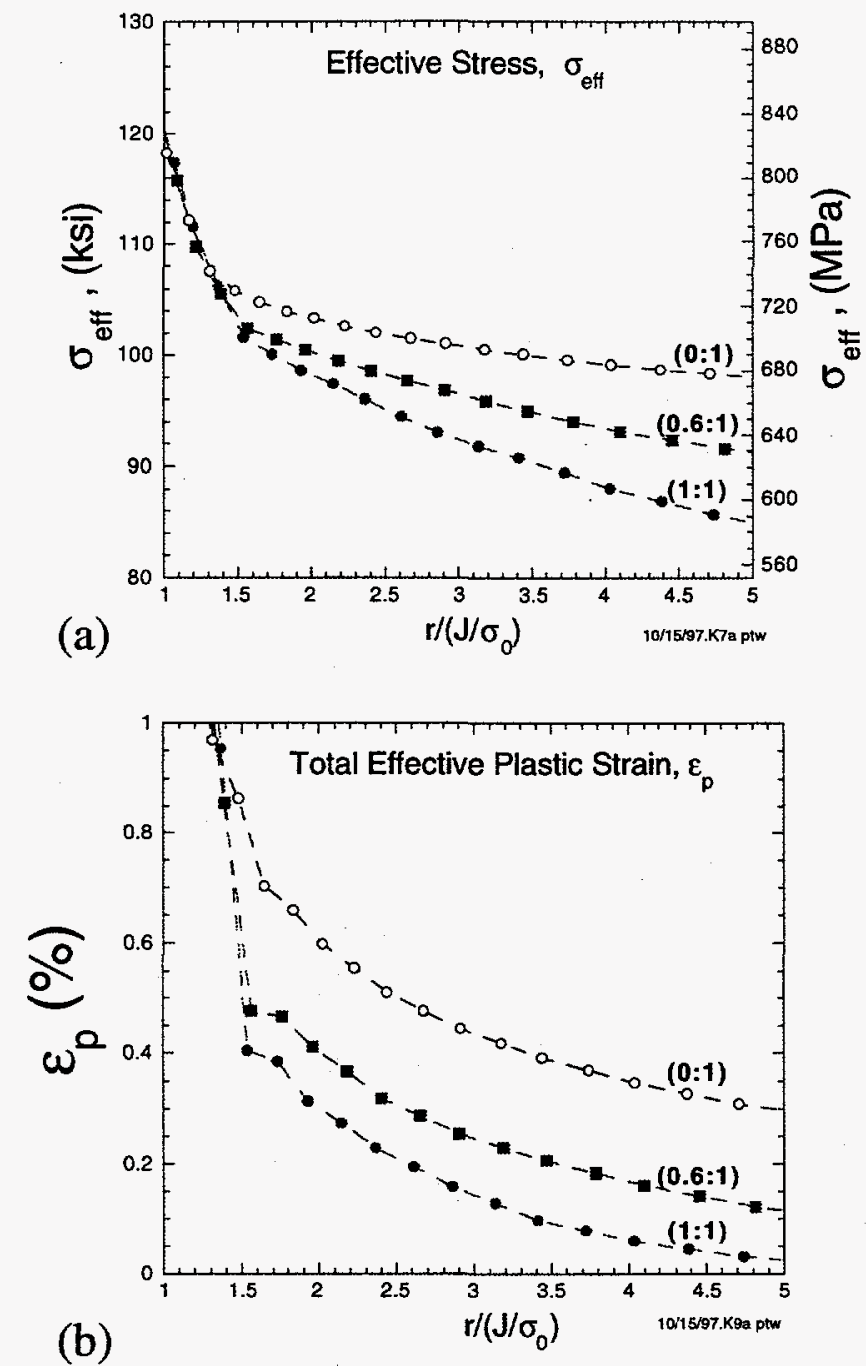

Fig. 17 Profiles of (a) effective stress, $\sigma_{e f f}$, and (b) total effective plastic strain, $\varepsilon_{p}$, for uniaxial ( $0: 1)$ and biaxial $(x: 1)$ loading cases at $J \approx 131 \mathrm{~kJ} / \mathrm{m}^{2}(0.75$ in.$\left.\mathrm{kip} / \mathrm{in}^{2}\right)$. 

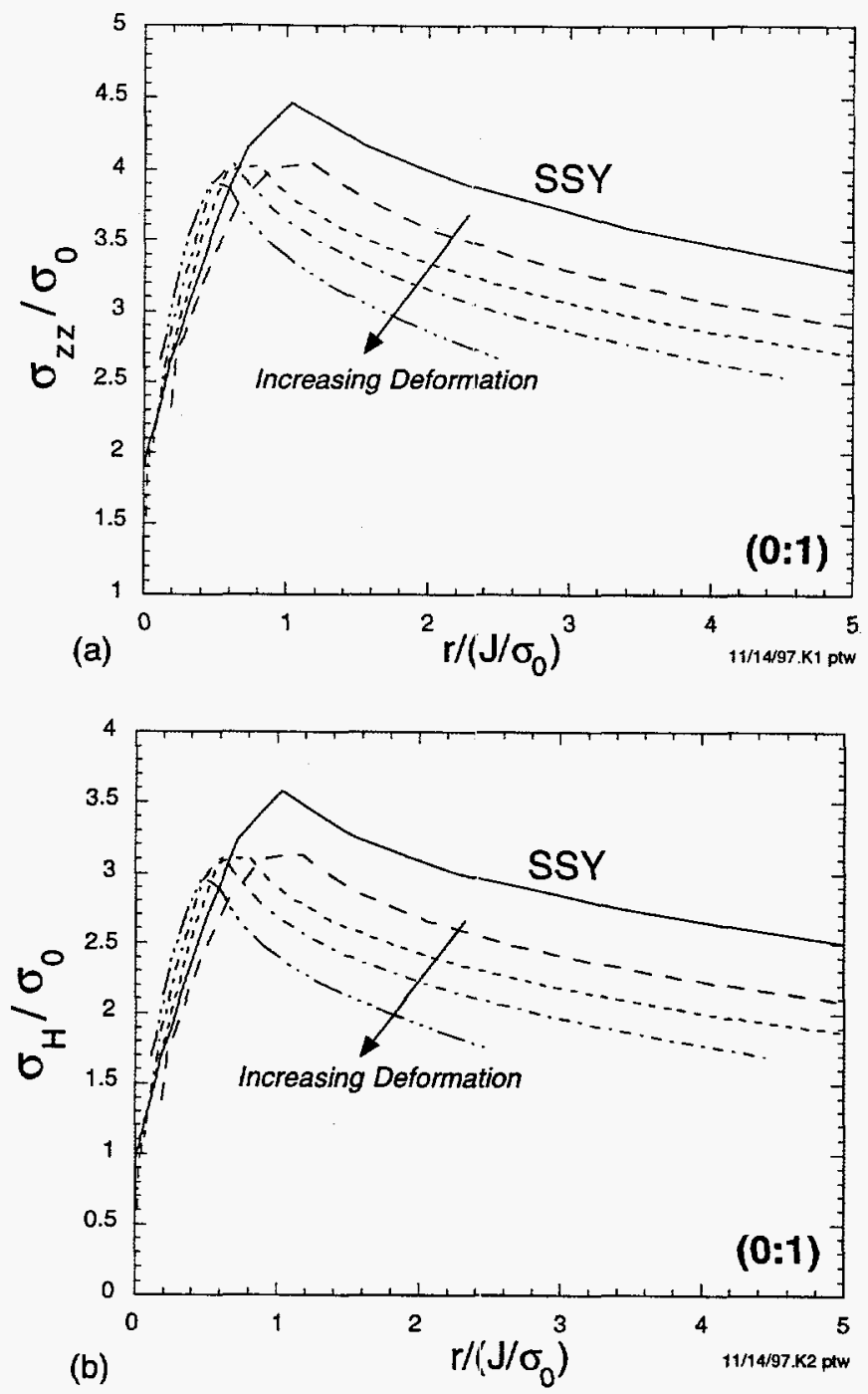

Fig. 18 Comparison of uniaxial (0:1) to SSY. solution profiles of (a) opening mode , $\sigma_{z z}$, and (b) hydrostatic, $\sigma_{H}$, stresses near the crack tip for $J=(66,147,272$, $470 \mathrm{~kJ} / \mathrm{m}^{2}$ ). 

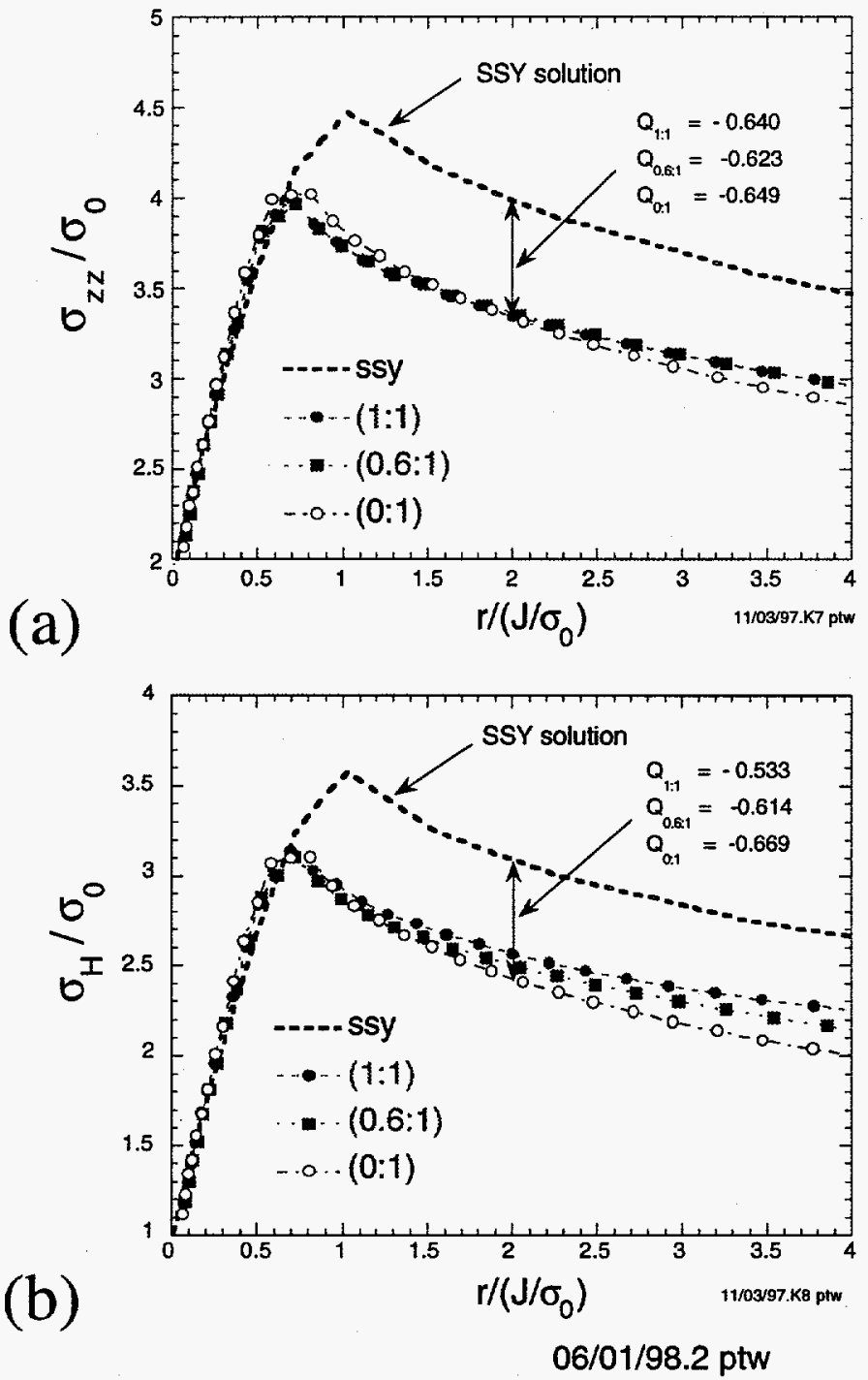

Fig. 19 Sensitivity to biaxiality for $Q$-stress based on (a) opening mode, $\sigma_{z z}$, and (b) hydrostatic, $\sigma_{H}$, stress at $J \approx 131 \mathrm{~kJ} / \mathrm{m}^{2}$. 

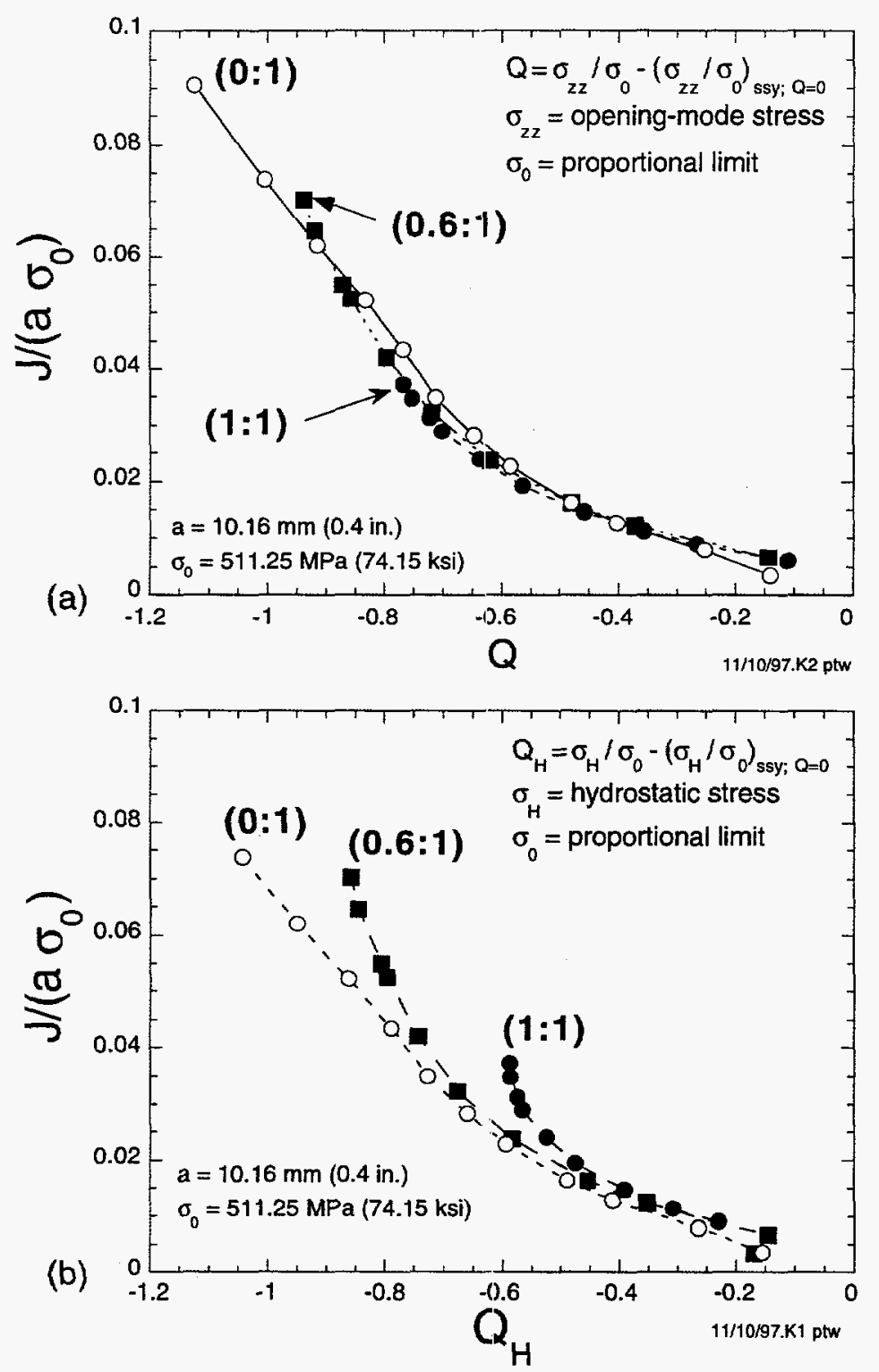

Fig. 20 Evolution of $Q$-stress at $\mathrm{r} /\left(\mathrm{J} / \sigma_{\mathrm{o}}\right)=2$ based on (a) opening mode , $\sigma_{z z}$, and (b) hydrostatic, $\sigma_{H}$, stress. 


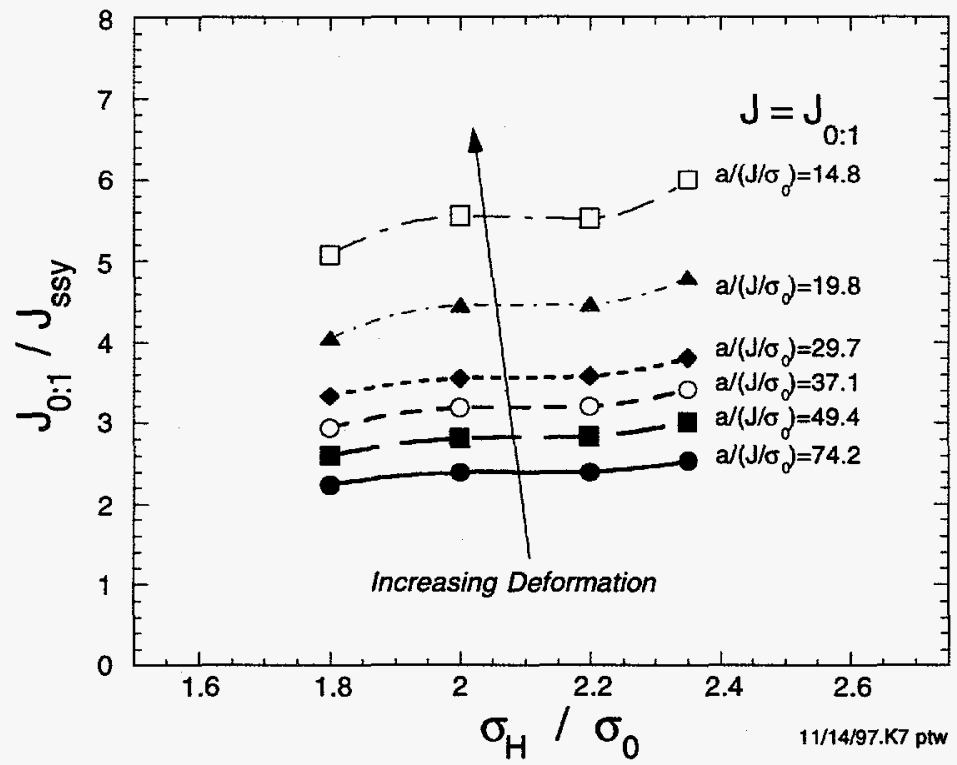

Fig. 21 Ratios of $J_{0: I} / J_{s s y}$ for equivalent areas contained within $\sigma_{H} / \sigma_{0}$ contours.

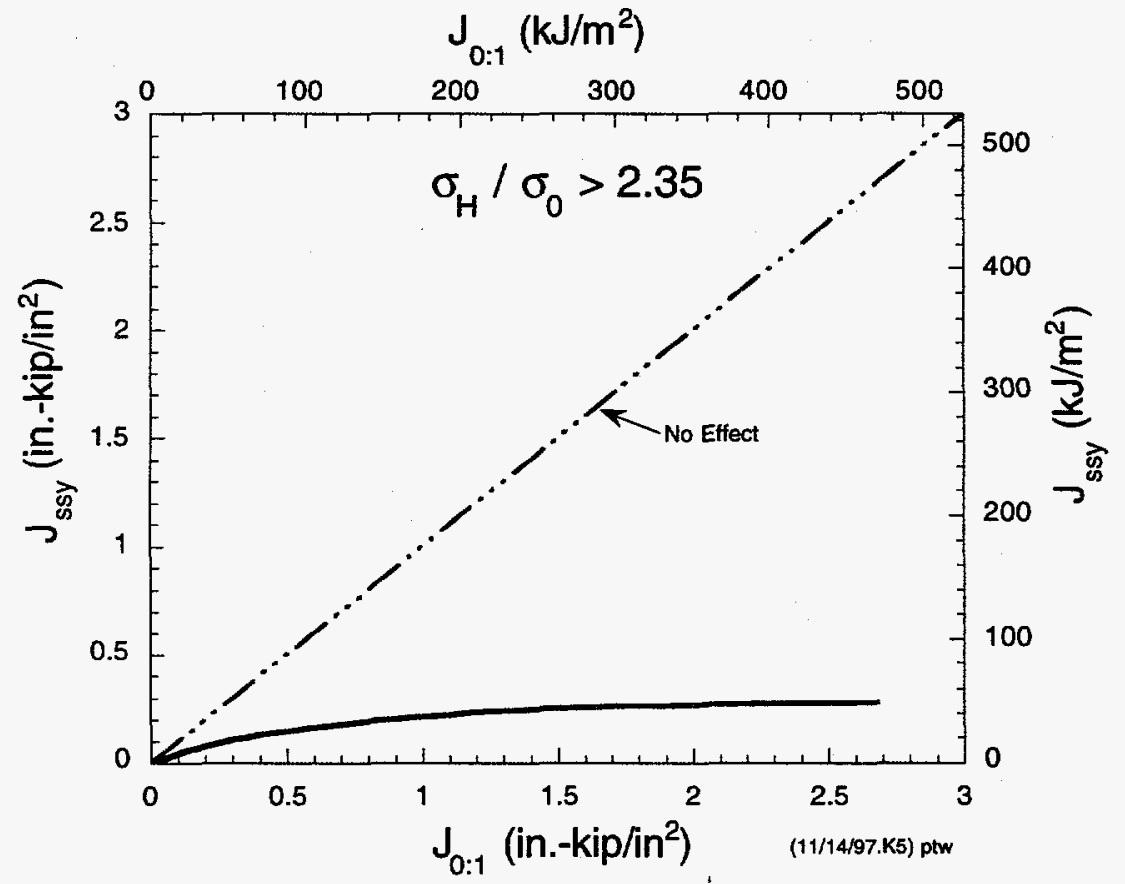

Fig. 22 Areas with equivalent hydrostatic stress: $J_{s s y}$ versus $J_{0: 1}$ for $\sigma_{H} / \sigma_{0}>2.35$. 

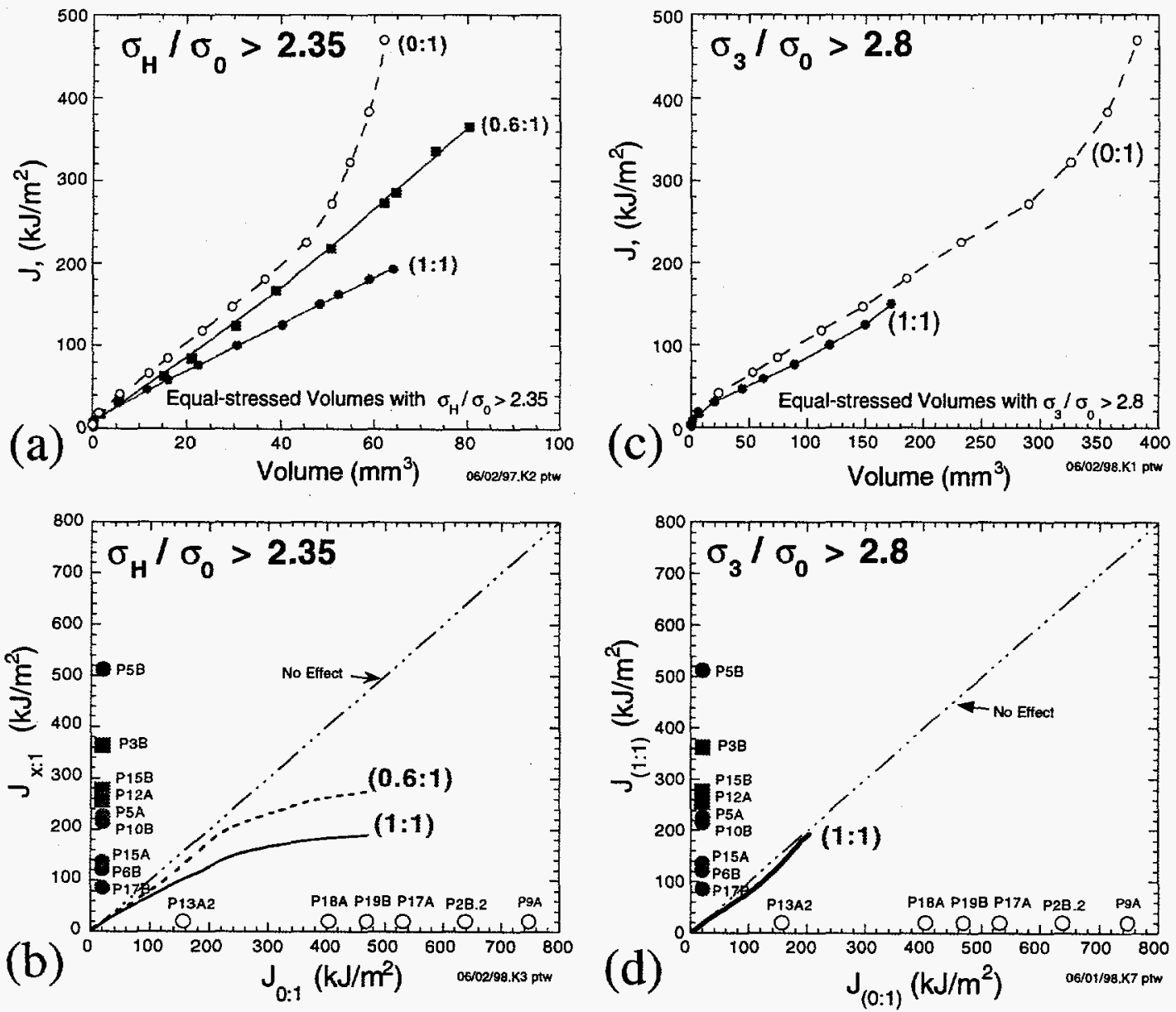

06/02/98.1 ptw

Fig. 23 Equal-stressed volumes with initiation loads for uniaxial $(0: 1)$ and biaxial $(x: 1)$ cruciform test specimens: (a) $J$ vs volume for $\sigma_{H} / \sigma_{0} \geq 2.35$, (b) $J_{1: 1}$ vs $J_{0: I}$ for $\sigma_{H} / \sigma_{0} \geq 2.35$, (c) $J$ vs volume for $\sigma_{3} / \sigma_{0} \geq 2.8$, and (d) $J_{x: 1}$ vs $J_{0: 1}$ for $\sigma_{3} / \sigma_{0} \geq 2.8$, 

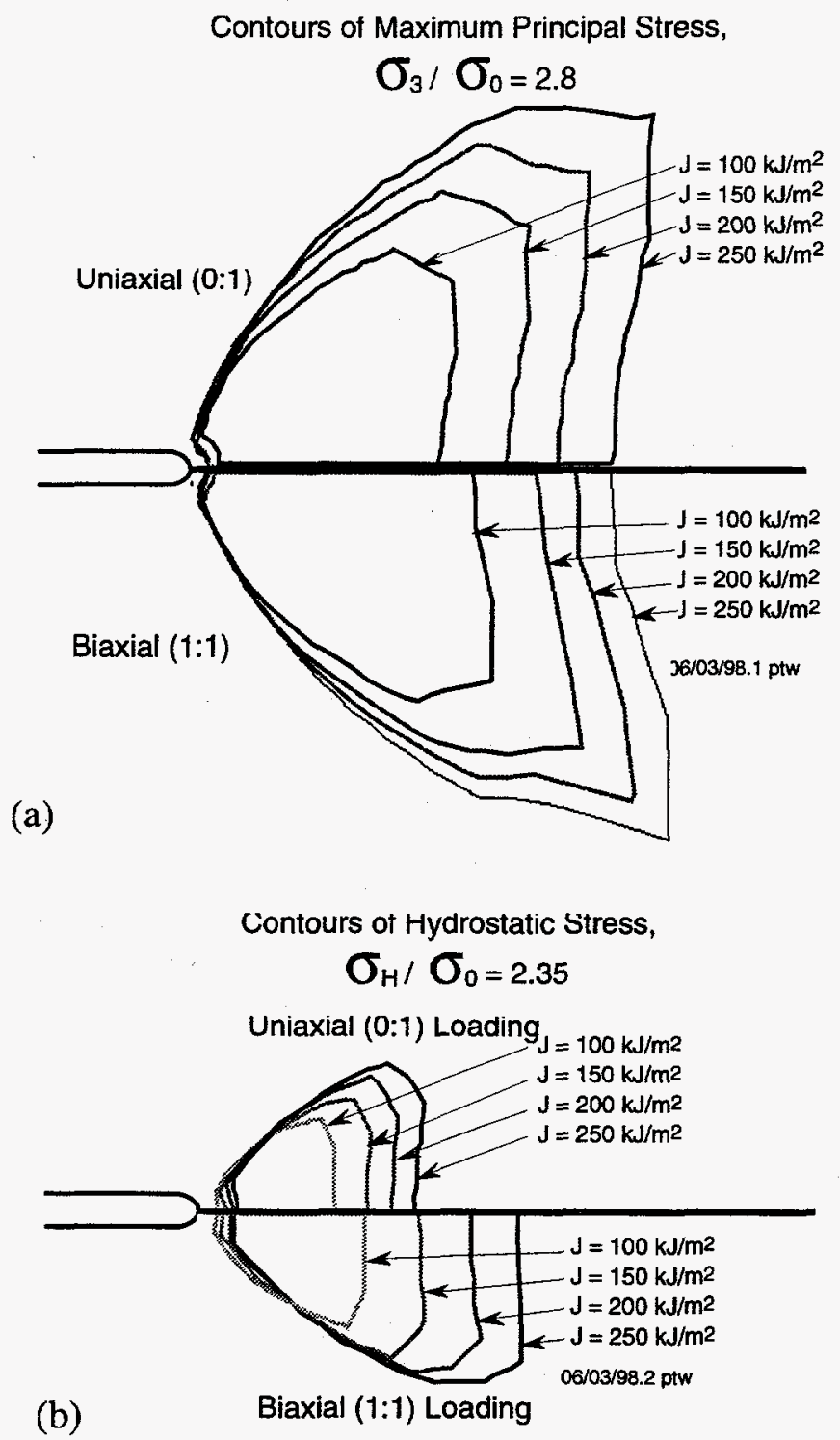

Fig. 24 Contours of (a) maximum principal stress: $\sigma_{3} / \sigma_{0}=2.8$, and (b) hydrostatic stress: $\sigma_{H} / \sigma_{0}=2.35$, near the crack tip. 

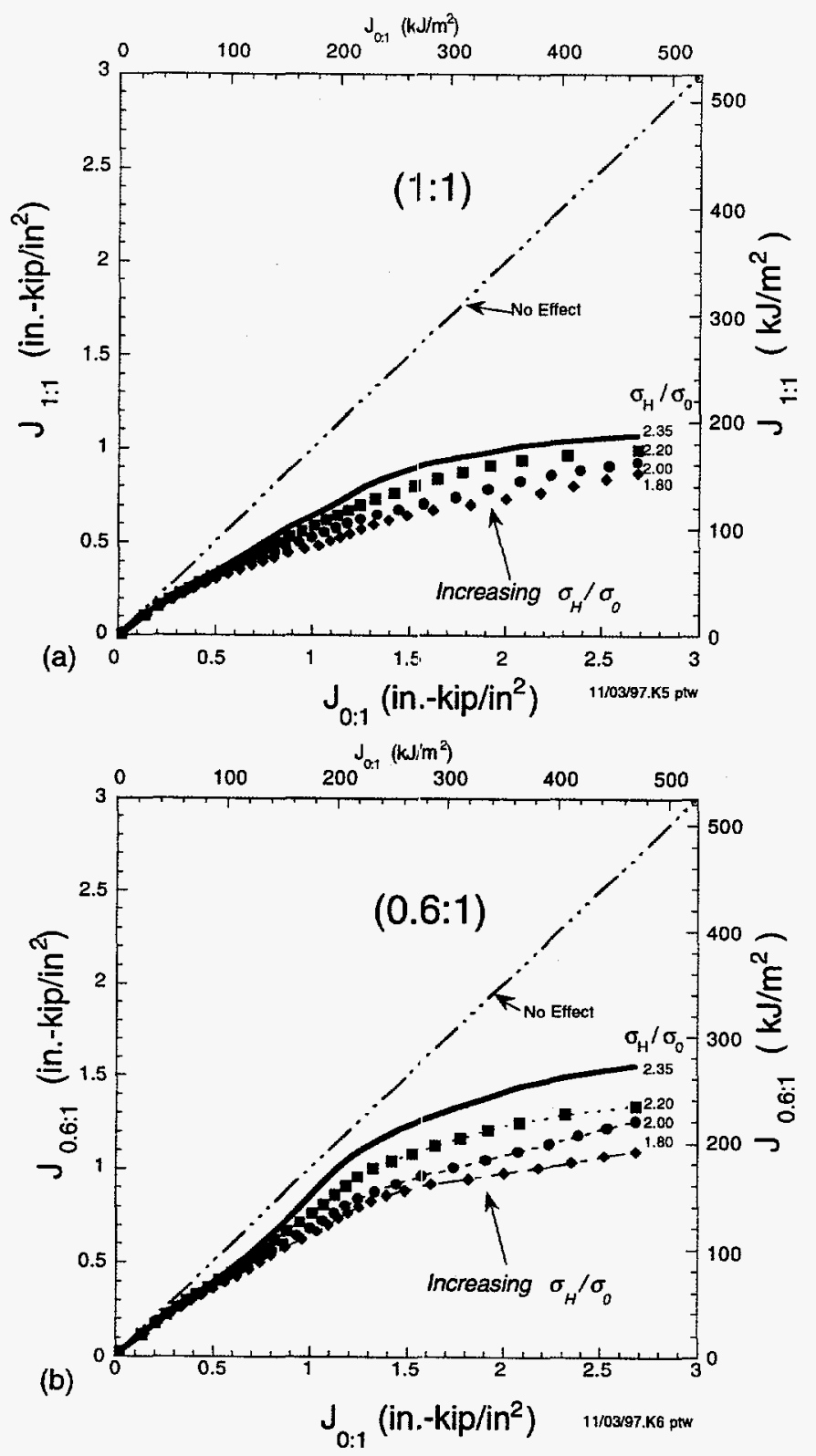

Fig. 25 Sensitivity of $J_{x: I}$ versus $J_{0: I}$ to selection of critical $\sigma_{H} / \sigma_{0}$ for (a) (1:1) and (b) $(0.6: 1)$ loading cases 

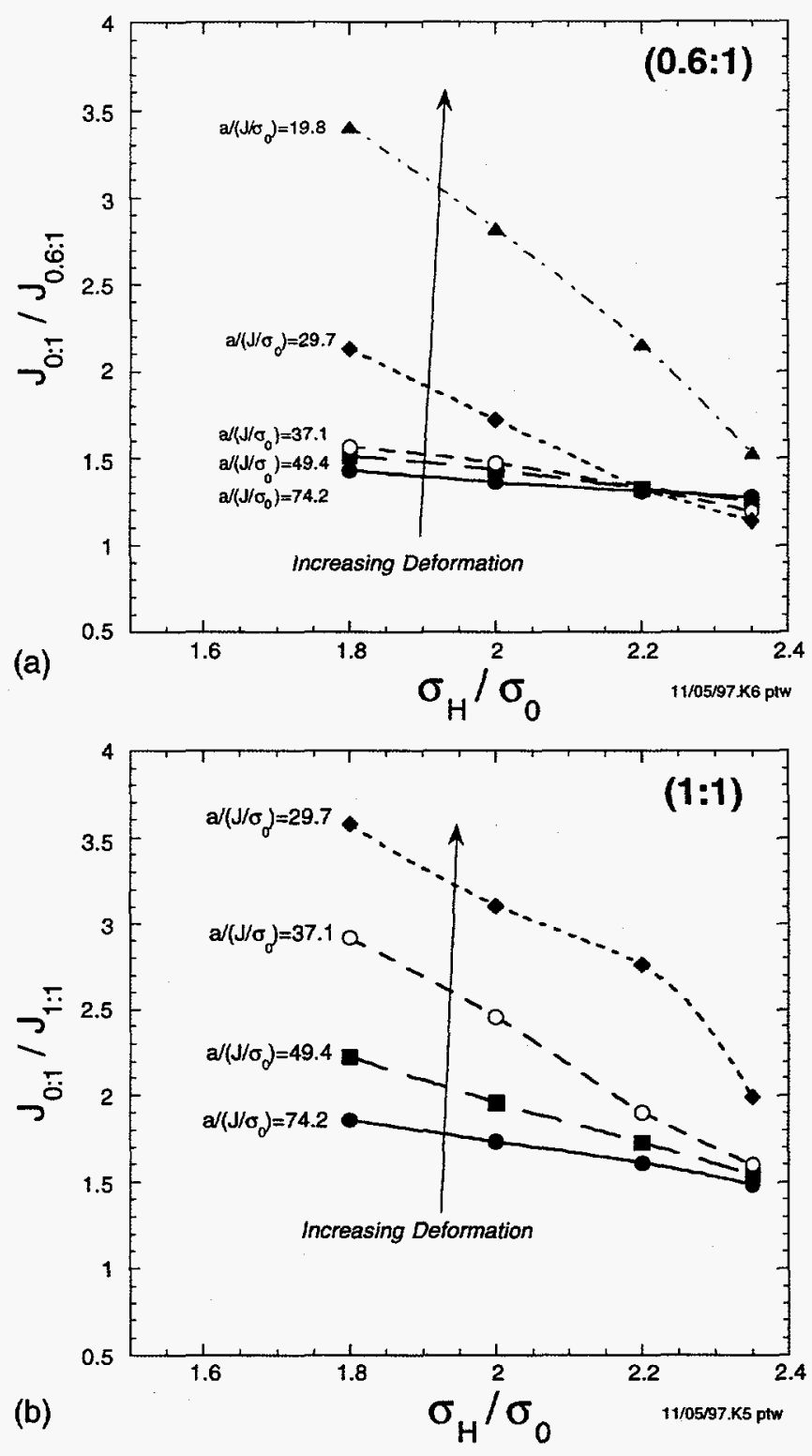

Fig. 26 Sensitivity of $J_{0: 1} / J_{x: 1}$ ratios with equivalent areas to selection of critical $\sigma_{H} / \sigma_{0}$ for (a) $(0.6: 1)$ and (b) (1:1) loading cases. 


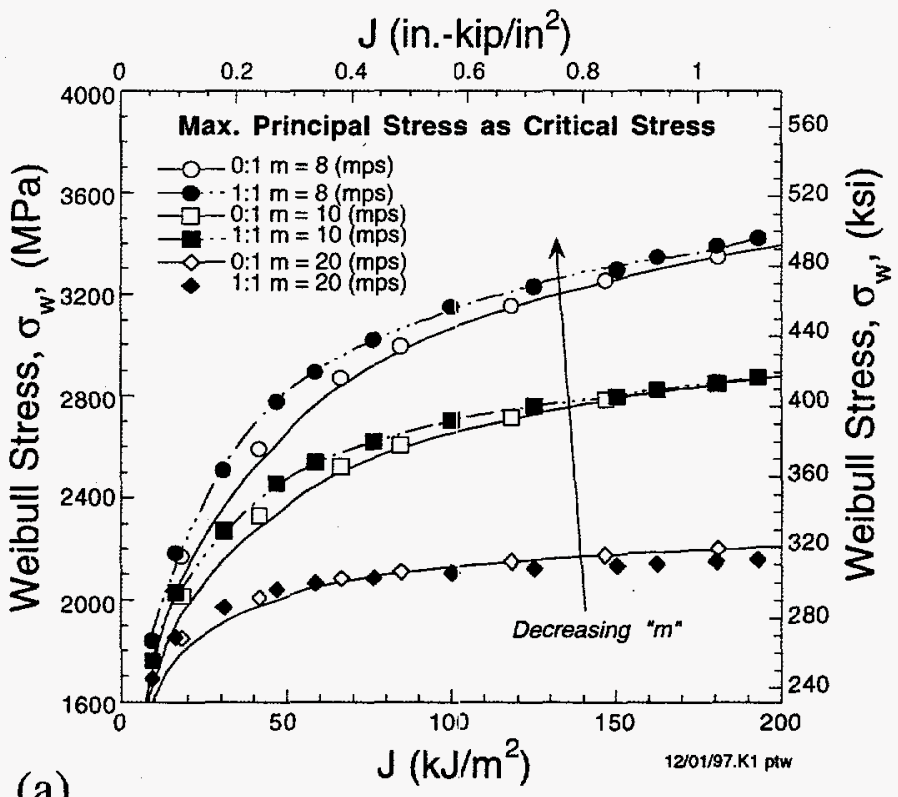

(a)

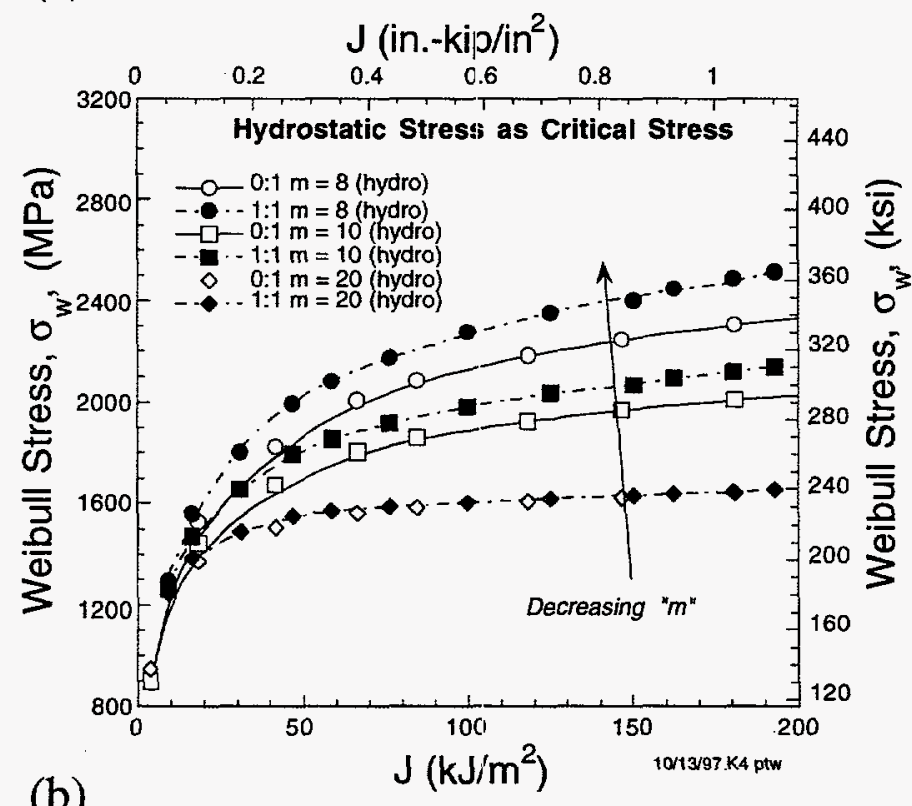

(b)

Fig. 27 Weibull stresses with (a) maximum principal stress, $\sigma_{3}$, and (b) hydrostatic stress, $\sigma_{H}$, as the equivalent stress, $\sigma_{q}$. 


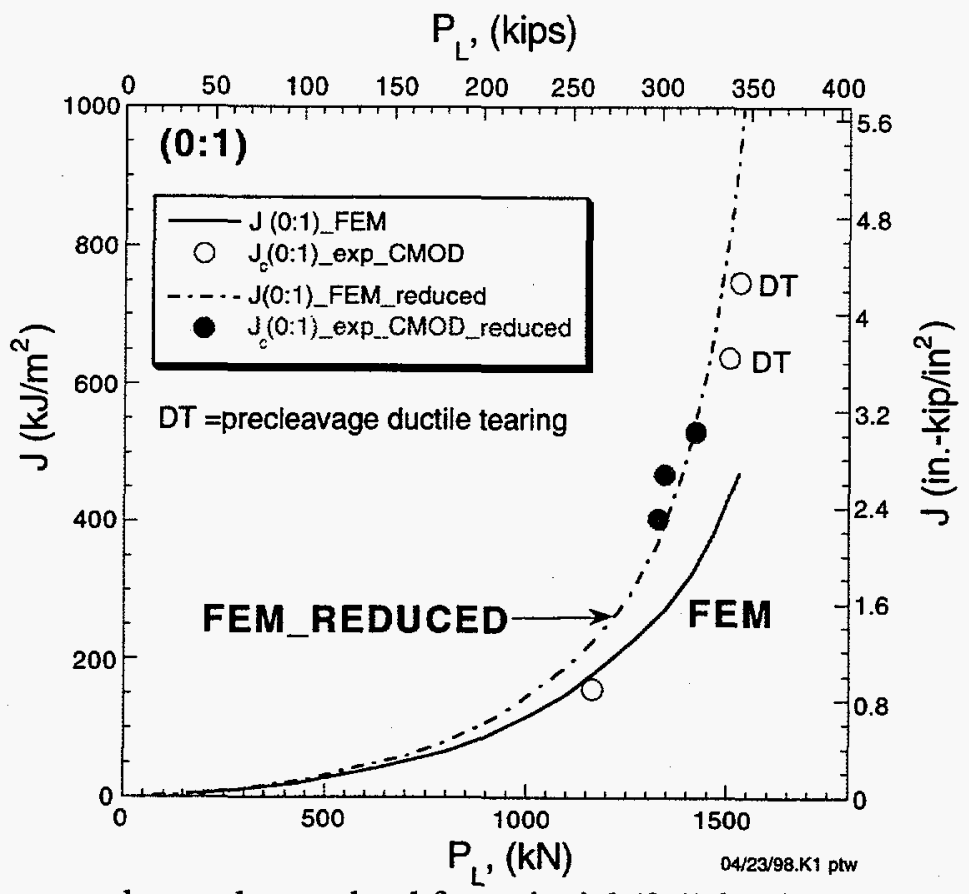

Fig. 28 Fracture toughness data vs load for uniaxial $(0: 1)$ loading of cruciform: Plate 14 material tested at $-5^{\circ} \mathrm{C}$.

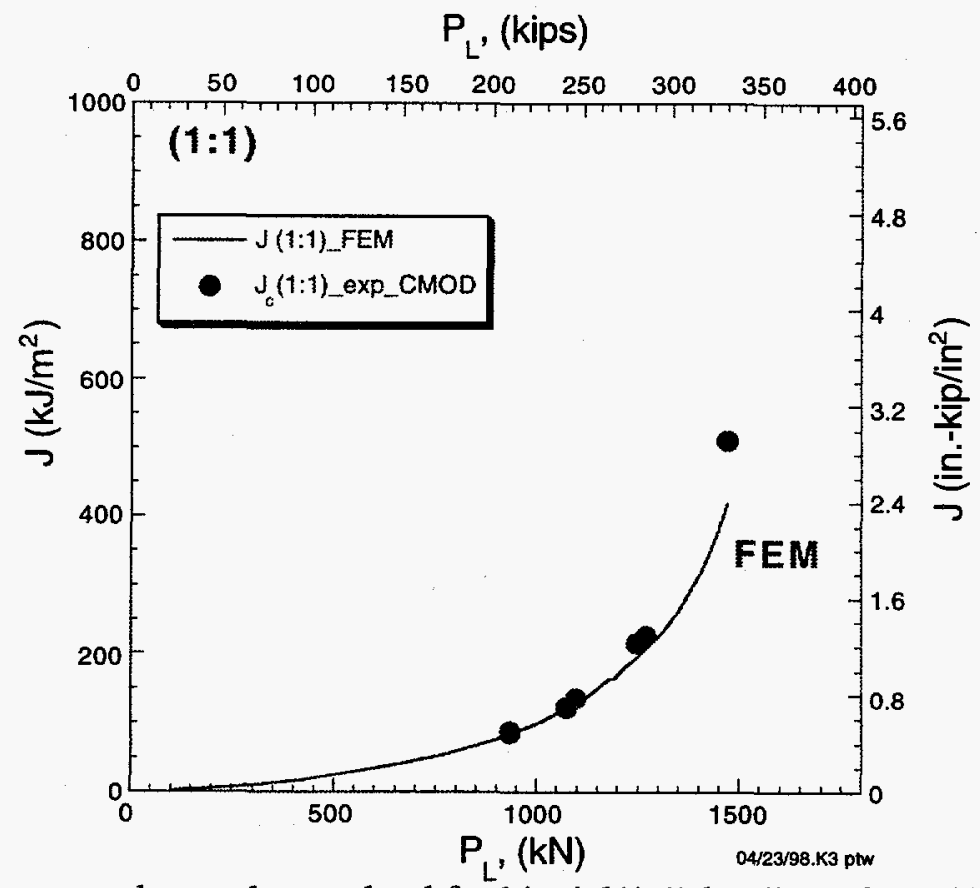

Fig. 29 Fracture toughness data vs load for biaxial(1:1) loading of cruciform: Plate 14 material tested at $-5^{\circ} \mathrm{C}$. 


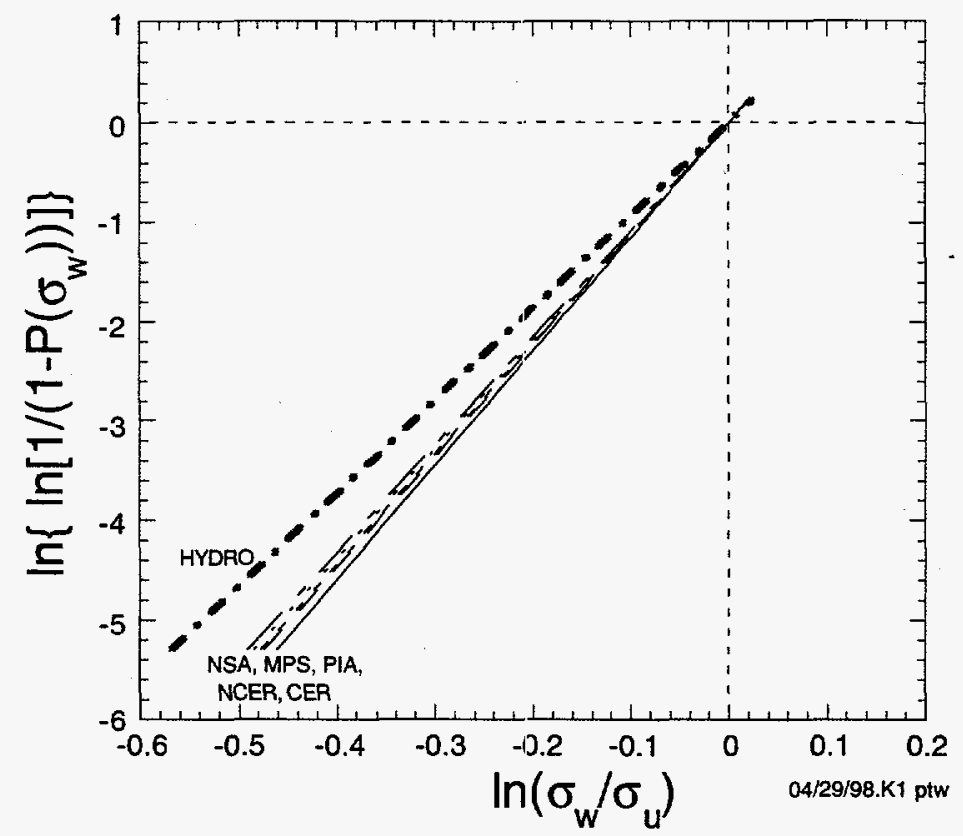

Fig. 30 Weibull probability plot for six fracture criteria with normalized Weibull stress using two-parameter model. Parameter estimation by statistical inference.

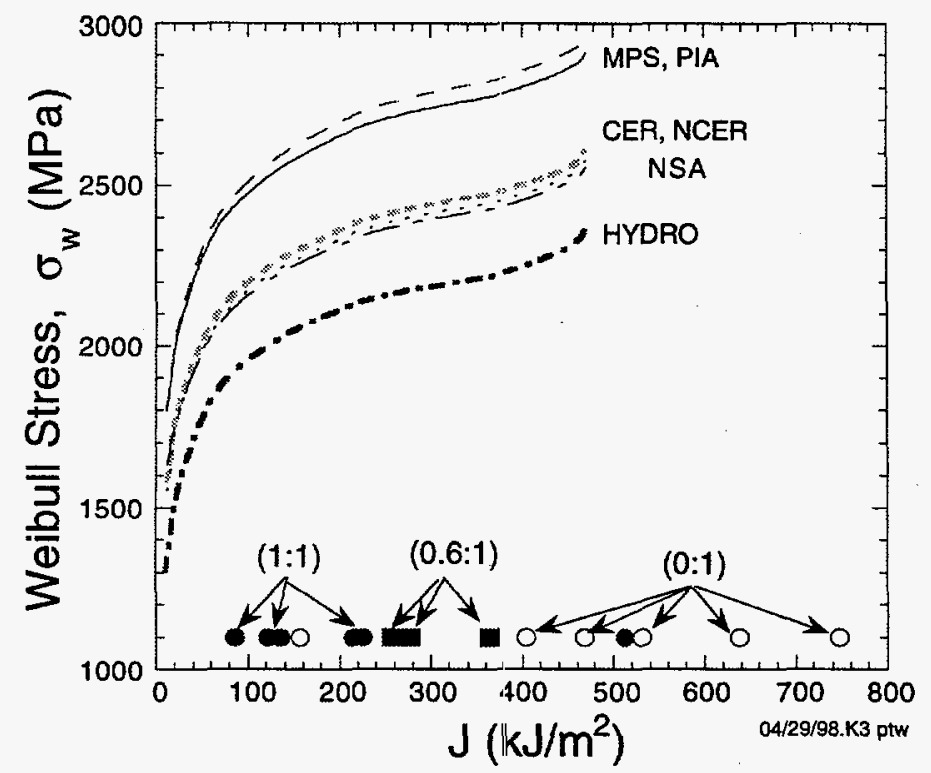

Fig. 31 Weibull stress vs $J$-integral for six fracture criteria using two-parameter model. Parameter estimation by statistical inference. 
(a)

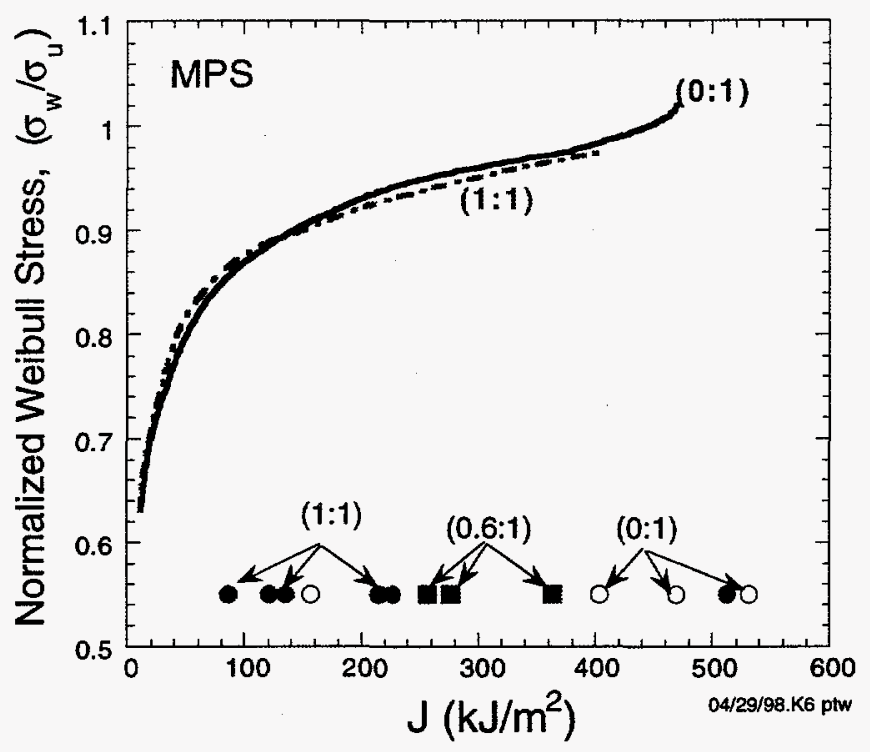

(b)

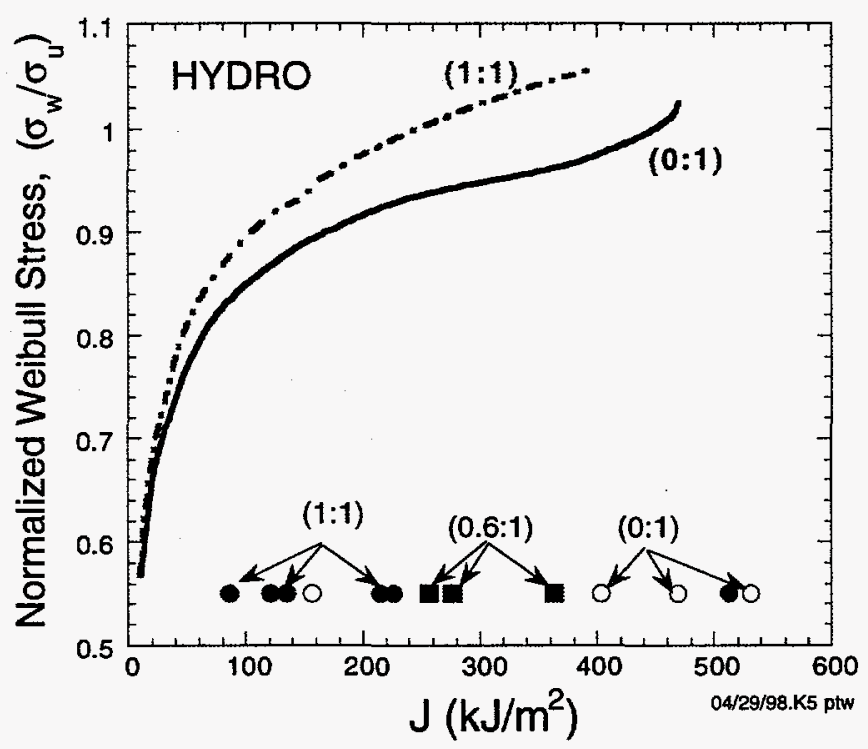

Fig. 32 Normalized Weibull stress versus $J$-integral comparing uniaxia $(0: 1)$ to biaxial (1:1) loading cases for: (a) maximum principal stress and (b) hydrostatic stress criteria using two-parameter model. 


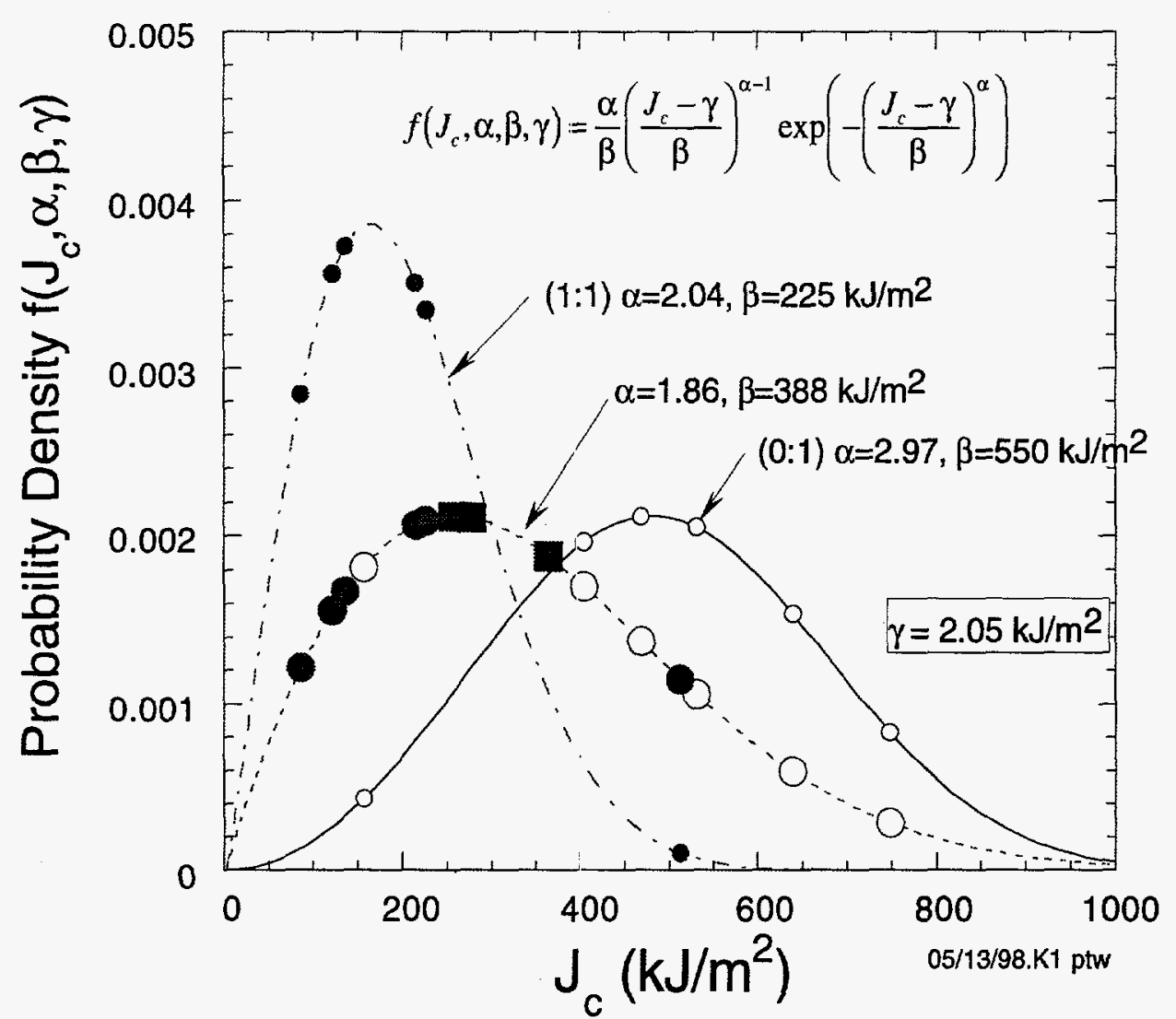

Fig. 33 Monte-Carlo generated Weibull probability density distributions for three sample populations of cruciform fracture toughness data $\left(N_{g e n}=10,000\right)$. Parameter estimation by statistical inference. 
(a)

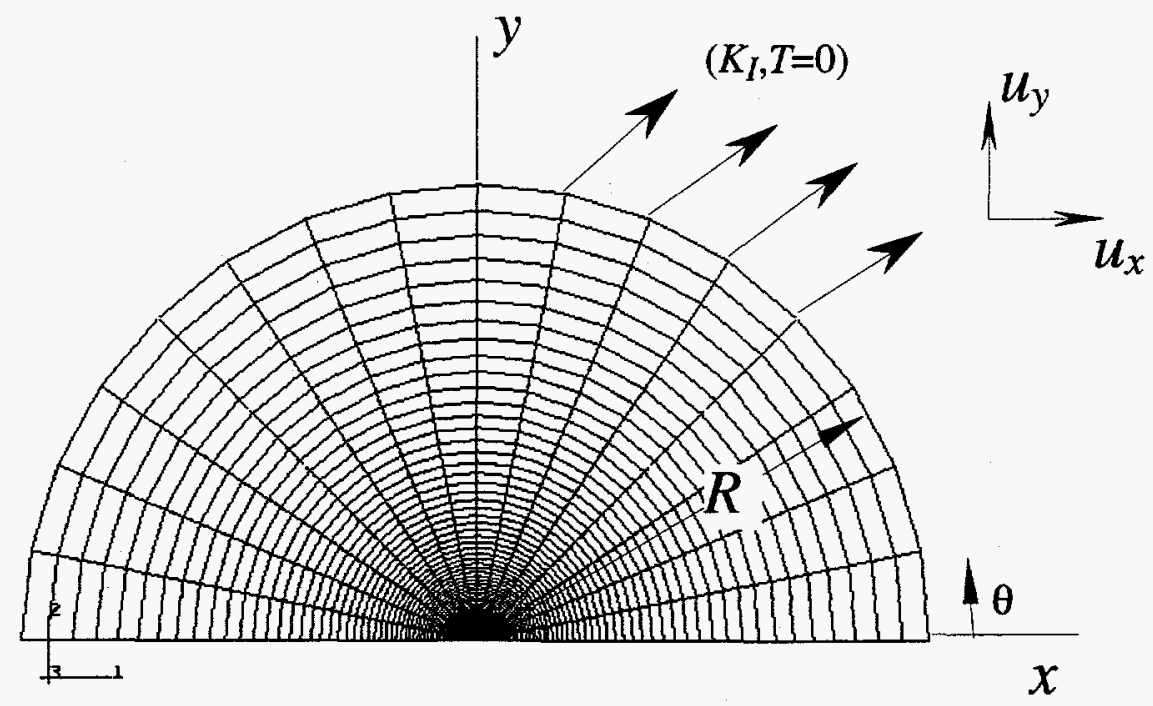

(b)

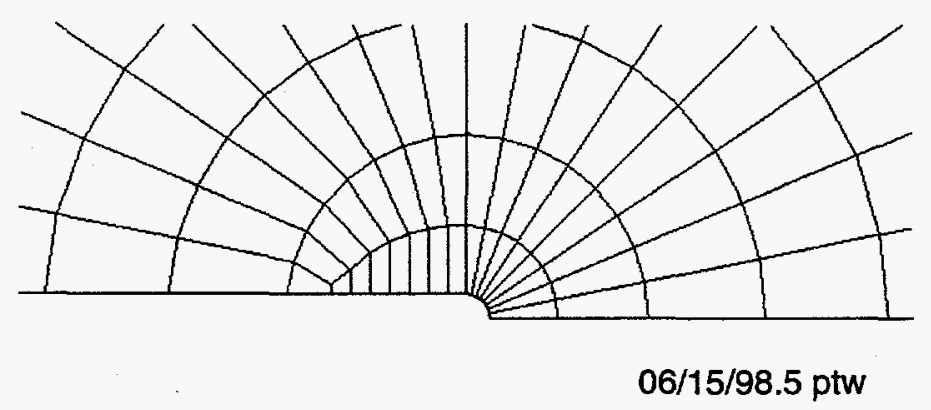

Fig. 34 Small-scale-yielding (SSY) plane-strain modified boundary layer (MBL) finiteelement model: (a) global mesh layout with 16 fans, 2671 elements, and 5708 nodes; (b) close up of finite root tip with $\rho_{0}=2.54 \mu \mathrm{m} ; \rho_{0} / R=10^{-7}$. 

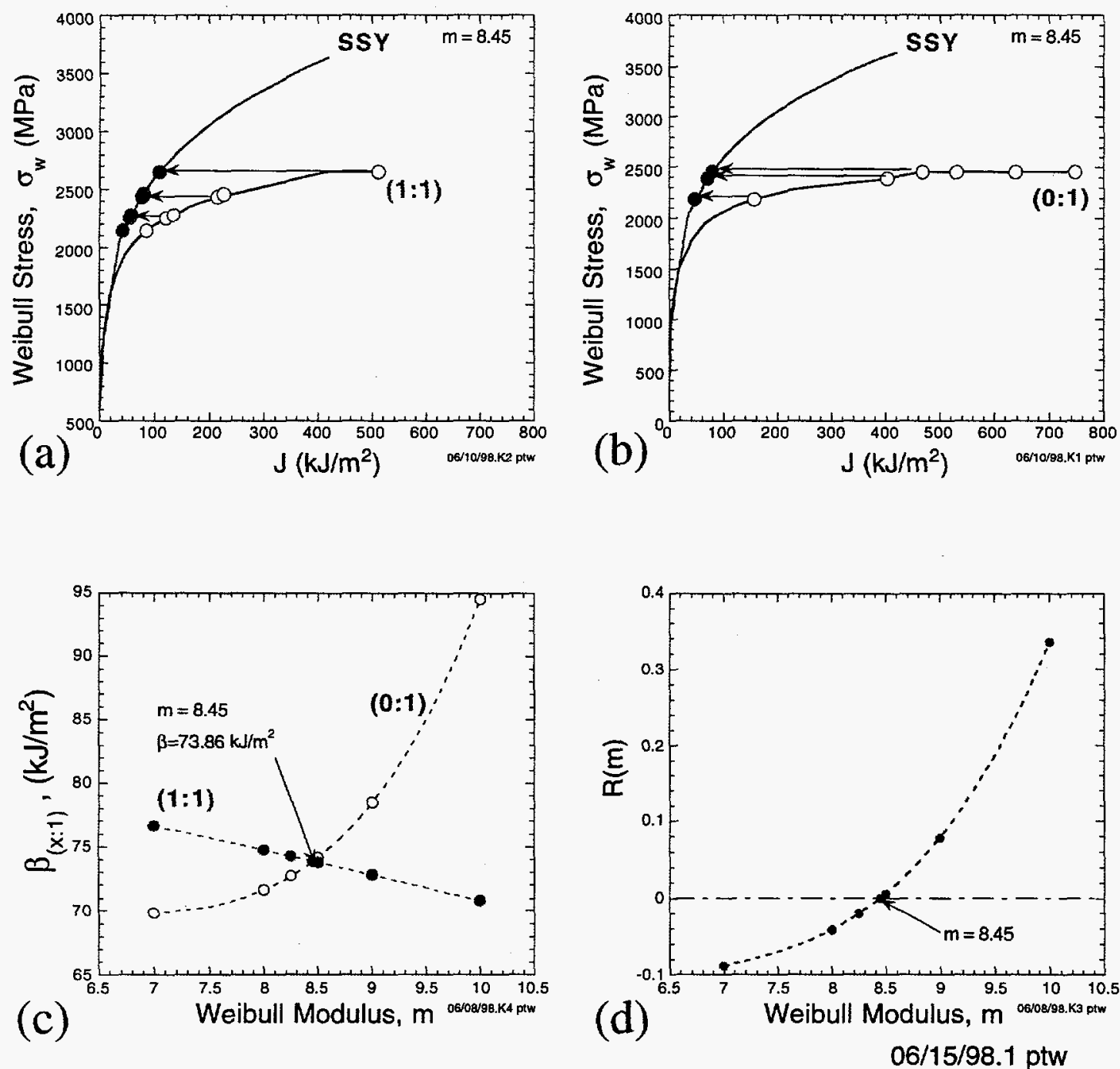

Fig. 35 Weibull parameter estimation by mapping to SSY Weibull stress space: (a) (1:1) and (b) (0:1) mappings for $m=8.45$; (c) estimated $\beta_{(x: 1)}$ values as a function of trial $m$; and (d) relative error $R(m)$ as a function of trial $m$. Censoring applied to uniaxial $(0: 1)$ toughness data. 

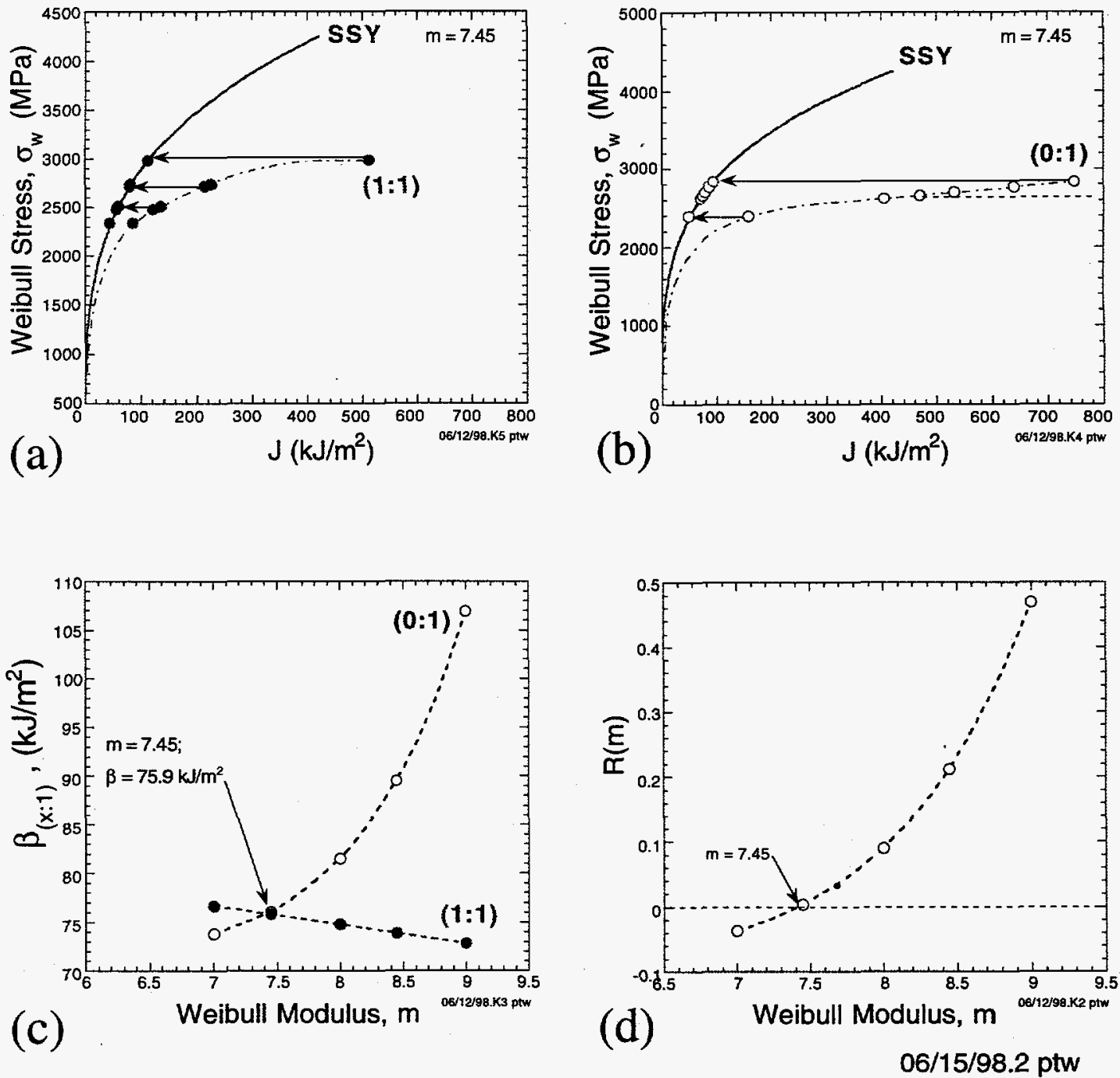

Fig. 36 Weibull parameter estimation by mapping to SSY Weibull stress space: (a) (1:1) and (b) (0:1) mappings for $m=7.45$; (c) estimated $\beta_{(x: 1)}$ values as a function of trial $m$; and (d) relative error $R(m)$ as a function of trial $m$. Linear extrapolation applied to uniaxial (0:1) toughness data. 

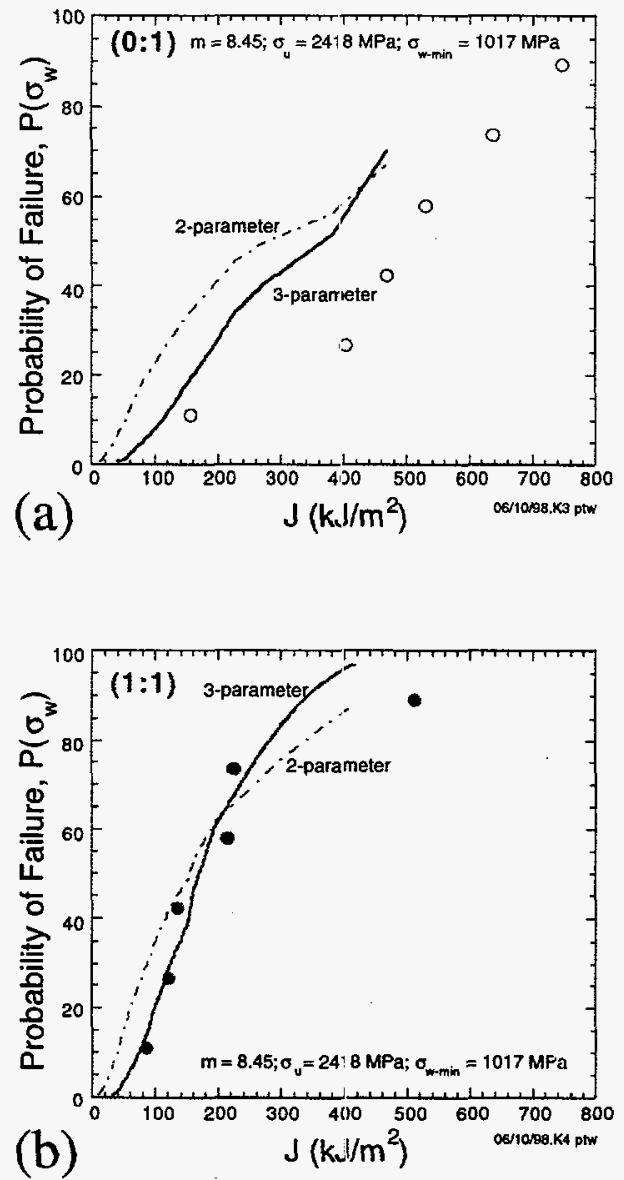

(b)

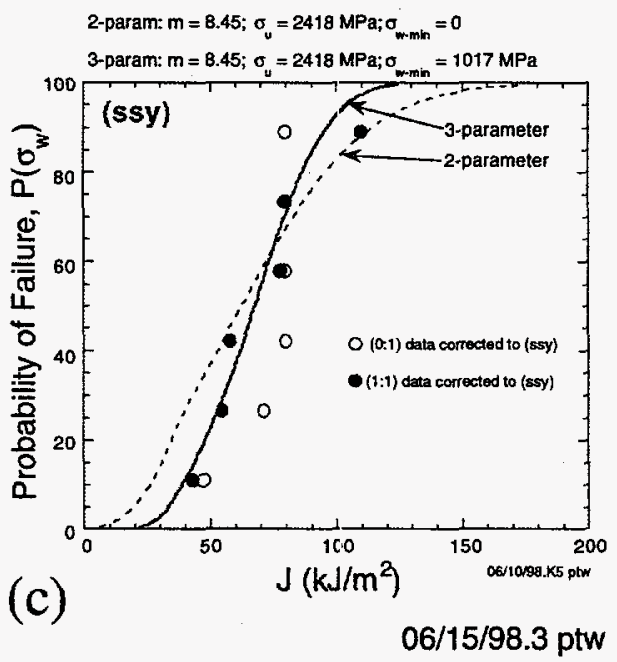

Fig. 37 Weibull parameter estimation by mapping to SSY Weibull stress space: (a) $(0: 1)$ and (b) (1:1) failure probabilities for $m=8.45$; (c) failure probabilites with toughness data mapped to SSY Weibull stress space. Censoring applied to uniaxial $(0: 1)$ toughness data. 

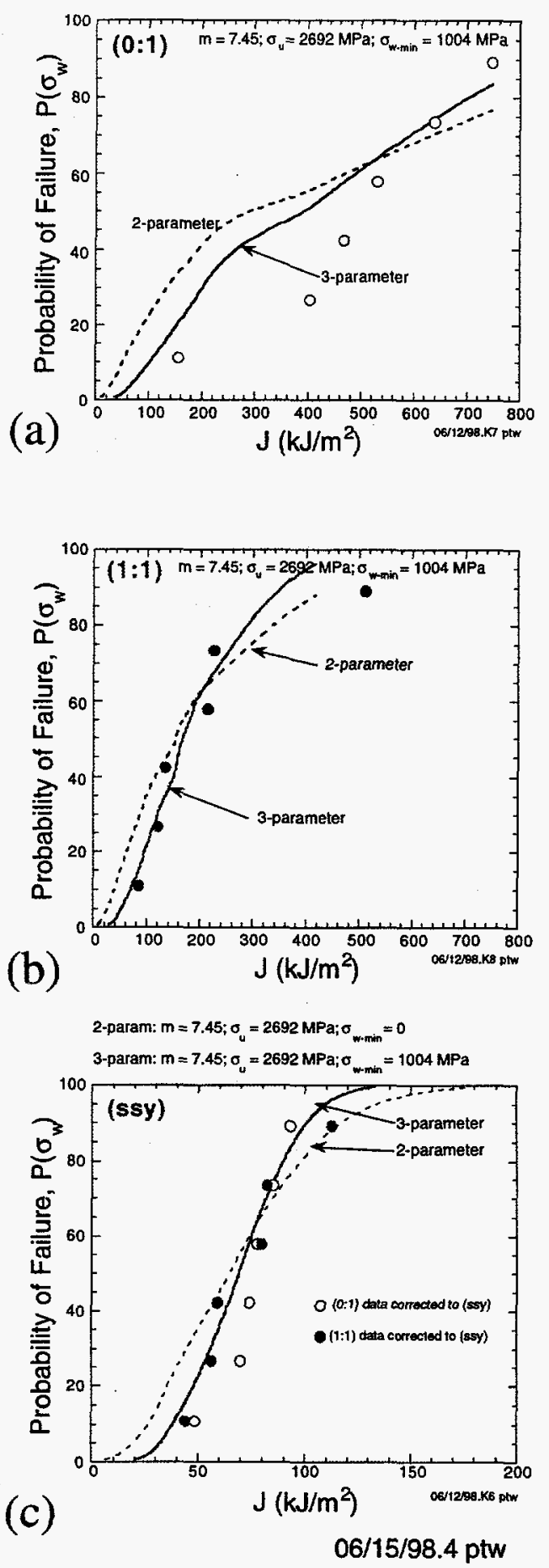

Fig. 38 Weibull parameter estimation by mapping to SSY Weibull stress space: (a) (0:1) and (b) (1:1) failure probabilities for $m=7.45$; (c) failure probabilites with toughness data mapped to SSY Weibull stress space. Linear extrapolation applied to uniaxial $(0: 1)$ toughness data. 


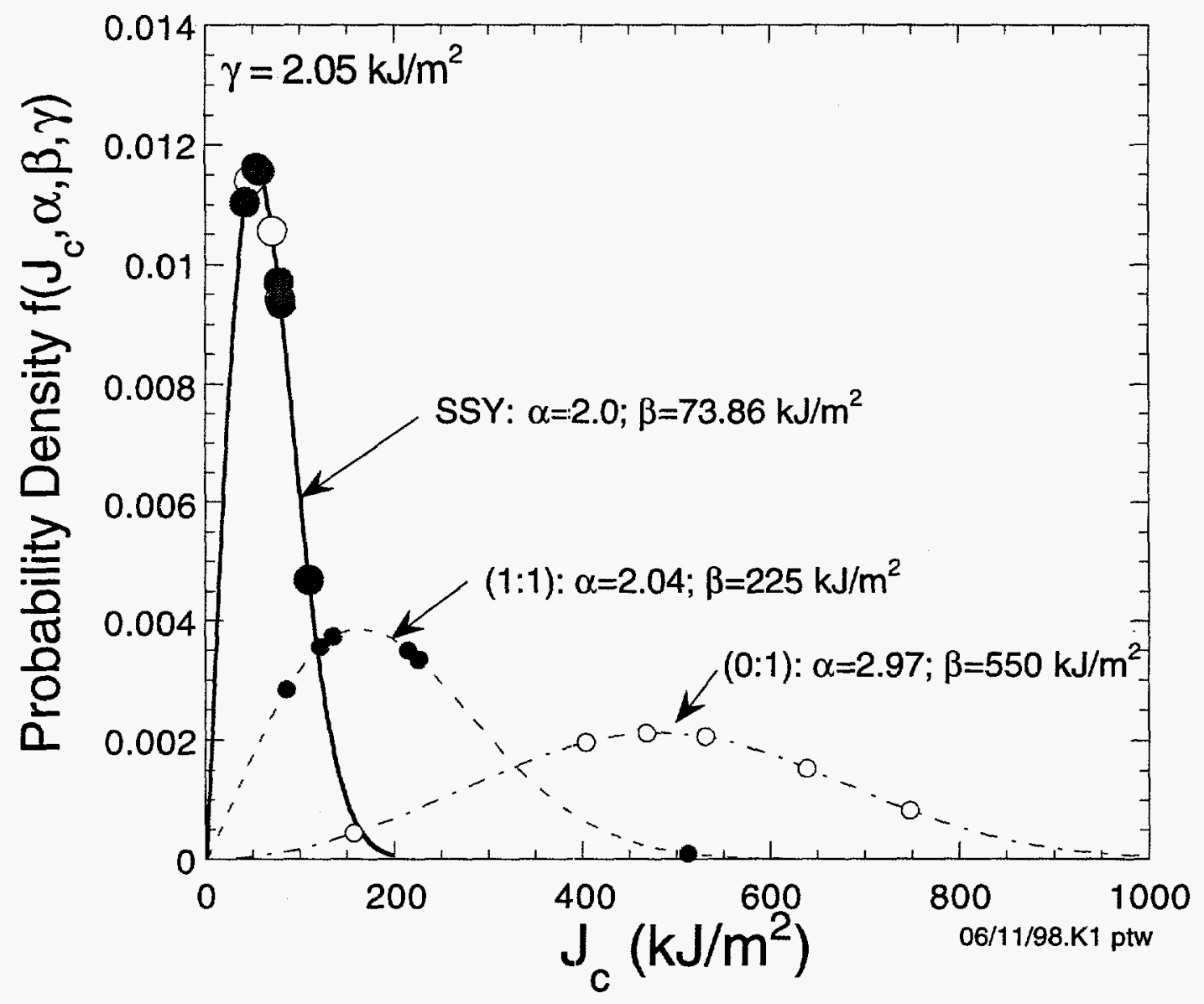

Fig. 39 Comparison of probability density distributions between (0:1) and (1:1) sample populations calculated from ML point estimates and SSY population distribution for $m=8.45$. 


$$
\sigma_{w}(J, m)=\left[\frac{1}{4 \pi V_{0}} \int_{\Omega} \int_{0}^{2 \pi} \int_{0}^{\pi} \sigma_{q}(J)^{m} \sin \varphi d \varphi d \theta d \Omega\right]^{\frac{1}{m}}
$$
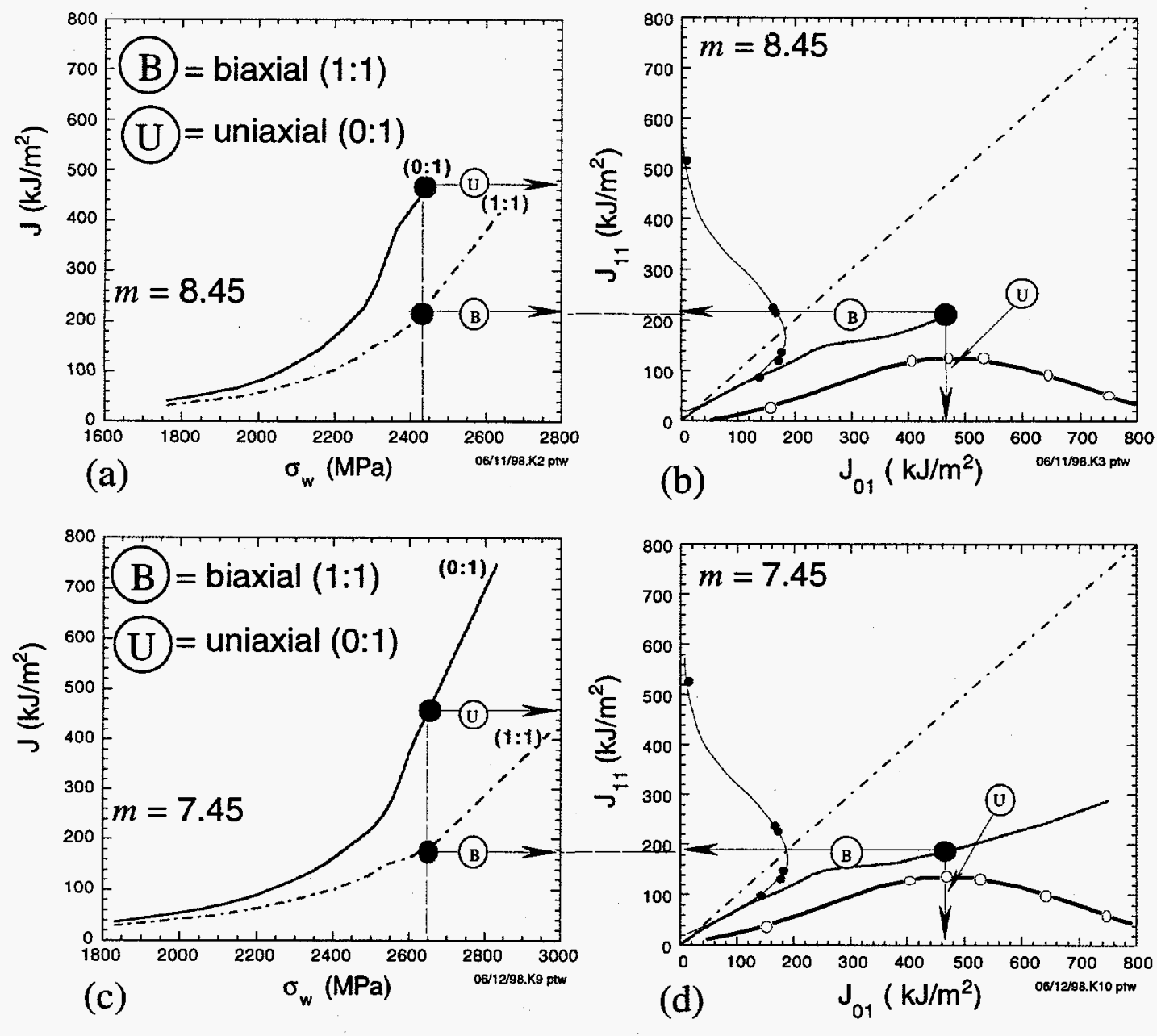

06/12/98.1 ptw

Fig. 40 (a) $J$ versus $\sigma_{w}$ trajectories for uniaxial (0:1) and biaxial (1:1) loading for $m=8.45$; (b) toughness scaling curve for $m=8.45$; (c) $J$ versus $\sigma_{w}$ trajectories for uniaxial (0:1) and biaxial (1:1) loading for $m=7.45$;

(d) toughness scaling curve for $m=7.45$ 

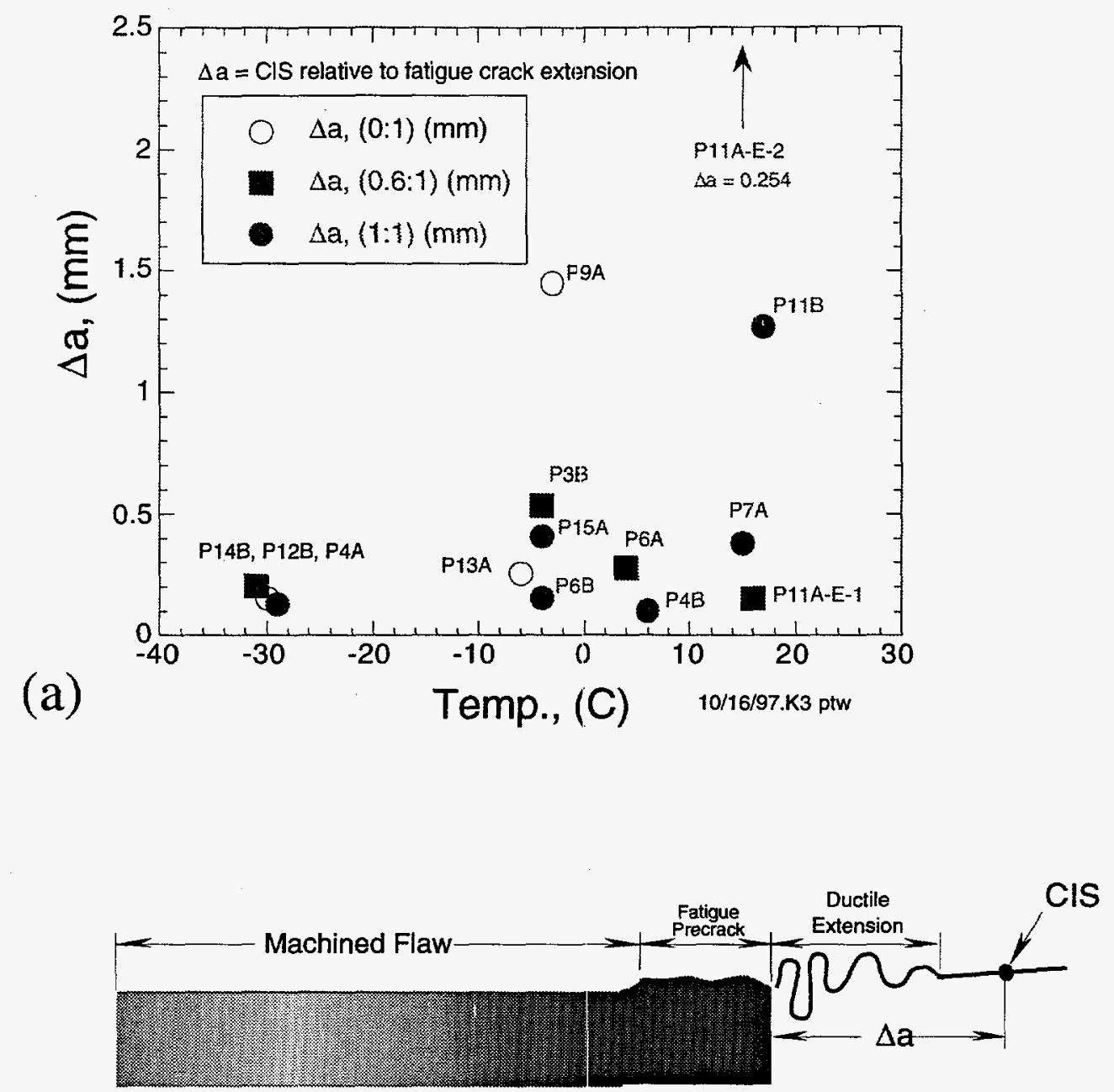

(b)

05/20/98.1 ptw

Fig. 41 Fractographic data describing measured distance to CIS for Plate 14 cruciform beam specimens: (a) measured distance, $\Delta a$, to CIS versus test temperature; and (b) definition of measured distance, $\Delta a$, to CIS. 


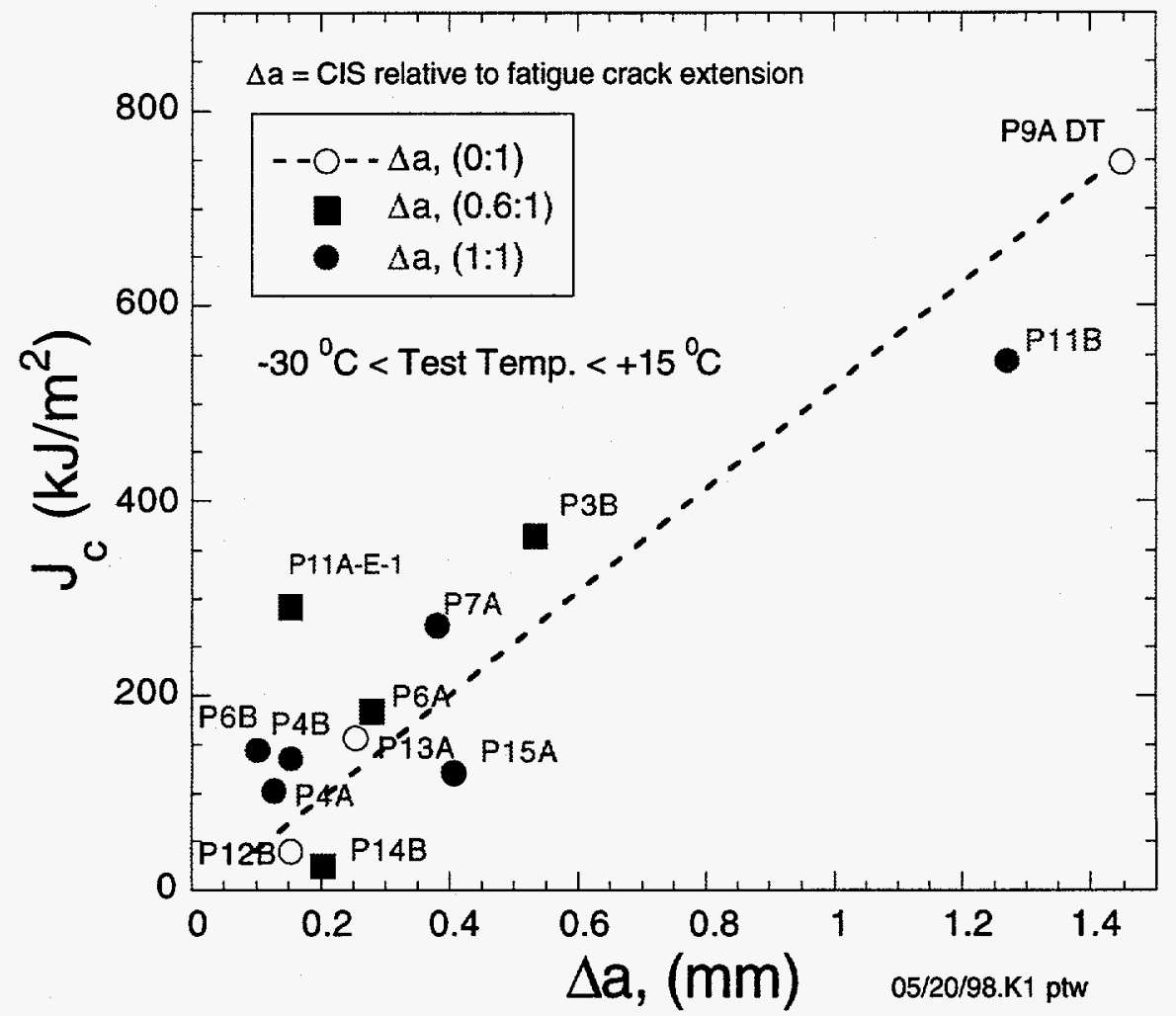

Fig. 42 Measured cleavage fracture toughness versus measured distance to CIS for Plate 14 cruciform beam specimens. 


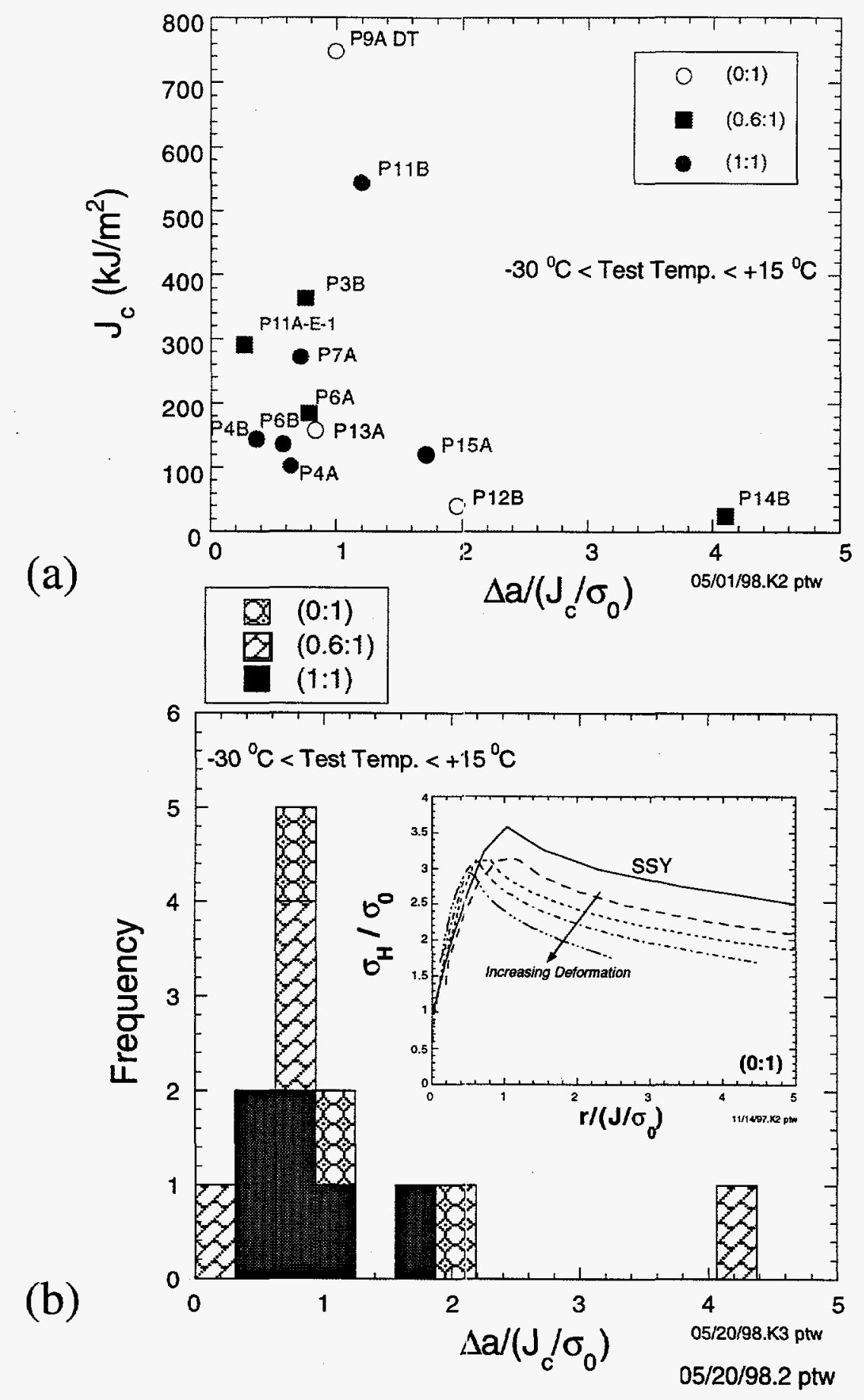

Fig. 43 Plots of cleavage fracture data versus normalized distance to CIS: (a) fracture toughness versus distance; and (b) distribution of CIS versus distance. 


\section{Appendix A: $\quad$ Computational Aspects of Dodds-Anderson Cleavage Toughness Scaling Model}

The Dodds-Anderson cleavage toughness scaling model requires the calculation of selected material areas or volumes within a predefined fixed fracture process zone ahead of the crack tip. These area/volume calculations are carried out computationally at the Gausspoint level with stress and strain data extracted from ABAQUS results files (*.fil) as a postprocessing operation. For each loading increment being tested, the post-processing code loops over all the elements in the model and samples the Gauss points within each finite element. After determining that the Gauss point is located within the process zone, the stress and/or strain data from the ABAQUS run are compared to the selection criteria. If the stress/strain data satisfy the criteria, then the area/volume associated with the Gauss point being sampled is calculated from the determinant of the transformation Jacobian (det $J$ ) and added to the area/volume sum. Typical test criteria involve the level of maximum principal stress, hydrostatic stress, and/or equivalent plastic strain.

\section{A.1 Calculation of Equal-Stressed Areas in 2-D Plane-Strain Analyses}

For 2-dimensional (2-D) plane-strain problems, the finite element used to construct the model is an 8-node isoparametric element. The node and Gauss numbering conventions applied by the ABAQUS code are shown in Fig. A1. The area of the element, $A^{(e)}$, is calculated in parametric space by the relation

$$
A^{(e)}=\int_{\Omega^{(e)}} \mathrm{d} \Omega=\int_{-1}^{+1} \int_{-1}^{+1} \operatorname{det} J(\xi, \eta)^{(e)} \mathrm{d} \eta \mathrm{d} \xi,
$$

where the transformation Jacobian, $J$, defined by

$$
J^{(e)}=\left[\begin{array}{ll}
J_{11} & J_{12} \\
J_{21} & J_{22}
\end{array}\right]^{(e)}=\left[\begin{array}{ll}
\frac{\partial x}{\partial \xi} & \frac{\partial y}{\partial \xi} \\
\frac{\partial x}{\partial \eta} & \frac{\partial y}{\partial \eta}
\end{array}\right]^{(e)}=\left[\begin{array}{cc}
\frac{\partial\left\{N_{i}\right\}^{T}}{\partial \xi}\left\{x_{i}\right\} & \frac{\partial\left\{N_{i}\right\}^{T}}{\partial \xi}\left\{y_{i}\right\} \\
\frac{\partial\left\{N_{i}\right\}^{T}}{\partial \eta}\left\{x_{i}\right\} & \frac{\partial\left\{N_{i}\right\}^{T}}{\partial \eta}\left\{y_{i}\right\}
\end{array}\right]^{(e)},
$$

maps the physical data from $\Re^{2}$ Euclidean space to parametric space. This mapping is oneto-one and onto its range if the Jacobian is nonsingular, i.e., the determinant of $J$ is not equal to zero. In Eq. (A2), $\left\{N_{i}\right\}$ is a column vector of polynomial interpolation functions; $\left\{x_{i}\right\}$ and $\left\{y_{i}\right\}$ are column vectors containing the $x$ and $y$ locations of the nodes; and $(\xi, \eta)$ are coordinates in parametric space. The determinant of $J$ is easily determined by 


$$
\operatorname{det} J=\left(J_{11} J_{22}-J_{21} J_{12}\right)=\frac{\partial\left\{N_{i}\right\}^{T}}{\partial \xi}\left\{x_{i}\right\} \frac{\partial\left\{N_{i}\right\}^{T}}{\partial \eta}\left\{y_{i}\right\}-\frac{\partial\left\{N_{i}\right\}^{T}}{\partial \eta}\left\{x_{i}\right\} \frac{\partial\left\{N_{i}\right\}^{T}}{\partial \xi}\left\{y_{i}\right\} .
$$

For an 8-node incomplete quadratic finite-element, the interpolation functions $\{N\}$ are

$$
\left\{N_{i}(\xi, \eta)\right\}=\left\{\begin{array}{c}
-\frac{1}{4}(1-\xi)(1-\eta)(1+\xi+\eta) \\
-\frac{1}{4}(1+\xi)(1-\eta)(1-\xi+\eta) \\
-\frac{1}{4}(1+\xi)(1+\eta)(1-\xi-\eta) \\
-\frac{1}{4}(1-\xi)(1+\eta)(1+\xi-\eta) \\
\frac{1}{2}\left(1-\xi^{2}\right)(1-\eta) \\
\frac{1}{2}(1+\xi)\left(1-\eta^{2}\right) \\
\frac{1}{2}\left(1-\xi^{2}\right)(1+\eta) \\
\frac{1}{2}(1-\xi)\left(1-\eta^{2}\right)
\end{array}\right\}
$$

and their derivatives with respect to the parametric coordinates are

$$
\frac{\partial\left\{N_{i}\right\}}{\partial \xi}=\left\{\begin{array}{c}
\frac{1}{4}(1-\eta)(2 \xi+\eta) \\
\frac{1}{4}(1-\eta)(2 \xi-\eta) \\
\frac{1}{4}(1+\eta)(2 \xi+\eta) \\
\frac{1}{4}(1+\eta)(2 \xi-\eta) \\
-(1-\eta) \xi \\
\frac{1}{2}\left(1-\eta^{2}\right) \\
-(1+\eta) \xi \\
-\frac{1}{2}\left(1-\eta^{2}\right)
\end{array}\right\} ; \quad \frac{\partial\left\{N_{i}\right\}}{\partial \eta}=\left\{\begin{array}{c}
\frac{1}{4}(1-\xi)(2 \eta+\xi) \\
\frac{1}{4}(1+\xi)(2 \eta-\xi) \\
\frac{1}{4}(1+\xi)(2 \eta+\xi) \\
\frac{1}{4}(1-\xi)(2 \eta-\xi) \\
-\frac{1}{2}\left(1-\xi^{2}\right) \\
-(1+\xi) \eta \\
\frac{1}{2}\left(1-\xi^{2}\right) \\
-(1-\xi) \eta
\end{array}\right\} .
$$

In Eqs. (A4) and (A5), the ABAQUS node numbering convention of Fig. A1 has been followed. As evident by the definitions of $\left\{N_{i}\right\}, \partial\left\{N_{i}\right\} / \partial \xi$, and $\partial\left\{N_{i}\right\} / \partial \eta$, the interpolation functions and their derivatives are functions of the parametric coordinates $(\xi, \eta)$. Due to their complexity, however, the area integration of Eq. (A1) is carried out by numerical quadrature, typically Gaussian integration. Equation (A1) is approximated by

$$
A^{(e)} \approx \sum_{p=1}^{n} \sum_{q=1}^{n} w_{q} w_{p} \operatorname{det} J\left(\xi_{q}, \eta_{p}\right)^{(e)}
$$

where $n$ represents the order of the quadrature rule, $w_{q}$ and $w_{p}$ are the Gauss weights, and $\left(\xi_{q}, \eta_{p}\right)$ are the Gauss sampling points. In ABAQUS, a reduced integration rule of $(2 \times 2)$ is recommended as optimal for solution stability where the Gauss weights are $w_{1}=w_{2}=1$ 
and $\xi_{1}=\eta_{1}=-1 / \sqrt{3} ; \xi_{2}=\eta_{2}=+1 / \sqrt{3}$. At each Gauss point $\left(\xi_{q}, \eta_{p}\right)$, therefore, a subelement area can be calculated by

$$
\delta A\left(\xi_{q}, \eta_{p}\right)^{(e)}=w_{q} w_{p} \operatorname{det} J\left(\xi_{q}, \eta_{p}\right)^{(e)}
$$

The position of the Gauss point $\left(\xi_{q}, \eta_{p}\right)$ relative to the global coordinate system can be calculated by taking the inner products of the interpolation functions with the nodal $(x, y)$ coordinates:

$$
x_{\left(\xi_{q}, \eta_{p}\right)}=\left\{N_{i}\left(\xi_{q}, \eta_{p}\right)\right\}^{T}\left\{x_{i}\right\}^{(e)} ; y_{\left(\xi_{q}, \eta_{p}\right)}=\left\{N_{i}\left(\xi_{q}, \eta_{p}\right)\right\}^{T}\left\{y_{i}\right\}^{(e)}
$$

The Gauss-point position is then tested to determine if it is located within the process zone. The stress/strain data at the Gauss point $\left(\xi_{q}, \eta_{p}\right)$ are then checked to see if they meet the criteria for the Dodds-Anderson analysis. Upon passing these tests, the subarea $\delta A\left(\xi_{q}, \eta_{p}\right)^{(e)}$ is calculated and added to the running total of the critical area.

\section{A.2 Calculation of Equal-Stressed Volumes in 3-D Analyses}

Extension of the Dodds-Anderson toughness scaling model to three dimensions follows easily upon definition of a suitable 3-D finite element. The 3-D transformation Jacobian is defined as

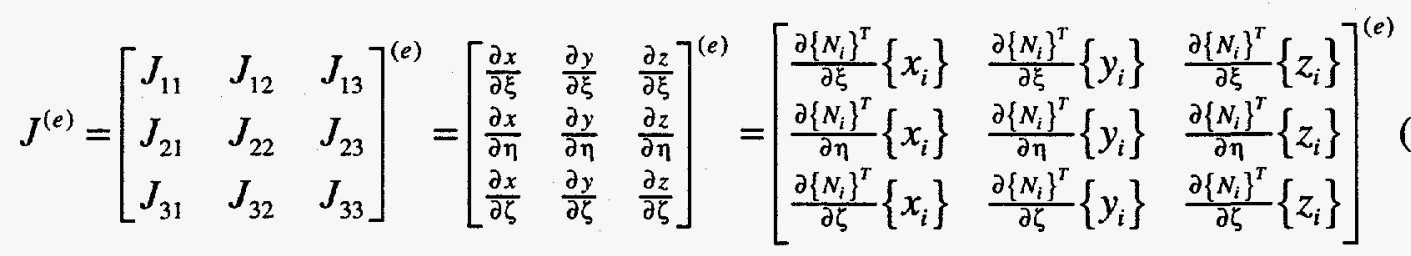

with its determinant equal to

$$
\operatorname{det} J=J_{11}\left(J_{22} J_{33}-J_{32} J_{23}\right)-J_{12}\left(J_{21} J_{33}-J_{31} J_{23}\right)+J_{13}\left(J_{21} J_{32}-J_{31} J_{22}\right) \text {. }
$$

The 3-D element employed is the 20-node hexahedron (see Fig. A2) with its incomplete quadratic interpolation functions and their corresponding derivatives presented in Eqs. (A11) and (A12): 


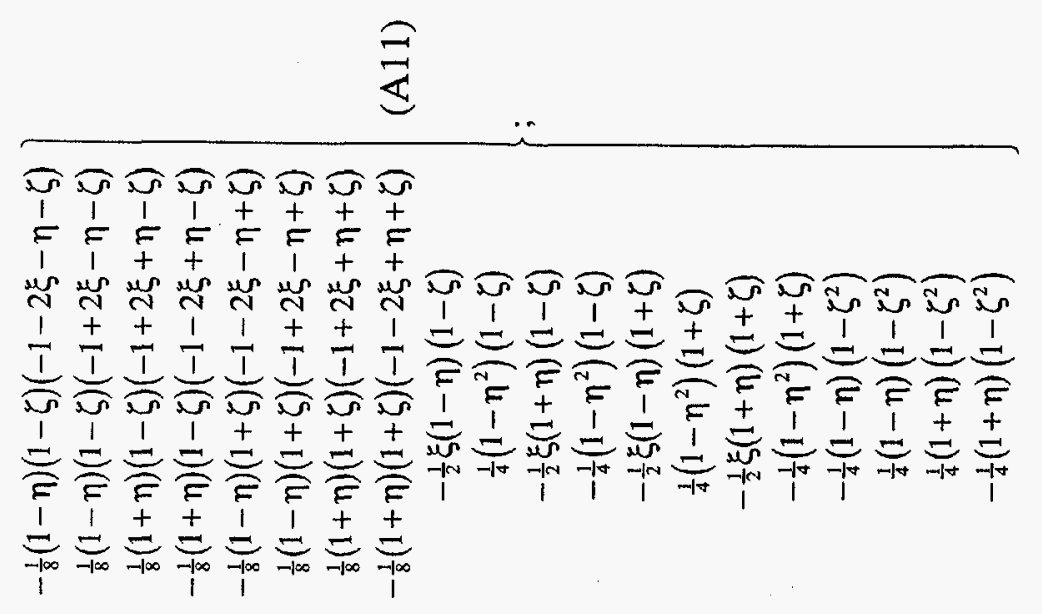

$\underbrace{11}_{\text {ziv }}$

का

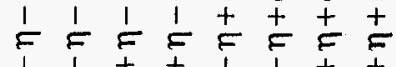

य N

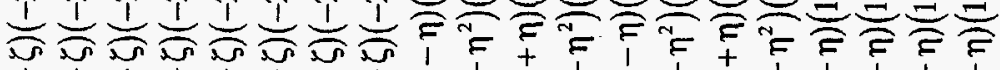

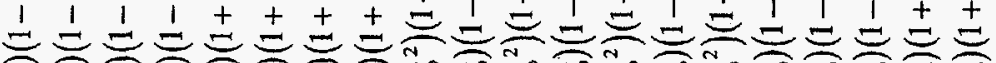

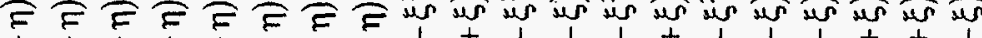

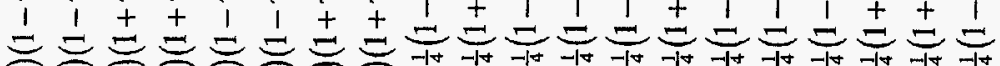

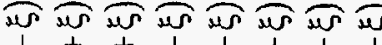

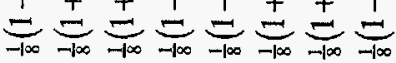

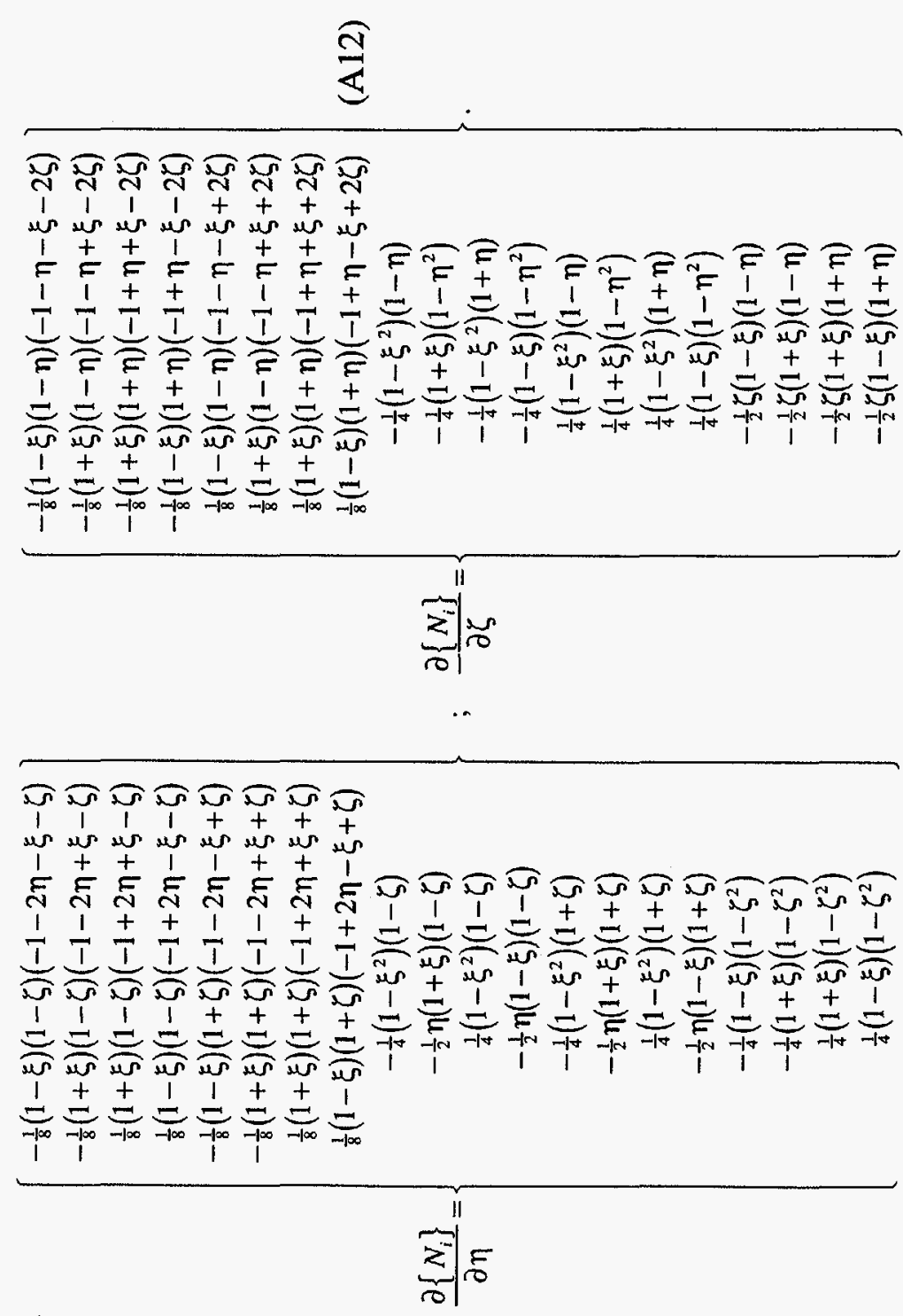

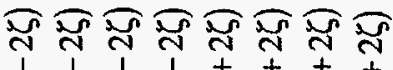

1

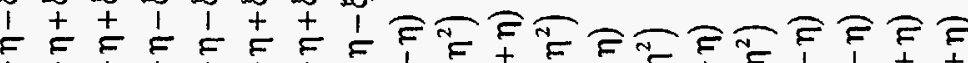
TI ITI I

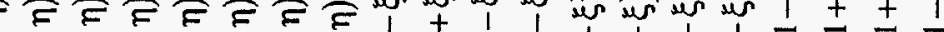

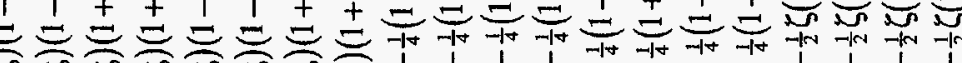

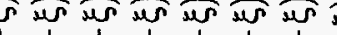

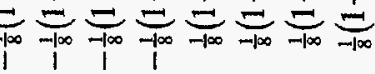


Extending Eq. (A1) to three dimensions, the volume of the element is

$$
V^{(e)}=\int_{\Omega^{(e)}} \mathrm{d} \Omega=\int_{-1}^{+1} \int_{-1}^{+1} \int_{-1}^{+1} \operatorname{det} J(\xi, \eta, \zeta)^{(e)} \mathrm{d} \xi \mathrm{d} \eta \mathrm{d} \zeta
$$

which can be approximated by

$$
V^{(e)} \approx \sum_{m=1}^{n} \sum_{p=1}^{n} \sum_{q=1}^{n} w_{q} w_{p} w_{m} \operatorname{det} J\left(\xi_{q}, \eta_{p}, \zeta_{m}\right)^{(e)}
$$

where a reduced $(2 \times 2 \times 2)$ quadrature rule is recommended for solution convergence and stability. A subvolume $\delta V\left(\xi_{q}, \eta_{p}, \zeta_{m}\right)^{(e)}$ can be calculated from

$$
\delta V\left(\xi_{q}, \eta_{p}, \zeta_{m}\right)^{(e)}=w_{q} w_{p} w_{m} \operatorname{det} J\left(\xi_{q}, \eta_{p}, \zeta_{m}\right)^{(e)}
$$

The position of the Gauss point $\left(\xi_{q}, \eta_{p}, \zeta_{m}\right)$ relative to the global coordinate system can be calculated by taking the inner products of the interpolation functions with the nodal $(x, y, z)$ coordinates:

$$
\begin{aligned}
& x_{\left(\xi_{q}, \eta_{p}, \zeta_{m}\right)}=\left\{N_{i}\left(\xi_{q}, \eta_{p}, \zeta_{m}\right)\right\}^{T}\left\{x_{i}\right\}^{(e)} ; \\
& y_{\left(\xi_{q}, \eta_{p}, \zeta_{m}\right)}=\left\{N_{i}\left(\xi_{q}, \eta_{p}, \zeta_{m}\right)\right\}^{T}\left\{y_{i}\right\}^{(e)} \\
& z_{\left(\xi_{q}, \eta_{p}, \zeta_{m}\right)}=\left\{N_{i}\left(\xi_{q}, \eta_{p}, \zeta_{m}\right)\right\}^{T}\left\{z_{i}\right\}^{(e)}
\end{aligned}
$$

The Gauss-point position $\left(\xi_{q}, \eta_{p}, \zeta_{m}\right)$ is then tested to determine if it is located within the process zone. The stress/strain data at the Gauss point are then checked to see if they meet the criteria for the Dodds-Anderson analysis. Upon passing these tests, the subvolume $\delta V\left(\xi_{q}, \eta_{p}, \zeta_{m}\right)^{(e)}$ is calculated and added to the running total of the critical volume. An effective cross-sectional area results by dividing the critical volume by the thickness of the process zone. 


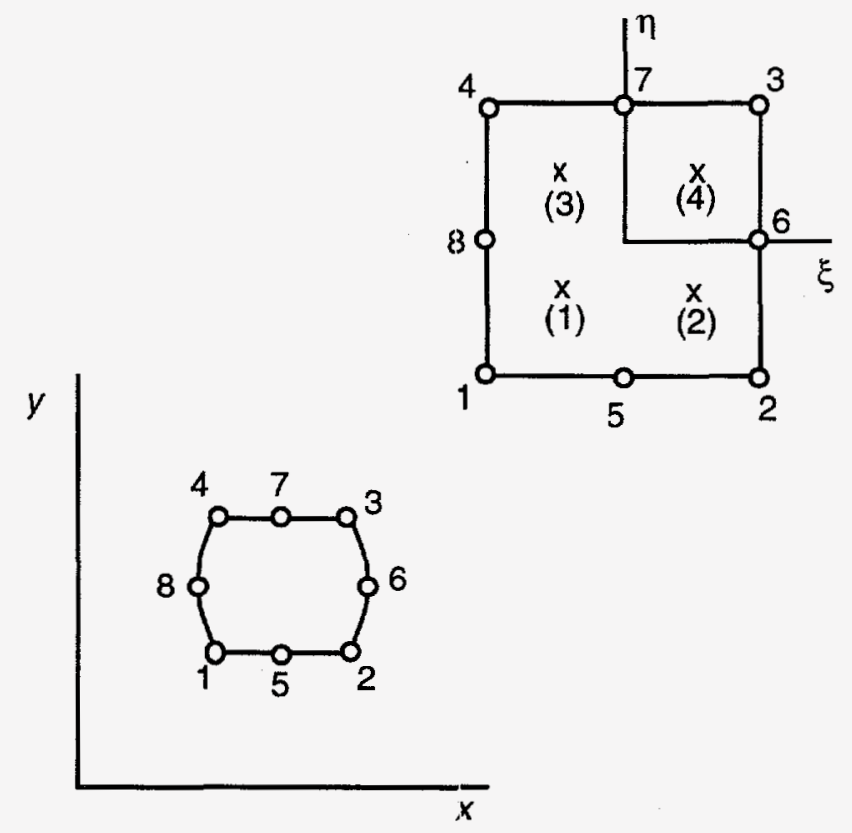

Fig. A1. Ordering of node numbers and Gauss points for an 8-node isoparametric quadrilateral finite-element.

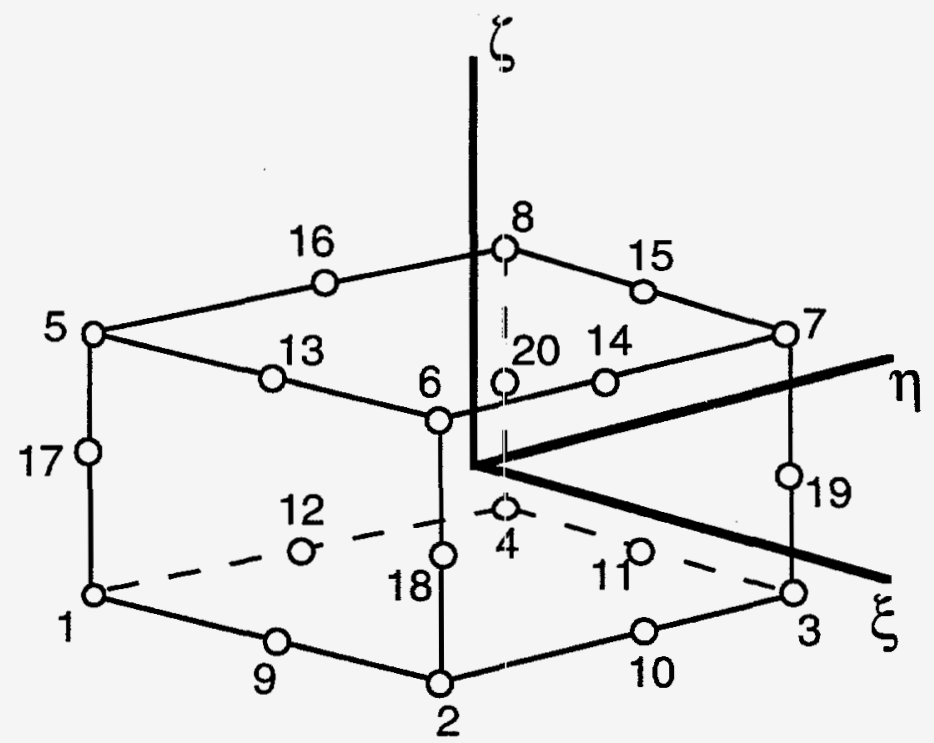

Fig. A2. Node number ordering for a 20-node isoparametric hexahedral finite element. 


\section{Appendix B: Theoretical Formulation of the Weibull Stress}

This appendix presents a formal discussion of the assumptions that are applied in the development of the Weibull stress based on the treatment given in Ref. B1. See Table B1 for a summary of the nomenclature used in this appendix.

\section{Propositions, Definitions, and Assumptions}

(B1) Let the fracture process zone $\Omega$ (see Fig. B.1) be defined as the volume of material ahead of the macrocrack tip contained within a maximum principal stress contour (isosurface in 3D) set equal to some arbitrarily defined cutoff point $\sigma_{3}=\lambda \sigma_{0}$, typically $\lambda=2$. The location and size of this fracture process zone changes with loading state. The process zone is assumed to consist of the union of $N$ nonoverlapping unit volumes $V^{(j)}$, i.e.,

$$
\Omega=\bigcup_{j=1}^{N} V^{(j)} \text { where } V^{(j)} \cap V^{(k)}=\varnothing \forall j \neq k
$$

(B2) For the unit volume $V^{(j)}$, the state of stress is defined by the principal stresses $\left(\sigma_{1}, \sigma_{2}, \sigma_{3}\right)$ which are assumed uniform (in magnitude and direction) within the volume. In the presence of steep stress gradients, this assumption may be somewhat weak, since $V^{(j)}$ is finite.

(B3) Each of the unit volumes $V^{(j)}$ is assumed to consist of the union of $n$ nonoverlapping elemental volumes $\delta V_{i}$ such that

$$
V^{(j)}=\bigcup_{i=1}^{n} \delta V_{i} \text { where } \delta V_{i} \cap \delta V_{k}=\varnothing \forall i \neq k
$$

(B4) Failures occurring in these elemental volumes $\delta V_{i}$ are assumed to be statistically independent events. The strength of this assumption has also been questioned in the literature.

(B5) The probability of failure for the elemental volume $\delta V_{i}$ is assumed proportional to its volume such that

$$
\delta \wp_{i}=\left(\int_{a_{c}}^{\infty} g(a) \mathrm{d} a\right) \delta V_{i}
$$


where the proportionality constant $\int_{a_{c}}^{\infty} g(a) \mathrm{d} a$ is the average number of microflaws with $a>a_{c}$ per unit volume; $g(a) \mathrm{d} a$ is the number density of microflaws with size $a<a^{*}<a+\mathrm{d} a$; and $a_{c}$ is a critical microflaw size. It follows that the probability of no failure is

$$
1-\delta \wp_{i}=1-\left(\int_{a_{\mathrm{c}}}^{\infty} g(a) \mathrm{d} a\right) \delta V_{i}
$$

From a Taylor series expansion of the exponential function, it can be shown that $e^{-x} \approx 1-x$ for small $x$; therefore, Eq. (B4) becomes

$$
1-\delta \wp_{i}=\exp \left[-\left(\int_{a_{c}}^{\infty} g(a) \mathrm{d} a\right) \delta V_{i}\right]
$$

(B6) Weakest Link Assumption No. 1: Let the failure of unit volume $V^{(j)}$ consist of a chain of statistically independent events, namely, the failure of the elemental volumes $\delta V_{i}$, where the failure of any elemental volume produces a failure of the whole chain; therefore,

$$
\wp_{0}^{(j)}=1-\prod_{i=1}^{n}\left(1-\delta \wp_{i}\right)=1-\prod_{i=1}^{n} \exp \left[-\left(\int_{a_{c}}^{\infty} g(a) \mathrm{d} a\right) \delta V_{i}\right]
$$

Equation (B6) relies on the assumption of statistical independence of $\delta \wp_{i}$ (Assumption B4) in order to apply the Product Law for Independent Events to calculate the probability of the joint event $\prod_{i=1}^{n}\left(1-\delta \wp_{i}\right)$. Noting that $e^{x_{1}} e^{x_{2}} \ldots e^{x_{n}}=e^{x_{1}+x_{2}+\cdots+x_{n}}$, Eq. (B6) becolmes

$$
\wp_{0}^{(j)}=1-\exp \left[-\sum_{i=1}^{n}\left(\int_{a_{c}}^{\infty} g(a) \mathrm{d} a\right) \delta V_{i}\right]
$$

(B 7) The number density distribution of the largest-sized microflaws is assumed to have the following asymptotic form [B2,B3]

$$
g(a)=\frac{1}{V_{0}}\left(\frac{k_{0}}{a}\right)^{\beta}
$$


where $V_{0}$ is a reference volume, and $\beta$ and $k_{0}$ are the parameters of the distribution. Specifically, $\beta$ is the dimensionless shape parameter, and $k_{0}$ is a scaling parameter with the dimensions of $\left[\mathrm{L}^{(\beta-1)^{\prime} \beta}\right]$.

Substituting Eq. (B8) into Eq. (B3) and carrying out the integration results in

$$
\delta \wp_{i}=\delta V_{i} \int_{a_{c}}^{\infty} g(a) \mathrm{d} a=\frac{\delta V_{i}}{V_{0}} \int_{a_{c}}^{\infty}\left(\frac{k_{0}}{a}\right)^{\beta} \mathrm{d} a=\frac{\delta V_{i}}{V_{0}} \frac{k_{0}^{\beta}}{(\beta-1)}\left(\frac{1}{a_{c}}\right)^{\beta-1}
$$

for the elemental probability of failure of the elemental volume.

(B8) An explicit relationship between the critical flaw size and corresponding fracture stress is assumed by employing the linear elastic fracture mechanics relation

$$
a_{c}=\frac{K^{2}}{Y} \frac{1}{\sigma_{q}^{2}} \Rightarrow \sigma_{q}^{2}=\frac{K^{2}}{Y} \frac{1}{a_{c}}
$$

where $K$ is a stress intensity factor, $\sigma_{q}$ is an equivalent tensile (opening mode) stress acting on the microcrack plane, and $Y$ is a geometry factor. (N.B. This assumption is fundamental to the analysis in that it assumes that all microcracks are Griffith cracks which fail in a linear elastic manner even in the presence of significant plastic deformation and nonlinear material behavior.)

Substituting Eq. (B10) in Eq. (B9) and collecting terms, one obtains the following relation for the probability of failure of the elemental volume

where

$$
\delta \wp_{i}=\frac{1}{V_{0}}\left(\frac{\sigma_{q}}{\sigma_{u}}\right)^{m} \delta V_{i}
$$

$$
\begin{aligned}
& m=2 \beta-2 \\
& \sigma_{u}=\left(\frac{\beta-1}{Y^{\beta-1}}\right)^{\frac{1}{m}} \frac{K}{k_{0}^{\beta / m}} \\
& \text { or } \\
& k_{0}=\left[\left(\frac{\beta-1}{Y^{\beta-1}}\right)^{\frac{1}{m}} \frac{K}{\sigma_{u}}\right]^{m / \beta}
\end{aligned}
$$


The relations in Eqs. (B12) give us some insight into the nature of the eventual Weibull modulus $m$ and the scaling stress $\sigma_{u}$. One observes that $m$ is directly related to the shape parameter of the microflaw size distribution and should, therefore, only be a function of those variables that affect that distribution (Eq. (B8)), e.g., material conditions, temperature, loading history, and possibly loading rate (but not the quasi-static far-field state of stress). The scaling stress, $\sigma_{u}$, in addition to the microflaw distribution, is also related to the assumed mode of fracture at the microcrack level (linear elastic Mode I) and the assumed geometry of the microflaw ( $Y$ geometry factor).

(B9) Returning to Eq. (B7), insert Eq. (B11) and take the limit as $n \rightarrow \infty$ to obtain

$$
\begin{aligned}
& \wp_{0}^{(j)}=\lim _{n \rightarrow \infty}\left\{1-\exp \left[-\sum_{i=1}^{n}\left(\int_{a_{c}}^{\infty} g(a) \mathrm{d} a\right) \delta V_{i}\right]\right\} \\
& \wp_{0}^{(j)}=1-\exp \left[-\frac{1}{V_{0}} \int_{V^{(j)}}\left(\frac{\sigma_{q}}{\sigma_{u}}\right)^{m} \mathrm{~d} V\right]
\end{aligned}
$$

The integration over the unit volume $V^{(j)}$ is carried out by assuming the volume is a sphere such that

$$
\begin{aligned}
& \int\left(\frac{\sigma_{q}}{\sigma_{u}}\right)^{m} \mathrm{~d} V=\int_{0}^{2 \pi} \int_{0}^{\pi} \int_{0}^{r}\left(\frac{\sigma_{q}}{\sigma_{u}}\right)^{m} \operatorname{det} J \mathrm{~d} r \mathrm{~d} \varphi \mathrm{d} \theta \\
& \operatorname{det} J=r^{2} \sin \varphi ; \text { for } V=1=\frac{4}{3} \pi r^{3} \Rightarrow r=\left(\frac{3}{4 \pi}\right)^{1 / 3} \\
& \int_{0}^{(3 / 4 \pi} r^{1 / 3} d r=r^{3} /\left.3\right|_{0} ^{(3 / 4 \pi)^{1 / 3}}=\frac{1}{4 \pi}
\end{aligned}
$$

where "det $J$ " is the determinant of the Jacobian $J$ (not the $J$-integral) of the coordinate transformation. This last step assumes that $\sigma_{q} \neq f(r)$ (see Assumption (B2)) but may be a function of $\sigma_{q}=f(\varphi, \theta)$, thus allowing the sensitivity of the orientation of the microcrack (since the integration is carried out over all possible solid angles within the sphere) and the directional dependence of the equivalent tensile stress acting on the microcrack plane to be incorporated into the final implementation. We now have the following form for the failure probability of the unit volume $V^{(j)}$ 


$$
\begin{aligned}
& \wp_{0}^{(j)}=1-\exp \left[-\frac{1}{V_{0}} \int_{V^{(j)}}\left(\frac{\sigma_{q}}{\sigma_{u}}\right)^{m} \mathrm{~d} V\right] \\
& \wp_{0}^{(j)}=1-\exp \left[-\frac{1}{4 \pi V_{0}} \int_{0}^{2 \pi} \int_{0}^{2 \pi}\left(\frac{\sigma_{q}}{\sigma_{u}}\right)^{m} \sin \varphi \mathrm{d} \varphi \mathrm{d} \theta\right]
\end{aligned}
$$

(B10) Weakest Link Assumption No. 2: To extend the analysis to the complete fracture process zone $\Omega$, the Weakest Link Assumption is applied for the second time. Applying Assumption (B1) and assuming that the failures of the unit volumes $V^{(j)}$ are also statistically independent, then the probability of failure for the process zone is

$$
\begin{aligned}
& \wp_{\Omega}=1-\prod_{j=1}^{N}\left(1-\wp_{0}{ }^{j}\right) \delta \Omega \\
& \wp_{\Omega}=1-\prod_{j=1}^{N} \exp \left[-\frac{1}{4 \pi V_{0}} \int_{0}^{2 \pi} \int_{0}^{2 \pi}\left(\frac{\sigma_{q}}{\sigma_{u}}\right)^{m} \sin \varphi \mathrm{d} \varphi \mathrm{d} \theta \delta \Omega\right] \\
& \wp_{\Omega}=1-\exp \left[-\sum_{j=1}^{N} \frac{1}{4 \pi V_{0}} \int_{0}^{2 \pi} \int_{0}\left(\frac{\sigma_{q}}{\sigma_{u}}\right)^{m} \sin \varphi \mathrm{d} \varphi \mathrm{d} \theta \delta \Omega\right] \\
& \wp_{\Omega}=\lim _{N \rightarrow \infty}\left\{1-\exp \left[-\sum_{j=1}^{N} \frac{1}{4 \pi V_{0}} \int_{0}^{2 \pi \pi} \int_{0}^{2}\left(\frac{\sigma_{q}}{\sigma_{u}}\right)^{m} \sin \varphi \mathrm{d} \varphi \mathrm{d} \theta \delta \Omega\right]\right\} \\
& \wp_{\Omega}=1-\exp \left[-\frac{1}{4 \pi V_{0}} \int_{\Omega} \int_{0}^{2 \pi \pi} \int_{0}^{m}\left(\frac{\sigma_{q}}{\sigma_{u}}\right)^{m} \sin \varphi \mathrm{d} \varphi \mathrm{d} \theta \mathrm{d} \Omega\right]
\end{aligned}
$$

Recognizing that the scaling stress $\sigma_{u}$ is a constant, the Weibull stress, $\sigma_{w}$, as introduced by the Beremin group [B4], can now be defined by

$$
\sigma_{w} \equiv\left(\frac{1}{4 \pi V_{0}} \int_{\Omega} \int_{0}^{2 \pi} \int_{0}^{\pi}\left(\sigma_{q}\right)^{m} \sin \varphi \mathrm{d} \varphi \mathrm{d} \theta \mathrm{d} \Omega\right)^{\frac{1}{m}}
$$

and the probability of failure for the process zone can be rewritten in the twoparameter form as

$$
\wp_{\Omega}=1-\exp \left[-\left(\frac{\sigma_{w}}{\sigma_{u}}\right)^{m}\right]
$$




\section{Summary}

Equation (B17) is the final form for a two-parameter Weibull distribution. Among the key assumptions in its formulation are:

(B4\& B10) The elemental and unit volume failure events are assumed to be statistically independent.

(B6 \& B10) The Weakest Link assumption is applied twice, at both the micro- and mesoscale levels.

(B5) The probability of failure for the elemental volume is assumed proportional to its volume.

(B7) A specific form (Eq. (B8)) is assumed for the number density distribution of microflaw sizes. The Weibull modulus $m$ is directly related to the shape parameter of this distribution.

(B8) An explicit relationship (Eq. (B10)) is assumed between the microflaw size and the applied tensile stress at fracture. The microflaws are treated as sharp cracks that fail under the assumptions of linear elastic fracture mechanics. The Weibull modulus $m$ is not dependent on this assumption directly, but the scaling stress $\sigma_{u}$ is derived in part from this Griffith crack assumption.

The two-parameter Weibull distribution for the probability of failure by cleavage fracture has the form

$$
\wp_{\Omega}=1-\exp \left[-\left(\frac{\sigma_{w}}{\sigma_{u}}\right)^{m}\right]
$$

where the Weibull stress, $\sigma_{w}$, emerges as a critical parameter

$$
\sigma_{w}=\left(\frac{1}{4 \pi V_{0}} \int_{\Omega} \int_{0}^{2 \pi \pi} \int_{0}\left(\sigma_{q}\right)^{m} \sin \varphi \mathrm{d} \varphi \mathrm{d} \theta \mathrm{d} \Omega\right)^{\frac{1}{m}}
$$




\section{References}

[B1] C. Ruggieri and R. H. Dodds, Jr., WSTRESS 2.0: Numerical Computation of Probabilistic Fracture Parameters, Department of Civil Engineering, University of Illinois, UILU-ENG-95-2013, May 1998.

[B2] A. M. Freudenthal, "Statistical Approach to Brittle Fracture," in Fracture: An Advanced Treatise. Volume II, Ed. H. Liebowitz, Academic Press, 592-619 (1968).

[B3] A. G. Evans and T. G. Langdon, "Structural Ceramics," in Progress in Materials Science, Vol. 21, ed. B. Chalmers, Pergamon Press, N.Y., 171-441 (1976).

[B4] F. M. Beremin, "A Local Criterion for Cleavage Fracture of a Nuclear Pressure Vessel Steel," Metallurgical Transactions 14A: 2277-2287 (1983). 


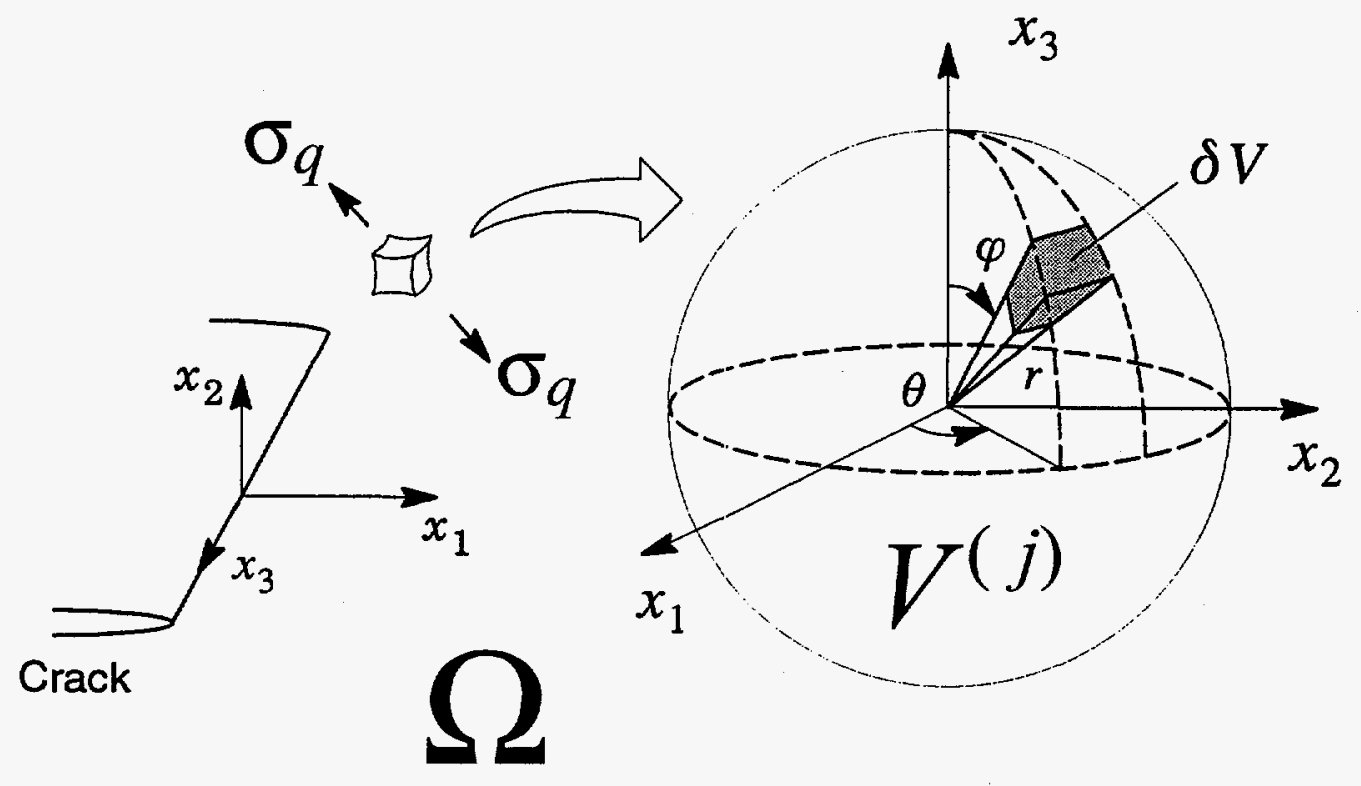

Fig. B.1. Description of the fracture process zone, $\Omega$, unit volume, $V^{(j)}$, and elemental volume, $\delta V_{i}$ (adapted from Ref. B1). 
Table B.1 Nomenclature employed in theoretical development of the Weibull stress

\begin{tabular}{ll}
\hline$a$ & size of microcrack [L] \\
$a_{c}$ & critical flaw size resulting in fracture under applied tensile stress $\sigma_{q}[\mathrm{~L}]$ \\
$g(a) \mathrm{d} a$ & number density of flaws with size $a<a^{*}<a+\mathrm{d} a\left[\mathrm{~L}^{-3}\right]$ \\
$k_{0}$ & scaling parameter for flaw size number density distribution $\left[\mathrm{L}^{(\beta-1) \beta}\right]$ \\
$K$ & stress intensity factor in relation between $\sigma_{q}$ and $a_{c}\left[\mathrm{~F} \mathrm{~L}^{-2} \mathrm{~L}^{1 / 2}\right]$ \\
$m$ & Weibull modulus $=2 \beta-2[\bullet]$ \\
$\delta \wp_{i}$ & probability of failure by cleavage fracture for material within elemental volume \\
& $\delta V_{i}[\bullet]$ \\
$\wp_{0}^{(j)}$ & probability of failure by cleavage fracture for material per unit volume $V^{(j)}$ \\
$\wp_{\Omega}$ & {$\left[\mathrm{L}^{-3}\right]$} \\
$\delta V_{i}$ & probability of failure by cleavage fracture for material within $\Omega[\bullet]$ \\
$V^{(j)}$ & elemental volume within unit volume $V^{(j)}\left[\mathrm{L}^{3}\right]$ \\
$V_{0}$ & unit volume within $\Omega\left[\mathrm{L}^{3}\right]$ \\
$Y$ & reference volume containing uniform number of microcracks with varying \\
distribution of flaw sizes $\left[\mathrm{L}^{3}\right]$
\end{tabular}


ORNL/NRC/LTR-98/9

\section{Internal Distribution}

1-5. B. R. Bass

6. J. W. Bryson

7. W. G. Craddick

8. T. L. Dickson

9. D. M. Hetrick

10. M. A. Kuliasha

11-15. W. J. McAfee
16. J. G. Merkle

17. R. K. Nanstad

18-19. W. E. Pennell

20. C. E. Pugh

21. T. M. Rosseel

22-26. P. T. Williams

27-30. Laboratory Records - RC

\section{External Distribution}

31. K. R. Wichman, EMCB/DE/NF'R, U.S. Nuclear Regulatory Commission, Mailstop O7 D4, Washington, D.C. 20555-0001

32. E. M. Hackett, EMMEB/DET/R.ES, U.S. Nuclear Regulatory Commission, Mailstop T10 E10, Washington, D.C. 20555-0001

33. S. N. Malik, EMMEB/DET/RES, U.S. Nuclear Regulatory Commission, Mailstop T10 E10, Washington, D.C. 20555-0001

34. M. E. Mayfield, DET/RES, U.S. Nuclear Regulatory Commission, Mailstop T10 E10, Washington, D.C. 20555-0001

35-39. M. G. Vassilaros, EMMEB/DE'T/RES, U.S. Nuclear Regulatory Commission, Mailstop T10 E10, Washington, D.C. 20555-0001

40. C. Santos, EMMEB/DET/RES, U.S. Nuclear Regulatory Commission, Mailstop T10 E10, Washington, D.C. 20555-0001

41. R. L. Tregoning, Fatigue and Fracture Branch, Carderock Division, Naval Surface Warfare Center, 9500 McArthur Blvd., West Bethesda, Maryland 20817-5700.

42. J. A. Joyce, U.S. Naval Academy, Mechanical Engineering Department, MS-11C, 590 Hollway Road, Annapolis, Maryland 21402

43-44. R. H. Dodds, Jr., 3140 Newmark Laboratory, 205 North Matthews, Urbana, Illinois 61801 